\title{
Current systematic carbon-cycle observations and the need for implementing a policy-relevant carbon observing system
}

\author{
P. Ciais ${ }^{1}$, A. J. Dolman ${ }^{2}$, A. Bombelli ${ }^{3}$, R. Duren ${ }^{4}$, A. Peregon ${ }^{1}$, P. J. Rayner ${ }^{5}$, C. Miller ${ }^{4}$, N. Gobron ${ }^{6}$, G. Kinderman ${ }^{7}$, \\ G. Marland $^{8}$, N. Gruber ${ }^{9}$, F. Chevallier ${ }^{1}$, R. J. Andres ${ }^{10}$, G. Balsamo ${ }^{11}$, L. Bopp ${ }^{1}$, F.-M. Bréon ${ }^{1}$, G. Broquet ${ }^{1}$, \\ R. Dargaville ${ }^{5}$, T. J. Battin ${ }^{12}$, A. Borges ${ }^{13}$, H. Bovensmann ${ }^{14}$, M. Buchwitz ${ }^{14}$, J. Butler ${ }^{15}$, J. G. Canadell ${ }^{16}$, \\ R. B. Cook ${ }^{10}$, R. DeFries ${ }^{17}$, R. Engelen ${ }^{11}$, K. R. Gurney ${ }^{18}$, C. Heinze ${ }^{19,20,21}$, M. Heimann ${ }^{22}$, A. Held ${ }^{23}$, M. Henry ${ }^{24}$, \\ B. Law $^{25}$, S. Luyssaert ${ }^{1}$, J. Miller ${ }^{15,26}$, T. Moriyama $^{27}$, C. Moulin ${ }^{1}$, R. B. Myneni' ${ }^{28}$, C. Nussli ${ }^{29}$, M. Obersteiner ${ }^{7}$,

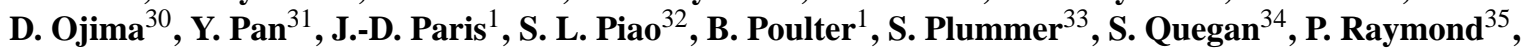 \\ M. Reichstein ${ }^{22}$, L. Rivier ${ }^{1}$, C. Sabine ${ }^{36}$, D. Schimel ${ }^{37}$, O. Tarasova ${ }^{38}$, R. Valentini ${ }^{3}$, R. Wang ${ }^{1}$, G. van der Werf ${ }^{2}$, \\ D. Wickland ${ }^{39}$, M. Williams ${ }^{40}$, and C. Zehner ${ }^{41}$
}

${ }^{1}$ Laboratoire des Sciences du Climat et de l'Environnement, CEA-CNRS-UVSQ, UMR8212, 91191, Gif sur Yvette Cedex, France

${ }^{2}$ VU University Amsterdam, Amsterdam, the Netherlands

${ }^{3}$ Euro-Mediterranean Center for Climate Change, CMCC, Division Climate Change Impacts on Agriculture, Forests and Natural Ecosystems; via Augusto Imperatore 16, 73100 Lecce, Italy

${ }^{4}$ Jet Propulsion Laboratory, California Institute of Technology, 4800 Oak Grove Dr, Pasadena, CA 91109, USA

${ }^{5}$ School of Earth Sciences, University of Melbourne, Australia

${ }^{6}$ Global Environmental Monitoring Unit, Institute for Environment and Sustainability, European Commission Joint Research Center, Ispra, Italy

${ }^{7}$ International Institute for Applied Systems Analysis (IIASA), Schlossplatz 1, Laxenburg, Austria

${ }^{8}$ Research Institute for Environment, Energy, and Economics, Appalachian State University, Boone, NC 28608, USA

${ }^{9}$ Institute of Biogeochemistry and Pollutant Dynamics and Center for Climate Systems Modeling, ETH Zürich, Zürich,

Switzerland

${ }^{10}$ Carbon Dioxide Information Analysis Center, Oak Ridge National Laboratory, Oak Ridge, TN 37831-6290, USA

${ }^{11}$ European Centre for Medium-Range Weather Forecast (ECMWF), Shinfield Park, Reading, RG2 9AX, UK

${ }^{12}$ Department of Limnology, University of Vienna, A-1090 Vienna, Austria

${ }^{13}$ Chemical Oceanography Unit, University of Liège, Institute de Physique (B5), 4000 Liège, Belgium

${ }^{14}$ Institute of Environmental Physics (IUP), University of Bremen, Bremen, Germany

${ }^{15}$ NOAA Earth System Research Laboratory (ESRL), 325, Broadway, Boulder, CO 80305-3337, USA

${ }^{16}$ CSIRO Marine and Atmospheric Research, Canberra, ACT 2601, Australia

${ }^{17}$ Department of Geography and Environment, Boston University, Boston, MA 02115, USA

${ }^{18}$ School of Life Sciences, School of Sustainability, Arizona State University, Tempe, AZ 85287, USA

${ }^{19}$ Geophysical Institute, University of Bergen, Allégaten 70, 5007 Bergen, Norway

${ }^{20}$ Bjerknes Centre for Climate Research, Bergen, Norway

${ }^{21}$ Uni Bjerknes Centre, Uni Research, Bergen, Norway

${ }^{22}$ Max-Planck-Institute for Biogeochemistry, Jena, Germany

${ }^{23}$ AusCover Facility, Terrestrial Ecosystem Research Network - TERN, CSIRO, GPO Box 3023, Canberra ACT 2601, Australia

${ }^{24}$ Forestry Department, Food and Agriculture Organization of the United Nations, Via delle Terme di Caracalla, 00153 Rome, Italy

${ }^{25}$ Department of Forest Ecosystems and Society, 321 Richardson Hall, Oregon State University, Corvallis, OR 97331, USA

${ }^{26}$ Cooperative Institute for Research in Environmental Sciences, University of Colorado, Boulder, CO 80309, USA

${ }^{27}$ Japan Aerospace Exploration Agency (JAXA), Tokyo

${ }^{28}$ Department of Earth and Environment, Boston University, Boston, MA 02215, USA 
${ }^{29}$ Thales Alenia Space, Toulouse, France

${ }^{30}$ Natural Resource Ecology Laboratory, Campus Mail 1499, Fort Collins, CO 80523-1499, USA

${ }^{31}$ US Department of Agriculture Forest Service, Newtown Square, PA 19073, USA

${ }^{32}$ Department of Ecology, Peking University, Beijing 100871, China

${ }^{33}$ ESA Climate Office, European Space Agency - Harwell, Didcot, Oxfordshire OX11 0QX, UK

${ }^{34}$ Centre for Terrestrial Carbon Dynamics, University of Sheffield, Hicks Building, Hounsfield Road, Sheffield S3 7RH, UK

${ }^{35}$ Yale School of Forestry and Environmental Studies, 195 Prospect Street, New Haven, CT 06511, USA

${ }^{36}$ Pacific Marine Environmental Laboratory, National Oceanic and Atmospheric Administration, Seattle, WA 98115, USA

${ }^{37}$ National Ecological Observatory Network, Boulder, CO 80301, USA

${ }^{38}$ World Meteorological Organization, 7bis Avenue de la Paix, 1211 Geneva, Switzerland

${ }^{39}$ National Aeronautics and Space Administration, Suite 3B74, 300 E Street SW, Washington, DC 20546, USA

${ }^{40}$ School of GeoSciences, University of Edinburgh, Edinburgh, EH9 3JN, UK

${ }^{41}$ ESA/ESRIN, Earth Observation Applications Engineer, Via Galileo Galilei CP, 64, Frascati Italy

Correspondence to: P. Ciais (philippe.ciais@1sce.ipsl.fr)

Received: 6 May 2013 - Published in Biogeosciences Discuss.: 10 July 2013

Revised: 6 March 2014 - Accepted: 21 March 2014 - Published: 3 July 2014

Abstract. A globally integrated carbon observation and analysis system is needed to improve the fundamental understanding of the global carbon cycle, to improve our ability to project future changes, and to verify the effectiveness of policies aiming to reduce greenhouse gas emissions and increase carbon sequestration. Building an integrated carbon observation system requires transformational advances from the existing sparse, exploratory framework towards a dense, robust, and sustained system in all components: anthropogenic emissions, the atmosphere, the ocean, and the terrestrial biosphere. The paper is addressed to scientists, policymakers, and funding agencies who need to have a global picture of the current state of the (diverse) carbon observations. We identify the current state of carbon observations, and the needs and notional requirements for a global integrated carbon observation system that can be built in the next decade. A key conclusion is the substantial expansion of the ground-based observation networks required to reach the high spatial resolution for $\mathrm{CO}_{2}$ and $\mathrm{CH}_{4}$ fluxes, and for carbon stocks for addressing policy-relevant objectives, and attributing flux changes to underlying processes in each region. In order to establish flux and stock diagnostics over areas such as the southern oceans, tropical forests, and the Arctic, in situ observations will have to be complemented with remote-sensing measurements. Remote sensing offers the advantage of dense spatial coverage and frequent revisit. A key challenge is to bring remote-sensing measurements to a level of long-term consistency and accuracy so that they can be efficiently combined in models to reduce uncertainties, in synergy with groundbased data. Bringing tight observational constraints on fossil fuel and land use change emissions will be the biggest challenge for deployment of a policy-relevant integrated carbon observation system. This will require in situ and remotely sensed data at much higher resolution and density than cur- rently achieved for natural fluxes, although over a small land area (cities, industrial sites, power plants), as well as the inclusion of fossil fuel $\mathrm{CO}_{2}$ proxy measurements such as radiocarbon in $\mathrm{CO}_{2}$ and carbon-fuel combustion tracers. Additionally, a policy-relevant carbon monitoring system should also provide mechanisms for reconciling regional top-down (atmosphere-based) and bottom-up (surface-based) flux estimates across the range of spatial and temporal scales relevant to mitigation policies. In addition, uncertainties for each observation data-stream should be assessed. The success of the system will rely on long-term commitments to monitoring, on improved international collaboration to fill gaps in the current observations, on sustained efforts to improve access to the different data streams and make databases interoperable, and on the calibration of each component of the system to agreed-upon international scales.

\section{Introduction}

Global mean atmospheric levels of $\mathrm{CO}_{2}$ have increased by $40 \%$ from about $280 \mathrm{ppm}$ in pre-industrial times (Etheridge et al., 1996) to $393.6 \mathrm{ppm}$ by the end of 2012 (WMO, 2010; Dlugokencky and Tans, 2012). Levels of $\mathrm{CH}_{4}$ reached $1813 \pm 2$ ppb in 2011 (WMO, 2012), nearly 2.5 times their pre-industrial value of $700 \mathrm{ppb}$ (Etheridge et al., 1996). The increase of $\mathrm{CO}_{2}$ and $\mathrm{CH}_{4}$ is caused by fossil fuel combustion and land use change. The primary anthropogenic $\mathrm{CH}_{4}$ emissions are leaks from natural gas extraction and distribution, the oil industry and coal extraction, livestock and rice paddies, landfills and human-caused biomass burning (Denman et al., 2007). Natural emissions of $\mathrm{CH}_{4}$ are dominated by wetlands and lakes, with smaller contributions from geological natural venting, wildfires, and termites. 
Fossil fuel emissions increased at a rate of $3.1 \%$ per year over the last decade (Le Quéré et al., 2013). Rates of land use change $\mathrm{CO}_{2}$ emissions have slightly declined in the past decade (Friedlingstein et al., 2010).

Emission reduction programs are developed in support of international agreements, such as United Nations Framework Convention on Climate Change (UNFCCC). Yet, anthropogenic emissions of $\mathrm{CO}_{2}$ and $\mathrm{CH}_{4}$ estimated from inventories cannot be validated by independent observations. The ability of nations, provinces, and local municipalities to implement policies that reduce emissions or create sinks of $\mathrm{CO}_{2}$ and $\mathrm{CH}_{4}$ (de Richter and Caillol, 2011; Kucharczyk, 2011; Stolaroff et al., 2012) will partly depend upon their ability to measure progress, and evaluate effectiveness of national and sub-national actions. Uncertainties in inventories need to be dramatically reduced to support effective policies. To date, efforts to monitor and report emissions of $\mathrm{CO}_{2}$ and $\mathrm{CH}_{4}$ have been based mostly on limited large-scale, subsampled land use observations, self-reported data on land and energy use, and extrapolated emission factor measurements. These data have uncertainties that limit their ability to support greenhouse management strategies (e.g. Schulze et al., 2009). For instance, even in developed nations where uncertainties in annual fossil $\mathrm{CO}_{2}$ emissions are $\sim 5 \%$ (Andres et al., 2012), the total uncertainty associated with those estimates over multiple years exceed the magnitude of the trends defined as the target of emission reduction policies (e.g. the Kyoto Protocol target set by EU15 members of a collective reduction of $8 \%$ of during 2008-2012 of their emissions below the 1990 level; EEA, 2009, p. 9).

Improved scientific understanding of the carbon cycle is a critical foundation to providing policy-relevant information regarding climate change mitigation and adaptation in three ways: (1) by providing understanding of the processes controlling the carbon cycle to estimate ex ante the likely impacts of implementation the greenhouse gas (GHG) management strategies, (2) by informing the construction of an accurate baseline of GHG fluxes and carbon stocks against which climate policies can be evaluated, and (3) by monitoring the variability and long-term trends of GHG fluxes over each region ex post assessment of the efficacy of mitigation policies (most of which span decades).

Anthropogenic emissions would need to be measured not only for global annual totals but also for their spatiotemporal distribution. Timely delivery of such information is critical for policy. For example, Reduced Emissions from Deforestation and Degradation (UN-REDD, 2008) projects under the UNFCCC have been held back due to technical and institutional barriers, with one analysis suggesting that only 3 out of 99 tropical countries have the capacity to produce good quality forest area change and forest inventories (Herold, 2009). As an example, Panama's deforestation would need to increase by $50 \%$ in absolute value before it could be detected by the current national capability (Pelletier et al., 2011). The scope of climate policies will have a significant impact on the design details of the monitoring system and their costs. Issues of economies of scale, i.e. single country or even projects versus a global system, and economies of scope generated by constellations of monitoring systems are crucial determinants of choice (Böttcher et al., 2009).

Natural fluxes need to be measured in order to understand the mechanisms controlling atmospheric concentrations. Globally, natural land and ocean sinks have absorbed $56 \pm 6 \%$ of $\mathrm{CO}_{2}$ from anthropogenic emissions since 1959 (Ciais et al., 2013). Regionally, ocean gyres and subcontinental fluxes can be either sources or sinks of $\mathrm{CO}_{2}$. At synoptic scales, the uncertainty of natural fluxes is as large as their mean value (NRC, 2010; Denman et al., 2007). The global growth rate of $\mathrm{CO}_{2}$ exhibits interannual fluctuations that reflect climate-induced changes in terrestrial (mainly tropical) ecosystem fluxes (Le Quèrè et al., 2009; Alden et al., 2010). Regionally, interannual variability of ocean fluxes can also be significant, for example, in the tropical Pacific and the North Atlantic (Watson et al., 2009; Feely et al., 1999). This interannual variability of fluxes requires longer time series of atmospheric measurements to detect slow changes in $\mathrm{CO}_{2}$ and $\mathrm{CH}_{4}$ emissions and sinks. The current state of research-based observations can neither confidently account for regional fluxes that control the $\mathrm{CO}_{2}$ and $\mathrm{CH}_{4}$ average growth rate nor their interannual changes.

Making accurate future projections requires a quantification of the history of ecosystems' carbon pools and their likely changes in response to business as usual (BAU) human behavior and climate policy interventions. Further, changes in the role of the ocean as a global sink for atmospheric $\mathrm{CO}_{2}$ can have huge consequences for greenhouse gas (GHG) management, so that monitoring ocean fluxes, and their changes in response to climate, is also a key for making accurate future projections.

The RECCAP (REgional Carbon Cycle Assessment and Processes) project (Canadell et al., 2011) attempts to reconcile bottom-up and top-down flux estimates. However, it also exposed large data gaps and uncertainties that prevent current systems from delivering information to support climate policies or to resolve carbon-climate feedbacks. Unlike other emission reduction efforts, such as the 1987 Montreal protocol, reducing $\mathrm{CO}_{2}$ and $\mathrm{CH}_{4}$ emissions will have to involve many economic sectors of society. It will also require many decades of sustained effort (Pacala and Socolow, 2004), and sufficient spatial resolution to be able to monitor and manage impacts resulting from specific governmental policies. Large-scale, non-carbon emission reductions in the past have all required some approach to monitoring and verification to ensure that the desired outcomes are achieved (e.g. measurements of $\mathrm{pH}$ in lakes and rain for sulfur emission reduction; measurements of ozone and ozone-depleting gases for stratospheric ozone recovery; and measurements of ozone, reactive gases and particulate matter for regional air quality improvement). However, the global scale of the problem, the natural and anthropogenic components, the many sources of 
carbon and other GHGs, and links to many sectors of the economy make independent monitoring and verification of the effectiveness of GHG management strategies a necessary albeit daunting task. Thus, the ability to measure GHG fluxes and carbon pools at high spatial and temporal resolution is fundamental to making this task tractable.

Last, it is possible that continued climate change driven by GHG emissions could cause $\mathrm{CO}_{2}$ and $\mathrm{CH}_{4}$ losses from natural ecosystems, acting as positive feedbacks on climate change. These feedbacks could become particularly intense. A detailed spatially resolved observing system with the capacity of accurate monitoring of trends or abnormal variability in $\mathrm{CO}_{2}$ or $\mathrm{CH}_{4}$ fluxes, and changes in carbon storage, could be used in an "early warning" mode to detect "hotspots" and to guide adaptation planning. Observations with particular emphasis over sensitive regions of the global carbon cycle (permafrost, tropical forests, North Atlantic and southern oceans where deep water formation occurs) are thus essential to improve our knowledge of carbon-cycle feedbacks.

This paper describes the current state of research-based carbon observations (Sect. 3) and a strategy for a globally integrated carbon-cycle monitoring system (Sect. 4) designed to make possible the estimation of the distribution of $\mathrm{CO}_{2}$ and $\mathrm{CH}_{4}$ fluxes with sufficient accuracy to assess natural processes and human intervention. In addition, the monitoring system will be able to assess the spatial and temporal distribution of fossil fuel and land use related emissions to support the verification of emission reduction at national and regional scales, while linking them back to global emission quantities and growth in atmospheric $\mathrm{CO}_{2}$ and $\mathrm{CH}_{4}$.

\section{Framework for the carbon monitoring system}

Although research priorities for carbon-cycle science are established, climate policies including detailed provisions of emission reduction treaties, national legislation, and voluntary programs are only partially defined and will continue to evolve over the coming decades. This complicates the formulation of requirements for an integrated carbon monitoring system, and the assessment of relative strengths of different observational approaches and model-data integration schemes. In order to provide a necessary context for the proposed strategy, we establish in this study a framework for a carbon monitoring system based on the following questions:

- What are and were the magnitudes, distribution, variability and trends of anthropogenic $\mathrm{CO}_{2}$ and $\mathrm{CH}_{4}$ emissions, including their attribution to relevant sectors?

- How effective will national, regional, and city- and project-scale policy interventions be in reducing greenhouse gas emissions and/or increasing carbon sequestration?
- What are the magnitudes, distribution, variability, and trends of regional natural $\mathrm{CO}_{2}$ and $\mathrm{CH}_{4}$ fluxes, and what does this information tell us about the underlying natural and human induced mechanisms in each region?

- What and were are the magnitudes, distribution, variability, and trends of regional carbon stocks in natural and managed ecosystems?

- How are $\mathrm{CO}_{2}$ and $\mathrm{CH}_{4}$ sources and sinks likely to behave in the future under higher atmospheric $\mathrm{CO}_{2}$ concentrations and altered patterns of atmospheric composition (nitrogen deposition, elevated ozone), climate, land vegetation, and ocean circulation as well as from human appropriation of terrestrial and marine resources impacting the carbon cycle?

- How soon might positive/negative feedbacks that may enhance/reduce natural $\mathrm{CO}_{2}$ and $\mathrm{CH}_{4}$ emissions, reduce/enhance sinks, possibly associated with thresholds, come into play over different sensitive regions, and how could these feedbacks be detected and quantified by observations?

This study builds on the Integrated Global Observing System-Partnership (IGOS-P) Carbon Theme Team report (Ciais et al., 2004) and on a more recent report prepared for the Group on Earth Observations (GEO) (Ciais et al., 2010), and the US National Research Council report on quantifying and verifying greenhouse gas emissions (NRC, 2010). The carbon observing system outlined in this study will ultimately need to address all carbon greenhouse gases and $\mathrm{N}_{2} \mathrm{O}$, but we are focusing on a "carbon system" for $\mathrm{CO}_{2}$ and $\mathrm{CH}_{4}$ because these two gases represent the highest share of increased radiative forcing (Hofmann et al., 2006). An integrated observing system with the capacity to enable estimations of $\mathrm{N}_{2} \mathrm{O}$ fluxes is not described here, but could be established following similar principles and technology as for $\mathrm{CH}_{4}$ (Hirsch et al., 2006; NRC, 2010; Phillips et al., 2007; Corazza et al., 2011). National and sovereign circumstances will naturally dictate the complexity and type of national monitoring systems that individual countries might agree to establish for reporting emissions to the United Nations Framework Convention on Climate Change (UNFCCC) and for avoiding greenhouse gas losses from ecosystems. Organizations like the Group on Earth Observation (GEO), the World Meteorological Organization (WMO), and the Food and Agriculture Organization (FAO) can play an impartial, international, scientific role here in coordinating global observations and facilitating unencumbered access by all countries to relevant data, information, tools, and methodologies. Existing institutions could also be improved to fulfill such a role (Le Quéré et al., 2010). Policy frameworks on how to manage the biospheric carbon cycle for GHG mitigation are still in a primordial state. In this paper we do not foresee yet specific climate policy implementation mechanisms such as 
performance base payments or activity-based mechanisms, which would obviously drive the design of specific observational components.

\section{Current carbon-cycle observations}

\subsection{State of the art}

The spatial and temporal scales of coverage of current terrestrial and oceanic observation assets are depicted in Fig. 1a and $b$, along with processes impacting the carbon balance of ecosystems and air-sea fluxes (Fig. 1c and d). There is (to our knowledge) no global data-product providing the global spatial distribution of fossil fuel $\mathrm{CO}_{2}$ and $\mathrm{CH}_{4}$ emissions, or of land use change $\mathrm{CO}_{2}$ emissions, including detailed (e.g. hourly) temporal profiles. One can see from Fig. 1 that the mechanisms controlling carbon fluxes in the long term will evolve during the next decades, and are not well sampled by current observing systems.

Over the past ten years, carbon measurements have been collected through various programs and projects. Spatial coverage has either stagnated (many regions still un-sampled) or moderately increased through the establishment of in situ monitoring stations (e.g. ICOS - Integrated Carbon Observation System in Europe; http://www.icos-infrastructure. $\mathrm{eu}$ ), and better access and continuity to key space-based remote-sensing platforms. Implementation has largely remained through research programs, rather than being designed with an operational integrated monitoring system in mind. There is attrition (e.g. closure of Canadian Carbon Program flux sites, risks for the National Oceanic and Atmospheric Administration - Earth System Research Laboratory (NOAA-ESRL) flask sampling network (Houweling et al., 2012) and some atmospheric monitoring stations in Europe). Another obvious gap is the lack of global biomass monitoring capacity.

\subsection{Fossil fuel emissions}

Current data sets of fossil fuel $\mathrm{CO}_{2}$ emissions averaged by country, sector and year are maintained by the International Energy Agency (IEA, 2012) (http://www.iea.org/ co2highlights/co2highlights.pdf), the Carbon Dioxide Information Analysis Center (CDIAC) (Boden et al., 2012) based on the United Nations Statistics Division (UNSO) energy data set, and Emission Database for Global Atmospheric Research - EDGAR4.2 (a product of the Joint Research Center of the European Commission (JRC) together with the Netherlands Environmental Assessment Agency (PBL) (EDGAR4-database, 2009) based on IEA energy data set. Emission maps exist over the globe from different data products (Andres et al., 1996) with limited temporal information (e.g. monthly in Andres et al., 2011).
Because fossil $\mathrm{CO}_{2}$ emissions are currently prescribed as boundary conditions of atmospheric inversion models, they must be measured at the same space/time resolution as the numerical simulation of transport. This implies the objective of characterizing emissions at the scales of $1 \mathrm{~km}$ each hour, including geo-referenced information on large point sources, as appropriate to meso-scale inversion models (Broquet et al., 2011; Lauvaux et al., 2012). This is why over some regions, like North America (Gurney et al., 2009; Pétron et al., 2008), Europe (Pregger et al., 2007) and Southeast Asia (Ohara et al., 2007; Wang et al., 2013) pilot fossil $\mathrm{CO}_{2}$ emissions data products exist at higher spatial resolution, partitioned between economic sectors and temporal profiles. Usually, no error structure is associated with fossil fuel emission data products, although Rayner et al. (2010) described an algorithm to generate one.

Three examples of global and regional fossil emission georeferenced data-products are shown in Fig. 2. The first one is the above-listed EDGAR (www.edgar.jrc.ec.europa.eu) at $10 \mathrm{~km}$ spatial resolution, with no temporal profile. The second is the VULCAN detailed US fossil fuel emission inventory here given hourly at $10 \mathrm{~km}$ resolution, obtained from local/regional air pollution monitoring data complemented with census, traffic, and digital road data sets (vulcan.project. asu.edu/index.php; Gurney et al., 2009). The third one is a $\sim 1 \mathrm{~km}$ spatial resolution map of emissions, with temporal allocation, covering Europe (here we show France only) obtained by disaggregating national emission totals using various activity data for industry, road traffic, and urban use (www.carboeurope.ier.uni-stuttgart.de/).

Global annual fossil fuel $\mathrm{CO}_{2}$ emission values are estimated to have an uncertainty in the range 3-10\% (1-sigma; most of the uncertainty can be considered as bias, e.g. from the use of different statistical data), depending on whether or not the data of three primary fuels (gas, oil, and coal) are independent of each other (Marland et al., 2009). Estimates for individual countries can have much larger uncertainty, up to several tens of \%, especially for developing countries (NRC, 2010). A comparison between the CDIAC and the Dutch National Institute for Public Health and the Environment (RIVM) of fossil $\mathrm{CO}_{2}$ emissions at the country level showed that the largest percentage emission differences are for some developing countries (Marland et al., 1999) but that the largest absolute differences remains for high-emission countries with the best statistical system. The two estimates for the USA, for example, differed by only $0.9 \%$, but in absolute terms this difference was larger than the total emissions from 147 of the 195 countries considered. Better data on fossil fuel consumption and the human activities that are most related to fuel-consumption will be essential in establishing priorities, evaluating success, and confirming agreements (NRC, 2010). Potential approaches for this are addressed in Sect. 4. 

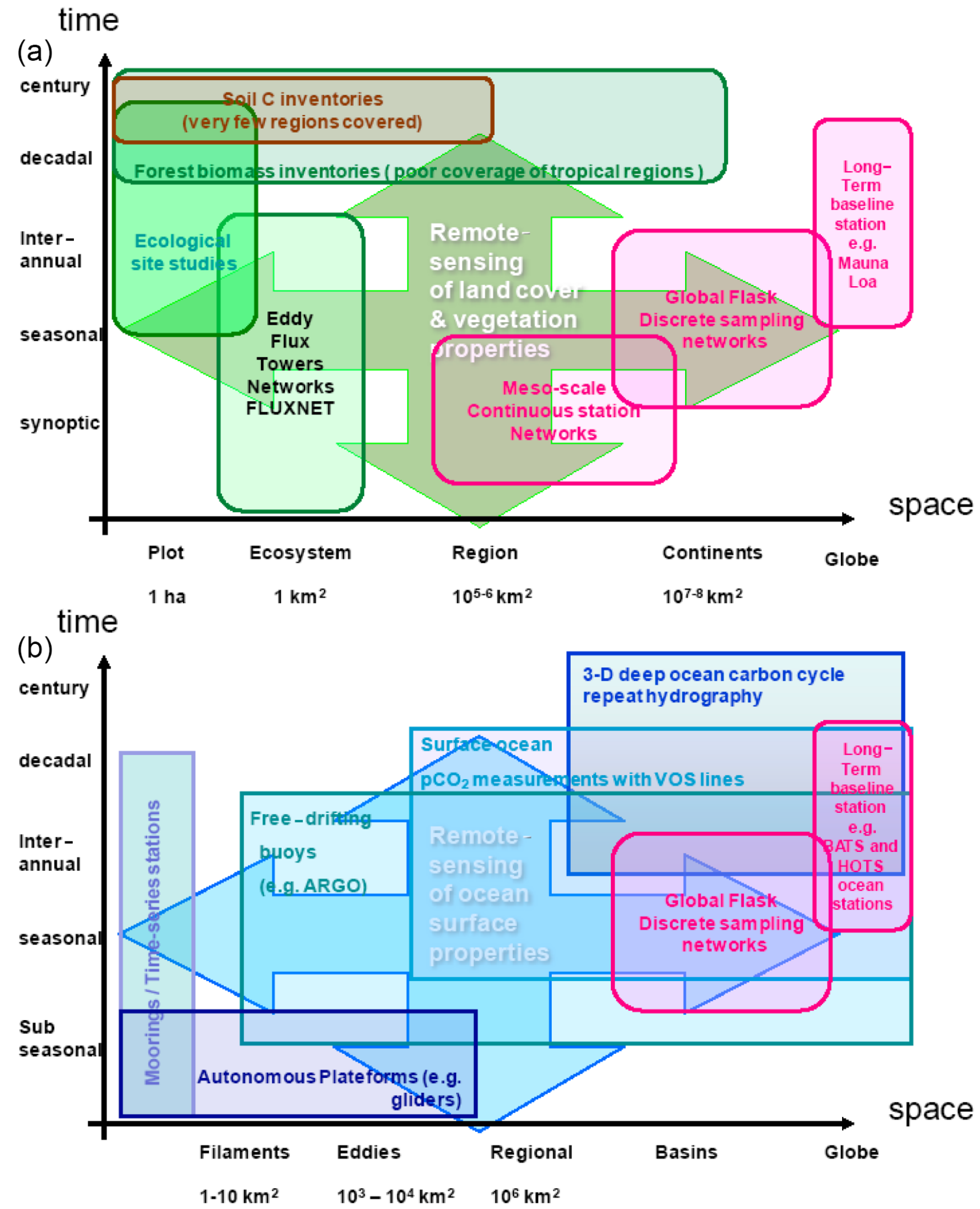

Figure 1. Example of the range of diverse carbon observations that need to be integrated across time and space scales. (A) Terrestrial flux perspective, (B) marine fluxes perspective, (C) terrestrial carbon-cycle processes action on the same space-time diagram, and (D) marine carbon processes. 
Time

(c)

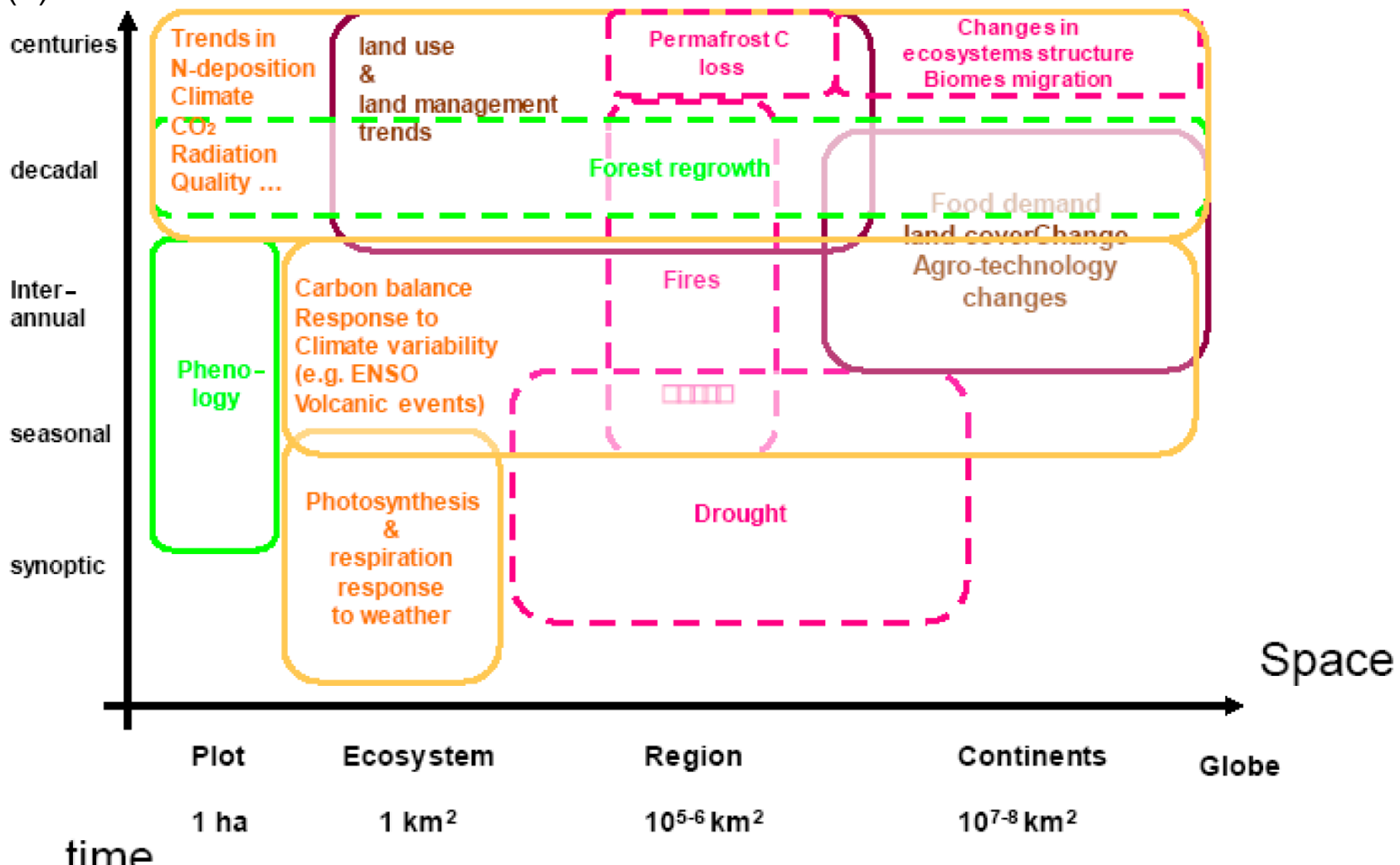

(d)

time

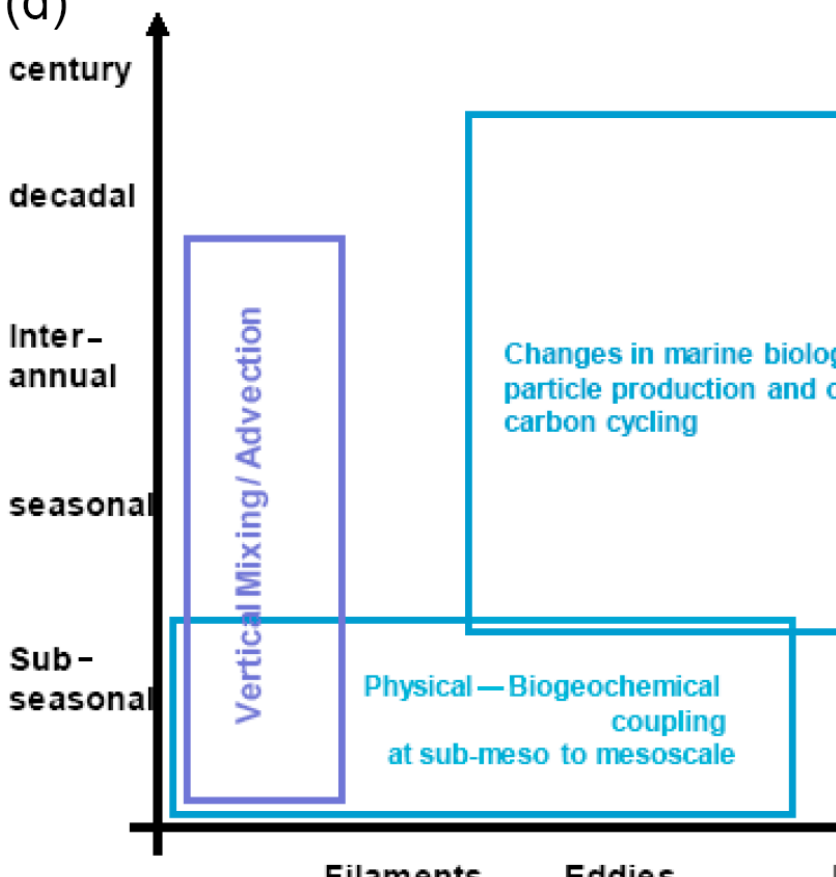

Eddies

Regional

Changes in globalscale circulation (deep water

formation, ...)

$1-10 \mathrm{~km}^{2}$

$10^{3}-10^{4} \mathrm{~km}^{2}$

$10^{6} \mathrm{~km}^{2}$

Figure 1. Continued. 

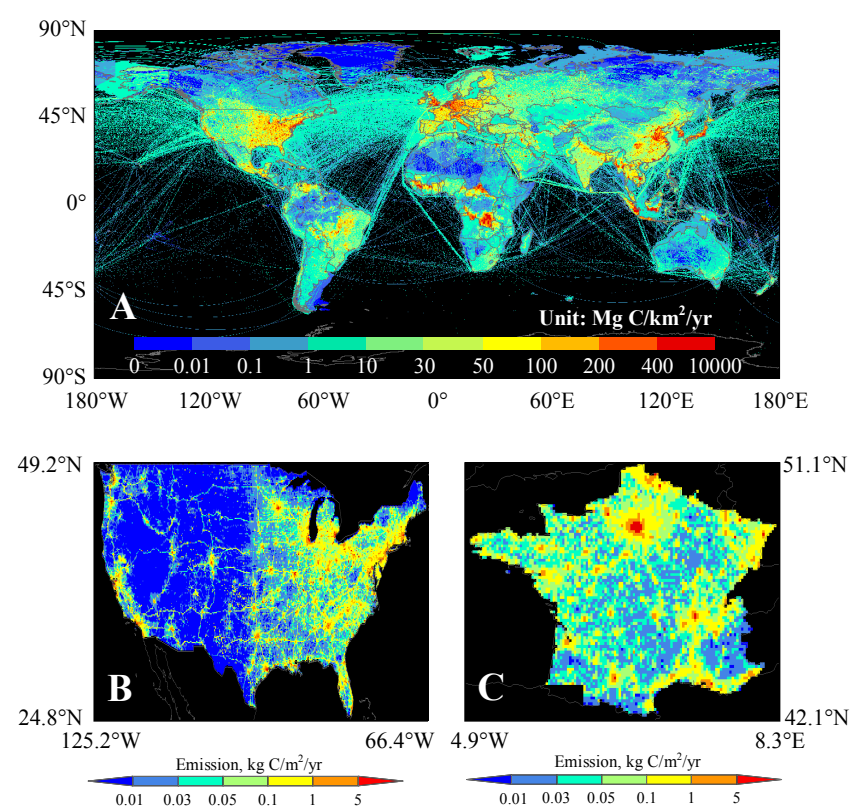

Figure 2. Fossil fuel emission maps obtained from current inventories. (A) Annual emission map for the year of 2010 from EDGAR (release version-4.2 FT2010). The resolution is $10 \mathrm{~km}$. (B) Fossil fuel emission map of the US for the year of 2002 with temporal variability obtained from air pollution data, traffic, and other industrial activity data from the VULCAN project (version 2.2). The resolution is the one of each activity. (C) Map of fossil fuel emissions for the year of 2007 at $10 \mathrm{~km}$ - hourly for France, obtained by disaggregation of national emission statistics using activity data and emission factors for each source of emission from IER, Stuttgart (the IER product has a European coverage). The same color scale is applied for (B) and (C).

\subsection{Atmospheric domain}

\subsubsection{Surface networks of in situ measurement stations, and flask air-sampling stations}

Measurements of atmospheric $\mathrm{CO}_{2}$ and $\mathrm{CH}_{4}$ complement local (i.e. $\sim 1 \mathrm{~m}^{2}$ to $\sim 1 \mathrm{~km}^{2}$ ) observations of fluxes and pools at the ocean and land surface to verify measurements of carbon stock changes and process-level variables at large spatial and temporal scales. The integrative properties of atmospheric mixing mean that atmospheric concentrations of $\mathrm{CO}_{2}$ and $\mathrm{CH}_{4}$ reflect flux processes over large spatial scales. While lacking the process specificity of small-scale ocean or land reservoirs, atmospheric measurements implicitly incorporate all sources and sinks (known and unknown) of a given gas.

Inversion of fluxes from concentrations to derive surface fluxes using transport models has already proved capable of providing global-scale, and in some instances continentalscale, information on fluxes with uncertainties. Some pilot studies have applied atmospheric inversion models at a finer scale down to $\sim 1 \mathrm{~km}$, constrained by regionally denser at- mospheric measurements (Schmitgen et al., 2004; Zupanski et al., 2007; Lauvaux et al., 2012; Göckede et al., 2010; Broquet et al., 2011; Lauvaux et al., 2009). However, the current sparseness of the ground-based network of atmospheric stations cannot constrain the patterns of $\mathrm{CO}_{2}$ sources and sinks at the scale of nations, states/provinces, or cities (Hungershoefer et al., 2010; Chevallier et al., 2010), although some country-level estimates have been derived for $\mathrm{CH}_{4}$ in Europe (Bergamaschi et al., 2010).

The current atmospheric concentration surface network contains 200 flask and in situ continuous measurement stations. Its density is higher in North America, Europe and Japan (Fig. 3). Data from stations reporting to the World Meteorological Organization (WMO) Global Atmosphere Watch (GAW) program can be found at the World Data Center for Greenhouse Gases (WDCGG; www.gaw.kishou.go.jp/ wdcgg/) (WMO, 2009). Atmospheric $\mathrm{CO}_{2}$ observations over the ocean are made on ships and moorings at a few locations. The current situation is that no accuracy information is reported with atmospheric measurements from each station. The tropics and Southern Hemisphere are under-sampled.

Aircraft vertical profile measurements of $\mathrm{CO}_{2}$ and $\mathrm{CH}_{4}$ are particularly important for the independent evaluation of vertical mixing in atmospheric transport models (Stephens et al., 2007) as well as elements of remote-sensing validation. Regular vertical-profile sites using dedicated aircraft exist at about 30 sites around the world without longterm funding (Fig. 3a), mostly in North America (Crevoisier et al., 2010), and operated by National Oceanic and Atmospheric Administration - Global Monitoring Division (NOAA-GMD) (www.esrl.noaa.gov/gmd/ccgg/aircraft/) or intensive research projects (e.g. California Nexus (CalNex), Wennberg et al., 2012). Research projects established regular aircraft measurements in Siberia (Levin et al., 2002; Maksyutov et al., 2003; Paris et al., 2010) and recently over the Amazon (Gatti et al., 2010; Miller et al., 2007).

Instrumented commercial aircraft programs (Machida et al., 2008; Matsueda et al., 2008) Comprehensive Observation Network for trace gases by Airliner (CONTRAIL) (http: //www.cger.nies.go.jp/contrai) and civil aircraft for the regular investigation of the atmosphere based on an instrument container (CARIBIC) (www.caribic-atmospheric.com/) have been collected both continuous and flask $\mathrm{CO}_{2}, \mathrm{CH}_{4}$, and other gases measurements of both vertical profiles during ascent and descent and horizontal transects at the cruising altitude of the aircraft (Fig. 3c).

In 2012, a Corporate Venture announced its intention to build up to $\sim 100 \mathrm{CO}_{2}$ in situ atmospheric continuous sites (Earth Networks; http://www.earthnetworks.com). The National Ecological Observatory Network (NEON) in the US (http://www.neoninc.org/) will operate 60 sites with highquality calibrated in situ $\mathrm{CO}_{2}$ observations, and the European Infrastructure ICOS (http://www.icos-infrastructure. $\mathrm{eu} /$ ) will develop about 35 stations in its first phase. While these efforts will likely increase observation density in North 

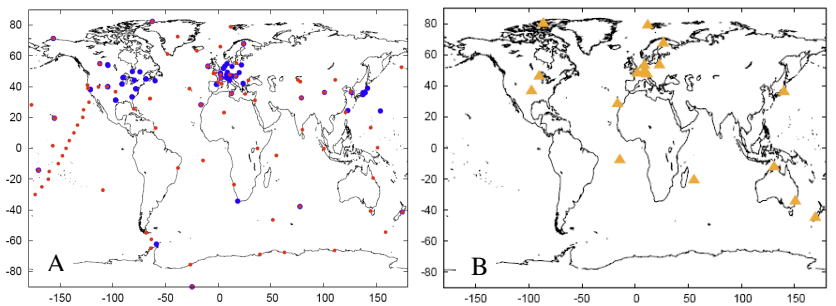

Dedicated aircraft profiles (pink) and passenger aircraft (blue)

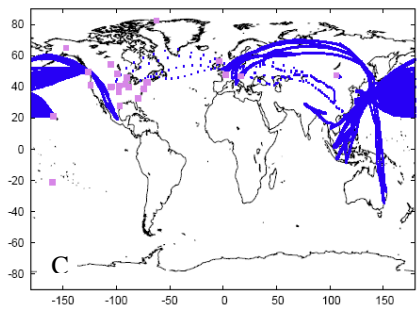

Figure 3. (A) Global network of $\mathrm{CO}_{2}$ surface stations with flask sampling (red symbols) and continuous measurement sites (blue symbols). The data from these sites and from additional stations can be found at WMO GAW World Data Center for Greenhouse Gases (http://ds.data.jma.go.jp/gmd/wdcgg/). (B) Locations of the Total Column Carbon Observing Network by year 2012. These stations are essential for satellite column $\mathrm{CO}_{2}$ and $\mathrm{CH}_{4}$ measurement validation. (C) Location of vertical profile sites, where GHG mixing ratios are measured by dedicated aircraft on a typical monthly basis (pink symbol), and location of passenger instrumented aircraft program flights CONTRAIL and CARIBIC (blue lines).

America and Europe, the commercialization of environmental monitoring is a new concept that has to be evaluated over an extended period. But large gaps in atmospheric observations still exist in northern Eurasia, Asia, Africa, and South America because very few research sites exist.

A key element of surface and aircraft in situ atmospheric observation programs is their unique capability to closely link all observations to a single $\mathrm{CO}_{2}$ and $\mathrm{CH}_{4}$ dry air mole fraction scale defined by the WMO. However, while most research groups make a concerted effort to calibrate their measurements to the WMO scale very frequently are obtained via regular analysis of standard gases. The current situation is that there is no regulatory quality-assurance system ensuring the monitoring of the compatibility and traceability of measurements at each site to the WMO scale. Ongoing voluntary-based comparisons of both standard gases and environmental air samples provide means to assess the quality of linkages between given sites or laboratory measurements to the international scales. If the effort to link measurements from multiple networks is to succeed, it is of the utmost importance that observed $\mathrm{CO}_{2}$ and $\mathrm{CH}_{4}$ concentration differences can be attributed unequivocally to physical processes (and not to differences in calibration).

\subsubsection{Satellite observations of column $\mathrm{CO}_{2}$ and $\mathrm{CH}_{4}$ mixing ratio}

Satellite remote sensing of column $\mathrm{CO}_{2}$ and $\mathrm{CH}_{4}$ mixing ratio with global coverage offers options to complete atmospheric observations over regions with too low surface network density (Fig. 4). Progress has been achieved in the exploitation of existing multipurpose sensors and towards the design of dedicated GHG satellite instruments. Accurate quantification of regional-scale GHG surface fluxes is however challenging, as demanding relative accuracy requirements have to be met, especially for $\mathrm{CO}_{2}$ (Bréon and Ciais, 2009). The initial version of the GOSAT (Greenhouse gases Observing SATellite) operational total column dry air mole fraction $\mathrm{XCO}_{2}$ and $\mathrm{XCH}_{4}$ retrieval algorithm suffered from significant biases and large scatter when compared to ground-based Total Carbon Column Observing Network (TCCON) observations, but this has been improved (Yoshida et al., 2013). Consequently, some preliminary $\mathrm{CO}_{2}$ flux estimates have been produced (Maksyutov et al., 2013; Basu et al., 2013). For methane the situation is better than for $\mathrm{CO}_{2}$, but satellites still need to be used with in situ data to infer methane surface fluxes, as shown by Bergamaschi et al. (2009) using $\mathrm{XCH}_{4}$ retrievals obtained from the SCanning Imaging Absorption spectroMeter for Atmospheric CHartographY (SCIAMACHY) together with flask measurements.

Existing/near-launch instruments for column GHG mixing ratios make measurements either in the thermal infrared spectral domain, with peak sensitivity in the middle troposphere: Atmospheric Infrared Sounder (AIRS), Infrared Atmospheric Sounding Interferometer (IASI), and Thermal Emission Spectrometer (TES), Greenhouse gases Observing SATellite (GOSAT), or in the solar infrared domain: SCIAMACHY (2002-2012), Greenhouse Gas Observing Satellite (GOSAT), Orbiting Carbon Observatory-2 (OCO-2), with a more uniform sensitivity to $\mathrm{CO}_{2}$ and $\mathrm{CH}_{4}$ throughout the atmospheric column, including the boundary layer (Fig. 4). The thermal infrared sounders are not well adapted to inferring surface fluxes as illustrated by Chevallier et al. (2009a), in contrast to near-infrared sounders. Despite this drawback, several groups have used thermal infrared sounders to provide information on column variability (Crevoisier et al., 2004; Chahine et al., 2008; Xiong et al., 2008).

The precision and accuracy of space-based remotely sensed GHG column concentration products vary with instrument and sampling strategy. Unlike in situ sensors, the concentrations of gases in the measurement path cannot be controlled. Thus the direct calibration to the WMO mole fraction scale cannot be established for space-based GHG column concentration. An indirect data evaluation can be made using TCCON total column measurement network data, which themselves can be evaluated against WMO mole fraction scale airborne in situ vertical profiles (Wunch et al., 2010, 2011a). For middle-tropospheric $\mathrm{CO}_{2}$ column abundances from infrared sounders, precision estimates of $1 \mathrm{ppm}$ 


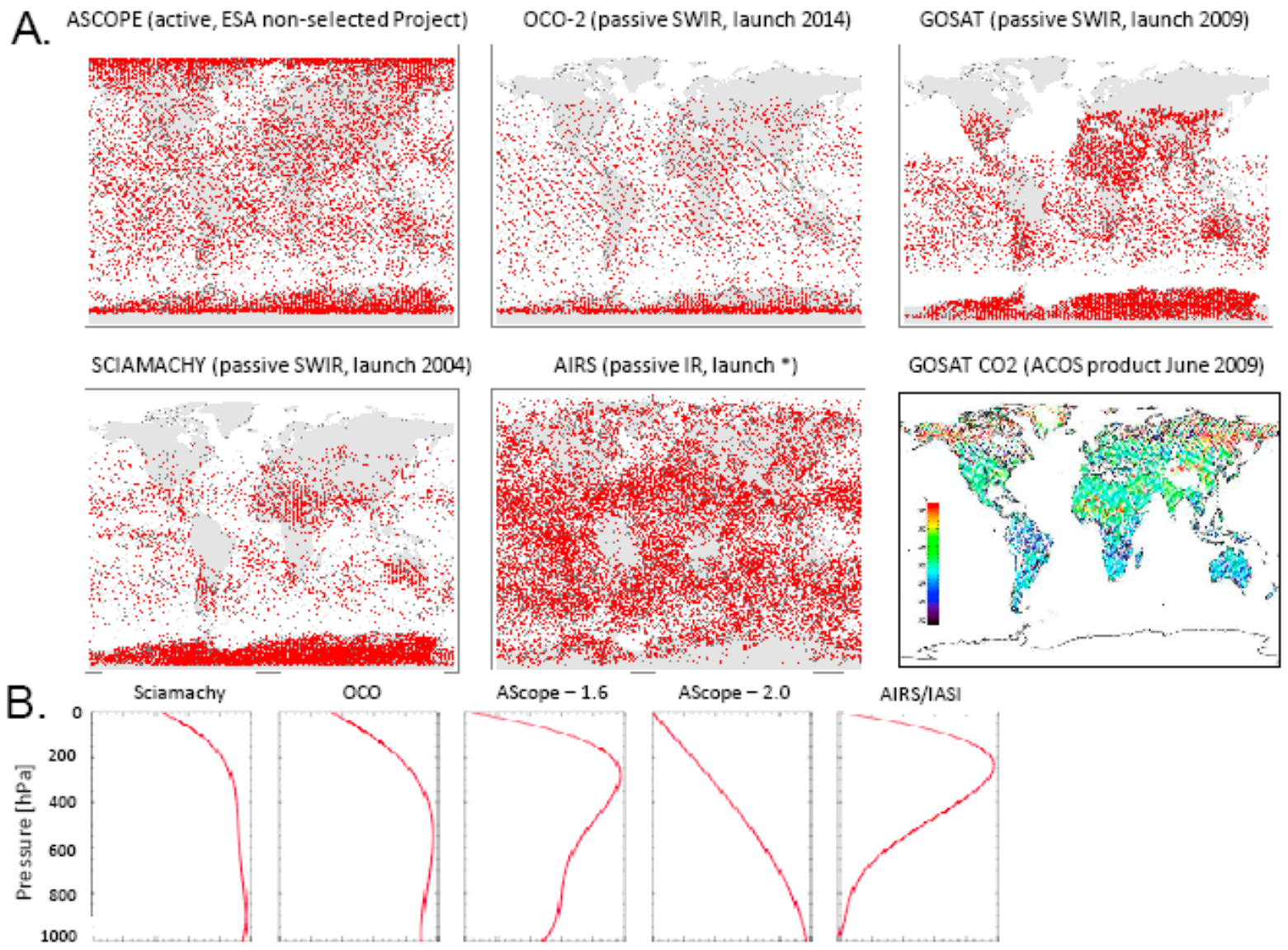

Figure 4. (A) Spatial sampling of the atmosphere by different satellite instruments ASCOPE (an active mission with a lidar not selected by ESA); OCO-2, GOSAT, and SCIAMACHY with measurements of reflected sunlight in near infrared, and their vertical weighting functions; AIRS (or IASI) with measurements from emission in the mid-IR domain, (B) actual column $\mathrm{XCO}_{2}$ measurements from GOSAT XCO (ACOS product, 2009). $X$ axis units is the dimensionless weight in each atmospheric layer.

on $2^{\circ}$ spatial and bi-weekly temporal scale for AIRS (Maddy et al., 2008), $2 \mathrm{ppm}$ precision on $5^{\circ}$ spatial and monthly temporal scale for IASI (Crevoisier et al., 2009a), and $10 \mathrm{ppm}$ single sounding precisions for TES (Kulawik et al., 2010) are reported. For $\mathrm{XCO}_{2}$ from solar backscatter measurements, precision estimates for single soundings of 3 ppm dry air mole fraction for SCIAMACHY (Reuter et al., 2011), and 2 ppm for GOSAT (Yoshida et al., 2013) are reported. Spatially and temporally aggregation of SCIAMACHY and GOSAT data further improve the precision, if errors are mainly random, depending on cloud cover and spatial sampling. Future missions like OCO-2 and Carbon Monitoring Satellite (CarbonSat) target aggregated precisions of $1 \mathrm{ppm}$ and better.

Biases of $\mathrm{XCO}_{2}$ at various space and timescales have hampered inversion studies from these products (Chevallier et al., 2005) despite the progress (Maksyutov et al., 2013). These biases can be caused by uncertainties in the spectroscopy used in the retrieval model, or aliasing with other atmospheric signals like aerosols (Houweling et al., 2005). Bi- ases (e.g. aerosol concentrations or albedo) are likely to be coherent over space and time, requiring significant care to avoid interpreting them as geophysical signals. The launch of GOSAT and the planned launch of OCO-2 in 2014 have raised expectations for $\mathrm{CO}_{2}$ inversions because these two instruments are the first ones to have been specifically designed for the detection of atmospheric $\mathrm{CO}_{2}$ (see for example, Chevallier et al., 2009b, their Fig. 4). In addition, the methods are under development to account for large-scale biases using TCCON data (Wunch et al., 2011b).

For current mid-to-upper tropospheric concentrations of methane $\left(\mathrm{CH}_{4}\right)$ from thermal infrared sounders like IASI, reported precision estimates are in the range of $17-35 \mathrm{ppb}$ on $5^{\circ}$ spatial and monthly temporal scale (Crevoisier et al., 2009b). For $\mathrm{XCH}_{4}$, reported precision estimates for individual soundings are about $17-35 \mathrm{ppb}$ for SCIAMACHY (Frankenberg et al., 2006) and $12.5 \mathrm{ppb}$ for GOSAT (Yoshida et al., 2013). Spatially and temporally aggregated precisions of SCIAMACHY and GOSAT can reach the $10 \mathrm{ppb}$ level (and even below for GOSAT) depending on cloud cover 
and spatial sampling. Future missions like CarbonSat target aggregated measurement precisions of $5 \mathrm{ppb}$. As shown by Bergamaschi et al. (2009), biases in satellite $\mathrm{XCH}_{4}$ retrievals can be (arbitrarily) corrected when calculating fluxes by anchoring the inversion with surface in situ station measurements. More development is required in the rigorous statistical weighting of sparse, but high-accuracy in situ observations with much more numerous, but potentially noisy and biased satellite observations. This opens the possibility of a decadal monitoring of global $\mathrm{CH}_{4}$ fluxes from SCIAMACHY and GOSAT, in orbit since March 2002 and January 2009, respectively, combined with surface in situ network.

The critical potential contribution of satellite $\mathrm{XCO}_{2}$ and $\mathrm{XCH}_{4}$ observations to improving atmospheric flux inversions is clearly their ability to increase the density of observations. Well-calibrated and precise satellite observations should offer the potential to reduce some of the uncertainties associated with sparse sampling. However current assets are far from perfect in terms of spatial coverage, spatial resolution, near-surface sensitivity, and temporal sampling. The current satellites have fairly large "footprints" (surface pixel scale), for example, IASI $=13 \mathrm{~km}$, and GOSAT $=10 \mathrm{~km}$. This translates into relatively few cloud-free scenes necessary to achieve good retrievals. These, combined with repeat intervals measured in days or weeks on polar orbits, result in fairly infrequent sampling of a given surface location, translating to information gaps on the variability of fluxes on timescales shorter than about a month. Additionally, many of these satellites are in sun-synchronous orbits so they are typically limited to providing one observation at a given local time on a given day rather than offering sampling of diurnal variations in atmospheric gases.

Table 1 summarizes the estimated precision of $\mathrm{XCO}_{2}$ and $\mathrm{XCH}_{4}$ retrieved products, surface (orbital along track) spatial resolution, and vertical sensitivity offered by current satellite atmospheric GHG sounders. In addition to $\mathrm{CO}_{2}$ and $\mathrm{CH}_{4}$ sounders, there are several satellites currently in operation that offer column-averaged soundings of other atmospheric, short-lived species such as CO (e.g., Measurements of Pollution in the Troposphere - MOPITT) and $\mathrm{NO}_{2}$ (e.g., Global Ozone Monitoring Experiment - GOME-2, Ozone Monitoring Instrument - OMI) associated with combustion processes that might be useful in improving source attribution (if properly integrated with $\mathrm{XCO}_{2}$ data). Such data fusion has not yet been systematically investigated (Berezin et al., 2013).

\subsubsection{Emerging airborne remote-sensing observations of $\mathrm{CO}_{2}$ and $\mathrm{CH}_{4}$ mixing ratio}

Airborne remote-sensing sensors offer emerging capabilities that complement surface and satellite observations. Those sensors are often significantly more capable than current satellite sensors - either due to lower operation altitudes (higher signal to noise ratio) or because they represent prototypes of next generation technology that has yet to com- plete space qualifications. One example of such a system is the NASA Carbon in Arctic Reservoirs Vulnerability Experiment (CARVE) which provides aircraft remote sensing of $\mathrm{XCO}_{2}$ and $\mathrm{XCH}_{4}$, backed by a comprehensive suite of flasks and in situ sensors, and a microwave soil-moisture sensor. Another example is the Methane Airborne Mapper (MAMAP) that includes a grating spectrometer offering remote sensing of $\mathrm{CO}_{2}$ and $\mathrm{CH}_{4}$ column averaged mixing ratios (Gerilowski et al., 2011). Data from MAMAP gathered during several campaigns and its analysis using inverse plume modeling demonstrated that single $\mathrm{CO}_{2}$ and $\mathrm{CH}_{4}$ point source emissions can be detected and quantified independently using remote-sensing data (Krings et al., 2011, 2013). In addition, light detection and ranging (lidar) airborne measurements of $\mathrm{CO}_{2}$ and $\mathrm{CH}_{4}$ have been performed, the latter in preparation of the Methane Remote Lidar (MERLIN) mission (Fig. 7).

\subsubsection{Surface network of remote-sensing measurement stations}

The Total Carbon Column Observing Network (TCCON) ground-based network (www.tccon.caltech.edu/, Wunch et al., 2011a) measured at some 18 stations in 2012 (Fig. 3b) in the near-infrared solar absorption spectrum. The current TC$\mathrm{CON}$ standard product already consisted of $\mathrm{XCO}_{2}, \mathrm{XCH}_{4}$, $\mathrm{XCO}, \mathrm{XN}_{2} \mathrm{O}, \mathrm{XH}_{2} \mathrm{O}, \mathrm{XHCl}, \mathrm{XHF}, \mathrm{XHDO}$, and all routinely submitted to TCCON data archive. More species are possible and could be retrieved from the already existing measured spectra. An extension of the TCCON wavelength range would allow measurements of $\mathrm{XOCS}, \mathrm{XC}_{2} \mathrm{H}_{6}$, and many other species, although it will require an upgrade of instrument and lead to costly logistics.

The TCCON instruments currently work to retrieve column-average mixing ratios with a precision of $\sim 1 \mathrm{ppm}$ for $\mathrm{XCO}_{2}$ and $3 \mathrm{ppb}$ for $\mathrm{XCH}_{4}$. These data are crucial for satellite column measurement validation. They can also be reliably used in inversions (Chevallier et al., 2011). Unlike surface in situ observations where the concentration of the gases in the observation path can be defined by introduction of standard gases, less certain, "vicarious" means of linkage to the WMO scales must be used (Wunch et al., 2010), which causes uncertainty in the calibration of TCCON to the WMO mole fraction scale. The "vicarious" means are typically aircraft measurements with instruments that are commonly used for continuous in situ measurements. The uncertainties are mostly due to parts of the atmosphere that are not easily accessible to in situ measurements (stratosphere) but are seen by both ground-based and space-borne remote-sensing instruments. Both the calibration factors for $\mathrm{XCO}_{2}$ and $\mathrm{XCH}_{4}$ and their uncertainties have been well established (Wunch et al., 2010; Messerschmidt et al., 2011; Geibel et al., 2012). TCCON does, however, provide a way to assess the compatibility of satellite measurements with the WMO mole fraction scale (Keppel-Aleks et al., 2012). 
Table 1. Measurement methods for $\mathrm{CO}_{2}$ and $\mathrm{CH}_{4}$ column measurements from space borne sensors, with precisions, sampling, and species measured.

\begin{tabular}{|c|c|c|c|c|c|c|c|}
\hline $\begin{array}{l}\text { Measure- } \\
\text { ment } \\
\text { method }\end{array}$ & Instrument & $\begin{array}{l}\mathrm{XCO}_{2} \\
\text { or } \mathrm{XCH}_{4} \\
\text { measure- } \\
\text { ment }\end{array}$ & $\begin{array}{l}\mathrm{XCO}_{2}, \\
\mathrm{XCH}_{4} \\
\text { product } \\
\text { precision* }\end{array}$ & $\begin{array}{l}\text { Aggregated } \\
\text { or single } \\
\text { sounding } \\
\text { precision }\end{array}$ & $\begin{array}{l}\text { Down } \\
\text { track } \\
\text { sampling }\end{array}$ & $\begin{array}{l}\text { Other } \\
\text { gases }\end{array}$ & $\begin{array}{l}\text { Main } \\
\text { reference }\end{array}$ \\
\hline \multicolumn{8}{|c|}{ Reflected sunlight in near infrared } \\
\hline & SCIAMACHY & $\begin{array}{l}\text { Total } \\
\text { column }\end{array}$ & $3 \mathrm{ppm}$ & $\begin{array}{l}\text { Single } \\
\text { sounding }\end{array}$ & $60 \mathrm{~km}$ & $\begin{array}{l}\mathrm{CH}_{4}, \mathrm{CO}, \mathrm{H}_{2} \mathrm{O}, \\
\mathrm{O}_{3}, \mathrm{O}_{2}, \mathrm{NO}_{2}, \\
\mathrm{HCHO}, \mathrm{SO}_{2}, \\
\mathrm{CHOCHO}, \\
\text { and others }\end{array}$ & $\begin{array}{l}\text { Reuter et al. } \\
(2011)\end{array}$ \\
\hline & $\begin{array}{l}\text { GOSAT } \\
\text { (NIR/SWIR) }\end{array}$ & $\begin{array}{l}\text { Total } \\
\text { column }\end{array}$ & $2 \mathrm{ppm}$ & $\begin{array}{l}\text { Single } \\
\text { sounding }\end{array}$ & $10.5 \mathrm{~km}$ & $\mathrm{CH}_{4}, \mathrm{H}_{2} \mathrm{O}, \mathrm{O}_{2}$ & $\begin{array}{l}\text { Yoshida et al. } \\
\text { (2013) }\end{array}$ \\
\hline \multicolumn{8}{|l|}{ Lidar } \\
\hline & MERLIN & $\begin{array}{l}\mathrm{CH}_{4} \text { total } \\
\text { column }\end{array}$ & $20 \mathrm{ppb}$ & $\begin{array}{l}\text { Average of } \\
50 \mathrm{~km} \text { along } \\
\text { track sounding }\end{array}$ & $50 \mathrm{~km}$ & & \\
\hline \multicolumn{8}{|c|}{ Emission in thermal infrared } \\
\hline & AIRS & Mid-trop & $2 \mathrm{ppm}$ & $\begin{array}{l}2^{\circ} \times 2^{\circ} \\
\text { bi-weekly }\end{array}$ & $45 \mathrm{~km}$ & $\begin{array}{l}\mathrm{CH}_{4}, \mathrm{CO}, \mathrm{H}_{2} \mathrm{O}, \\
\mathrm{O}_{3}, \mathrm{SO}_{2}\end{array}$ & $\begin{array}{l}\text { Maddy et al. } \\
(2008)\end{array}$ \\
\hline & IASI & Mid-trop & $2 \mathrm{ppm}$ & $\begin{array}{l}5^{\circ} \times 5^{\circ} \\
\text { monthly }\end{array}$ & $10 \mathrm{~km}$ & $\begin{array}{l}\mathrm{CH}_{4}, \mathrm{CO}, \mathrm{H}_{2} \mathrm{O} \text {, } \\
\mathrm{O}_{3}, \mathrm{SO}_{2}, \mathrm{HNO}_{3} \\
\text { and others }\end{array}$ & $\begin{array}{l}\text { Crevoisier et al. } \\
(2009 a)\end{array}$ \\
\hline & TES & Mid-trop & $10 \mathrm{ppm}$ & $\begin{array}{l}\text { Single } \\
\text { sounding }\end{array}$ & $100 \mathrm{~km}$ & $\begin{array}{l}\mathrm{CH}_{4}, \mathrm{CO}, \mathrm{N}_{2} \mathrm{O} \\
\mathrm{O}_{3}, \mathrm{H}_{2} \mathrm{O}, \mathrm{HNO}_{3}\end{array}$ & $\begin{array}{l}\text { Kulawik et al. } \\
\text { (2010) }\end{array}$ \\
\hline & & & $1-2 \mathrm{ppm}$ & $\begin{array}{l}20^{\circ} \times 30^{\circ} \\
\text { monthly }\end{array}$ & & & \\
\hline
\end{tabular}

* $\mathrm{CO}_{2}$ products often have different precision and spatial scale than for individual samples.

\subsection{Ocean domain}

\subsubsection{Ocean $\Delta p \mathrm{CO}_{2}$ data for air-sea flux products}

Surface ocean $\Delta p \mathrm{CO}_{2}$ measurements together with atmospheric $\mathrm{CO}_{2}$ measurements are essential for determining airsea $\mathrm{CO}_{2}$ fluxes. The current situation is illustrated by a published global flux map, based on a compilation of $\sim 3$ million measurements, for a typical "normal" non-El Niño year taken to be 2000 (Takahashi et al., 2009). The number of annual surface $\Delta p \mathrm{CO}_{2}$ observations has been growing since the late 1960 s such that today well over one million observations are reported to data centers each year. This increase in the number of observations provides new opportunities to look at the patterns of air-sea $\mathrm{CO}_{2}$ fluxes in greater detail to understand the seasonal to interannual variations and the mechanisms controlling them. Air-sea flux calculation from $\Delta p \mathrm{CO}_{2}$ requires knowledge of gas transfer velocities, which depend on wind speed, adding accuracy to flux estimates from $\Delta p \mathrm{CO}_{2}$ measurements.
A key ongoing international effort, the Surface Ocean $\mathrm{CO}_{2}$ Atlas (SOCAT) aims to synthesize $\Delta p \mathrm{CO}_{2}$ data collected over the last 40 years into a quality controlled data base, along with uniform metadata, that can be used to examine $\Delta p \mathrm{CO}_{2}$ variability over a range of time and space scales (Pfeil et al., 2013; Sabine et al., 2013). The current version of the SOCAT $\Delta p \mathrm{CO}_{2}$ database contains more than 6 million observations collected by research ships, commercial volunteer ships, and moorings (Fig. 5). It is expected to reach more than 10 million in the second release. Over the best-sampled ocean regions, such as the North Atlantic and the equatorial Pacific, mean air-sea $\mathrm{CO}_{2}$ fluxes can be reconstructed to within $20 \%$, and their interannual variation to within $10 \%$ (Watson et al., 2009). However, the majority of the ocean is still under-sampled despite the $40 \mathrm{yr}$ data set (Fig. 5). The use of autonomous platforms for making surface carbon measurements is a cost effective technology for mapping areas not typically covered by standard shipping routes. 

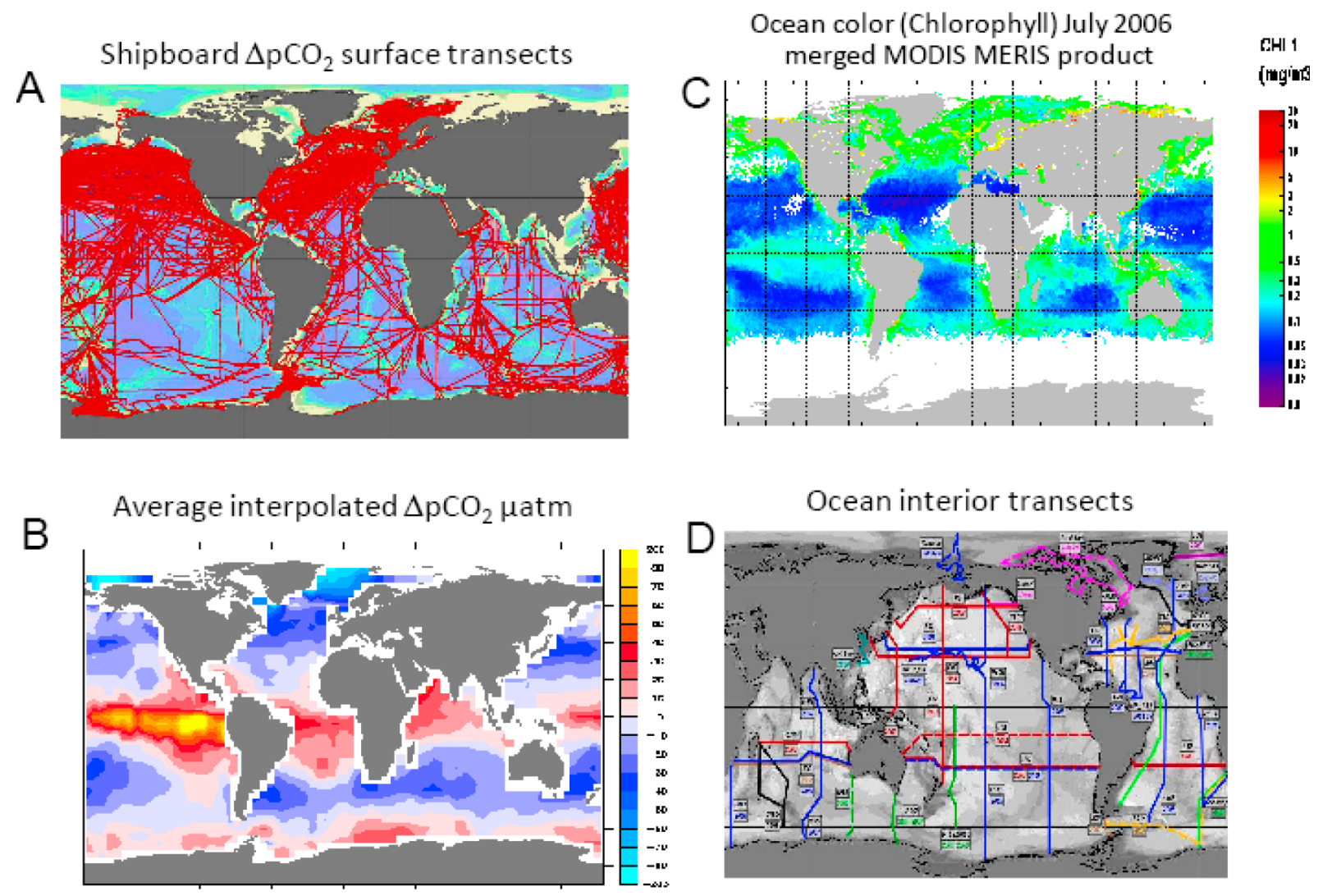

Figure 5. (A) Spatial sampling of surface ocean from research vessels and ships of opportunity observing $\Delta p \mathrm{CO}_{2}$ for air-sea flux (from SOCAT). (B) Global $\Delta p \mathrm{CO}_{2}$ climatology synthesis obtained from these more than 6 million local measurements (Takahashi et al., 2009). (C) Merged MERIS/MODIS ocean colour product ( $\mathrm{Chl} a$ ). (D) Transects of main ocean interior measurement campaigns (cross sections from GO-SHIP plan).

\subsubsection{Ocean interior measurements}

In the late 1980s and early 1990s, carbon samples in the ocean interior were collected and analyzed from 95 research cruises run over about a 10 year period, part of the Joint Global Ocean Flux Study (JGOFS) and World Ocean Circulation Experiment (WOCE) (Fig. 5). Based on these data, Sabine et al. (2004) estimated that the total inventory of anthropogenic carbon that had accumulated in the ocean up to 1994 was $118 \pm 19 \mathrm{PgC}$, accounting for $48 \%$ of $\mathrm{CO}_{2}$ released from fossil fuel burning between 1800 and 1994. Recent work shows that several marginal seas, not directly sampled by the data used by Sabine et al. (2004), stored more anthropogenic carbon per unit area than the open ocean, and that they contributed significant carbon to their adjacent major ocean basins (Lee et al., 2011).

Systematic and global re-occupation of select hydrographic sections was initiated by the international community in the early 2000 s to quantify changes in storage and transport of heat, fresh water, carbon dioxide $\left(\mathrm{CO}_{2}\right)$, and related parameters (internationally coordinated through the Global Ocean Ship-Based Hydrographic Investigation Pro- gram (GO-SHIP); www.go-ship.org). The current situation is that data from these repeat occupations have already revealed substantial changes in the ocean interior carbon storage in response to the continuing uptake of anthropogenic $\mathrm{CO}_{2}$ (e.g., Wanninkhof et al., 2010; Sabine et al., 2008; Murata et al., 2007; Feely et al., 2012) as well as the presence of a substantial amount of decadal variability in the ocean carbon cycle. In addition to documenting changes that already occurred since the first occupation, these repeat hydrographic measurements continue to serve as a baseline to assess future changes. Repeat surveys of the ocean with physical parameter measurements are also suited to detect changes in oceanic transport of heat, as well as changes in oxygen (Keeling et al., 2010) and nutrients. Below the level of the ARGO array of automated floats (www.argo.ucsd.edu/) repeat hydrography is the only global method capable of observing long-term trends in ocean carbon. The program also provides data for sensor calibration and to support continuing model development that lead to improved forecasting skills for oceans and global climate.

For the global ocean, the Global Ocean Data Analysis Project (GLODAP) data set (Key et al., 2004) that assembled 
the data from the first global survey has become a benchmark for testing biogeochemical ocean general circulation models. It also has served as the basis for first data assimilation efforts to estimate global-scale ocean-atmosphere $\mathrm{CO}_{2}$ fluxes (Gruber et al., 2009; Gloor et al., 2003). For different oceans or ocean basins, new repeat hydrography data syntheses have been created (e.g. CARbon dyoxide IN the Atlantic Ocean - CARINA, Key et al., 2010) or are emerging (e.g. PACIFic ocean Interior CArbon - PACIFICA data set through the North Pacific Marine Science Organization (PICES) and other partners). The data collected so far through the repeat hydrography program are too sparse to unambiguously document the global-scale accumulation of anthropogenic $\mathrm{CO}_{2}$ since the 1990s, although the data collection PACIFICA is now finalized and published at http://cdiac.ornl.gov/oceans/ PACIFICA/ and ongoing synthesis work will likely resolve this challenge soon (e.g. Sabine and Tanhua, 2010).

Currently, monitoring programs do not exist for oceanic $\Delta p \mathrm{CH}_{4}$, as the ocean is considered to be only a minor source of this greenhouse gas (Ciais et al., 2013). However, the potential for enhanced destabilization of $\mathrm{CH}_{4}$ gas hydrates under climate change requires attention, especially in vulnerable regions such as coastal slopes and the Arctic (Biastoch et al., 2011).

\subsubsection{Ocean in situ biological measurements related to carbon cycle}

Primary production, carbon and nitrogen fixation, metabolism, and biological species composition contribute to an understanding of the ocean carbon cycle. Those biological observations provide insight to marine populationand community-level changes and could ultimately lead to development of biological indicators, for example to characterize the biological effects of ocean acidification. In addition, measurements of ocean partial pressure of $\mathrm{N}_{2} \mathrm{O}$ and $\mathrm{CH}_{4}$ on research cruises have enabled partial/regional estimates of air-sea fluxes of these greenhouse gases. New observations of $\mathrm{O}_{2}$ vertical profiles within the ocean from ARGO free-drifting buoys have shown promising results, and an increase in the number of buoys carrying $\mathrm{O}_{2}$ sensors is expected as the technology improves the reliability and power consumption (Gruber et al., 2010). The development of optical sensors has allowed the measurement of phytoplankton fluorescence onboard ARGO buoys (Johnson et al., 2009; Claustre et al., 2010) providing a new tool to monitor biological productivity, and thus the carbon cycle, within the ocean interior. The increase in the number of bio-optical ARGO buoys in forthcoming years will complement available satellite ocean color data of surface chlorophyll concentration. Furthermore, the advent of $\mathrm{pH}$ and nitrate sensors provides the potential to expand the suite of measurements to assess the trophic status as well as ocean acidification (Johnson et al., 2009). A number of carbon-related ( $\triangle p \mathrm{CO}_{2}$, TA, $\mathrm{pH}$, DIC) sensors for ocean use on autonomous vehicles are being developed and tested.

\subsubsection{Remote sensing of ocean carbon-cycle parameters}

For the oceans, remote sensing is critical for understanding global patterns of ocean physics (e.g., temperature, dynamic height), biology (e.g., ocean color), chemistry (e.g., salinity) and air-sea forcing properties (e.g., surface winds, wave height). Two long time series of satellite data have greatly contributed to a better estimation of carbon fluxes: the Advanced Very High Resolution Radiometer (AVHRR) initiated sea surface temperature (SST) since the early 1980s, and the Sea-viewing Wide Field-of-view Sensor (SeaWiFS) initiated chlorophyll $a$ concentration (a proxy of the phytoplankton concentration in surface waters) available since the late 1990s (http://oceancolor.gsfc.nasa.gov/) (McClain, 2009). These records advanced the understanding of the temporal variability and spatial distribution of physical and biological parameters in the ocean, leading to important improvements in ocean modeling during the last decades. More recent sensors such as MODIS (Moderate-Resolution Imaging Spectroradiometer) (Franz et al., 2006) and MERIS (MEdiumResolution Imaging Spectrometer) (Rast et al., 1999) have strengthened and extended this space-based ocean observing system (Fig. 5). A third satellite data product of high importance for ocean carbon-cycle studies are direct wind speed measurements from a range of scatterometers, such as Quick Scatterometer - QuikSCAT/SeaWinds (http://winds.jpl.nasa. gov/missions/quikscat/).

Currently, estimating air-sea $\mathrm{CO}_{2}$ fluxes from combined satellite and in situ measurements remains a challenge because the carbon content in the ocean surface layer depends not only on the surface temperature and phytoplankton biomass (that can be monitored from space), but also on the mixed layer depth and water-mass history. Recent attempts that combine satellite data and model simulation showed the potential of this approach (Telszewski et al., 2009). Development of operational ocean circulation models associated with satellite products will probably lead to an acceleration of the use of these approaches to routinely produce ocean $\mathrm{CO}_{2}$ fluxes. In the near term, these methods will benefit from the sea surface salinity (SSS) measurement using the Soil Moisture Ocean Salinity (SMOS) sensor launched in 2009, and the Aquarius sensor launched in 2011. In regions affected by the discharge of large rivers, such as the equatorial Atlantic with the Amazon and Congo rivers' plumes, the thermodynamic processes that control $\Delta p \mathrm{CO}_{2}$ depend not only on the SST but also on the SSS (De La Paz et al., 2010).

New satellite products are expected to enhance ocean color products. The detection of the phytoplankton functional types is an example of product useful to better understand the biological pump of carbon in the ocean (Alvain et al., 2005; Uitz et al., 2010), because phytoplankton species play very different role in carbon uptake and export. All these 
new measurements and methods will allow more precise estimates of carbon fluxes in the open ocean, but their equivalent for the coastal ocean is still in the future. Despite its importance in global $\mathrm{CO}_{2}$ (Laruelle et al., 2010) and $\mathrm{CH}_{4}$ fluxes (Bange, 2006), the coastal ocean is particularly challenging to observe from space for reasons that range from the diurnal cycle of the biology to specific atmospheric corrections, and to the complex water optical properties (Borges, 2011). Ocean color sensors onboard geostationary platforms such as the Korean Geostationary Ocean Color Imager (GOCI) satellite (www.kosc.kordi.re.kr) are likely the most suitable approach to tackle the issue of monitoring coastal waters because of their high frequency of observation. New sensors making observations in ultraviolet wavelengths could enable detection of dissolved organic matter.

\subsection{Terrestrial Domain}

\subsubsection{Eddy covariance flux tower networks}

The FLUXNET program (www.fluxnet.ornl.gov/fluxnet/ index.cfm; www.fluxdata.org; Baldocchi et al., 2001) is a collaboration of regional networks monitoring $\mathrm{CO}_{2}$, water vapor and energy fluxes (together with microclimatic and ancillary data), intended to combine data for global synthesis of terrestrial sources and sinks of $\mathrm{CO}_{2}$. These measurements have a very limited spatial footprint for fluxes $\left(1 \mathrm{~km}^{2}\right)$ and rather high uncertainties (Hollinger and Richardson, 2005) but they seem to possess a large representativeness through up-scaling of site measured ecosystem responses (e.g. Jung et al., 2011; Xiao et al., 2011). The network expanded from $\sim 100$ towers in 2000 to almost 500 in 2009 (Fig. 6a). In the recent years, the number of flux towers stabilized after 2010 and declined in North America and Europe. The increased number of towers (now broadly representing different vegetation types, climates, and disturbances, although some biomes such as tropical forest and savanna are undersampled; Williams et al., 2009), and the increased length of time series (many sites have been operating for a decade or more) allow scientists to address more complex scientific questions and produce information more useful to decision makers (Baldocchi, 2008).

An effort to compare and standardize large parts of the flux processing has been made with respect to quality control, gap-filling, flux-partitioning, and uncertainty analysis (Reichstein et al., 2005; Papale et al., 2006; Desai et al., 2008; Lasslop et al., 2010). A standardized data set containing more than 950 years from 250 sites globally has been established. Research is ongoing with respect to flux correction and accuracy estimation, although uncertainties have been assessed by comparing data from co-located measurement systems at 84 sites in the US (Schmidt et al., 2012). Information from remote-sensing measurements of surface biophysical parameters (see list for instance in Law et al., 2008a), gridded climate data (using data mining), and empirical models based upon pattern recognition, optimal interpolation, and machine learning algorithms (Jung et al., 2009, 2011) allows production of global maps of photosynthesis (gross primary production - GPP) (Beer et al., 2010) (Fig. 6b), water, and energy exchange fluxes (Jung et al., 2010; Jiménez et al., 2011).

Current attempts to produce maps of Net Ecosystem $\mathrm{CO}_{2}$ Exchange (NEE) (Jung et al., 2011) from flux towers have been much less successful than for GPP and energy fluxes. Additional information on disturbance history and forest age (Pan et al., 2011a) must be considered in up-scaling NEE from sites to regions. Disturbance alters the balance of terrestrial $\mathrm{CO}_{2}$ exchange with the atmosphere, increasing respiration and reducing photosynthesis, thereby making ecosystems carbon sources. Disturbed ecosystems cover a variable, small, but unknown fractional area of the land, and are intense sources of $\mathrm{CO}_{2}$ to the atmosphere until plant production recovers, leading to a gradual change in activity towards a carbon sink. In recent years, there have been developments in the use of the eddy covariance measurement technique for measuring $\mathrm{CH}_{4}$ and $\mathrm{N}_{2} \mathrm{O}$ fluxes (Hargreaves et al., 2001; Rinne et al., 2007; Smeets et al., 2009; Kroon et al., 2010) but no global product exists to our knowledge.

\subsubsection{Forest biomass inventories}

Developed countries have forest-cover change mapping programs and national forest inventories that span decades and contain data from a large number of sampling locations (e.g. $>150000$ in the US). Forest inventories were set up to inform the national wood industry and therefore often exclude woodlands that do not contribute to wood harvest. Tropical countries have little or no inventory data, nor have comprehensive estimates of all relevant carbon pools, except for research networks such as RAINFOR in South America (Phillips et al., 1998, 2009), and CARBOAFRICA (Henry, 2010), AFRITRON (Lewis et al., 2009) and other regional studies (e.g. Ryan et al., 2011) in Africa.

The main source for global data sets covering each country remains the periodic reports of the Food and Agriculture Organization (FAO) Forest Resource Assessment (FAO, 2009, 2010). These reports suffer from data gaps, sampling biases, inconsistent methods, a lack of spatial information and unrepresentative samples (Grainger, 2008). These limitations suggest that FAO data are not accurate enough at required scales for constraining regional patterns in forest carbon stock changes. In forest inventories, individual plot data are not provided, and few data are available at sub-country scale. Estimation of whole stand biomass is based on measurement of stem diameter using empirical allometric relations elaborated by different methods in each country (Henry et al., 2010; Parresol, 1999; Wirth et al., 2004). These methods are not comparable between countries, or between different forests, which leads to regional bias.

Revisiting inventory plots allows one to measure biomass changes over the time period between two inventories, 

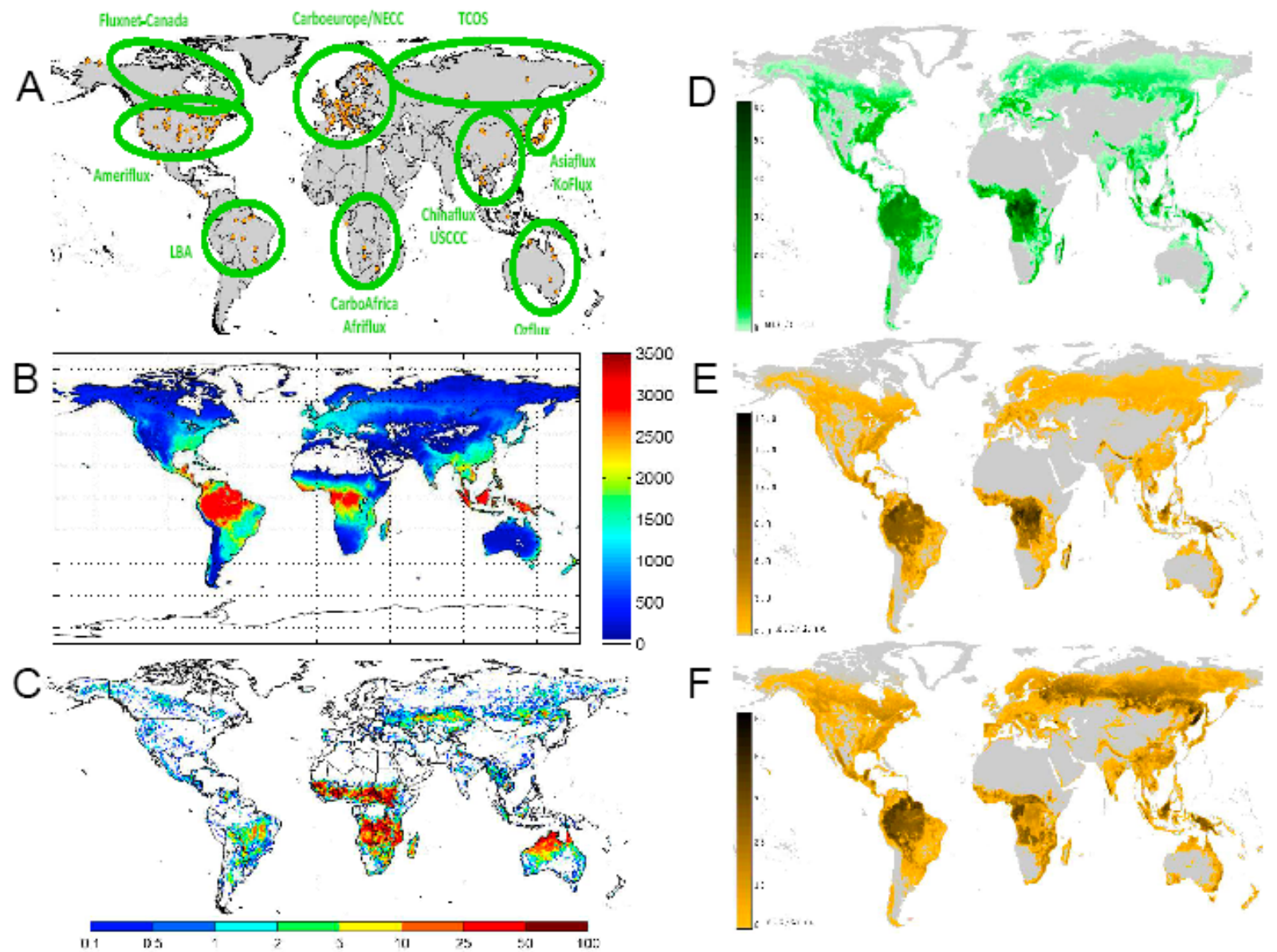

Figure 6. (A) Global network of eddy covariance flux towers in 2010; a larger number of towers exist, but not integrated in the FLUXNET database (http://fluxnet.ornl.gov/fluxnetdb). (B) Example of global distribution of the gross primary productivity obtained by fusion of FLUXNET measurements with global satellite fraction of absorbed photosynthetically active radiation, and gridded climate fields. (C) Global distribution of burned area from EOS-Terra-MODIS. (D) Global distribution of biomass obtained by disaggregating data from FAO reported by each country using satellite observations (http://www.iiasa.ac.at/Research/FOR/biomass.html), (E) below-ground biomass. (F) Soil carbon (from World Inventory of Soil Emission ISRIC-WISE database).

typically about five years to a decade (Pan et al., 2011b). High-resolution satellite data are used in some national inventory programs (e.g. USA). Usually, uncertainties are not reported with inventory data. By combining inventory and model estimates of North American terrestrial carbon sources and sinks, King et al. (2012) were able to reduce uncertainty to $25 \%$. In an earlier study, Phillips et al. (2000) estimated an error of up to $40 \%$ for the US forest stock annual volume change, mainly due to sampling errors.

Forest inventories provide important structural information such as age structure allowing for model-based approaches to factor out the impacts of age related changes in the assessment of additional sink.

\subsubsection{Soil carbon inventories}

Very few national/regional systematic soil carbon inventories are carried out to allow the quantification of carbons stocks and stock changes in soils. The National Research Council (NRC) report (NRC, 2010) concluded that the most important component to improve is agriculture, and other land use emissions of $\mathrm{CO}_{2}$ and $\mathrm{CH}_{4}$, because they have the greatest uncertainties in national inventories, mostly driven by large uncertainties in emission factors. The best soil carbon inventories sample countries with a typical grid of a few $\mathrm{km}$ and a revisit time of 10 years (Bellamy et al., 2005). Repeating soil inventories multiple times allows detection of regional changes driven by trends in climate or land use change. The depth over which soil carbon is sampled varies among soil carbon inventories, which is a major source of uncertainty. While most of these surveys suffer from the poor quality of data, they represent the only source of information currently available. At global scale, various efforts have been developed to harmonize the different soil classifications in already existing soil data, and to establish a world soil map 
(FAO/IIASA/ISRIC/ISSCAS/JRC, 2009; Kindermann et al., 2008).

The current situation is that there is neither continuous, standardized, and geo-referenced soil carbon inventories, nor a consistent network of detailed soil carbon measurement plots for use in model parameterization. Particularly in carbon rich soils such as those in frozen soil and peat, uncertainties are very large (Ping et al., 2008; Tarnocai et al., 2009), as are the estimates of carbon stocks. Peat carbon stocks and their past evolution are also poorly documented at global scale, with large data gaps for tropical peat, although several studies compiled regional (e.g. Yu et al., 2011 for highlatitudes, Byrne et al., 2004 for Europe, and Bridgham et al., 2007 for North America) and global information (Joosten, 2010).

\subsubsection{Lateral carbon transport through rivers}

Over land, significant amounts of carbon are transported from ecosystems to other places, where it is either stored or returned to the atmosphere by decomposition and respiration. This lateral transport of carbon is associated mainly with rivers, with a smaller contribution from agricultural and wood product transport for processing and trade. Lateral transport through rivers counts globally $\sim 3 \mathrm{Pg} \mathrm{C} \mathrm{yr}^{-1}$ (Aufdenkampe et al., 2011; Ciais et al., 2007; Battin et al., 2009).

Although individually, lateral transport may not be a very large flux, the sum of individual contributions is significant in the calculation of regional carbon budgets (Cole et al., 2007; Ciais et al., 2008; Raymond et al., 2008; Battin et al., 2009; West et al., 2009; Bastviken et al., 2011). Outgassing of $\mathrm{CO}_{2}$, originating from terrestrial ecosystems, by freshwater systems, is a significant $\mathrm{CO}_{2}$ flux to the atmosphere, impacting regional $\mathrm{CO}_{2}$ budgets. Incorporating lateral carbon transport by rivers and associated $\mathrm{CO}_{2}$ outgassing and burial in freshwater sediments in a global carbon observing system is needed to balance the carbon budget of each region and to compare top-down $\mathrm{CO}_{2}$ flux inversion results with bottomup ecosystem stock change observations.

Land-ocean transport of the various forms of carbon (inorganically and organically dissolved and respective particulate forms) also contributes to the biogeochemical state of coastal seas and on the large scale is essential to close the ocean carbon budget. These fluxes are not measured systematically, apart from few river basins. Measurements of lateral carbon fluxes from land to the oceans are needed to accurately access carbon budgets of single countries or groups of countries for emission verification purposes. Recent data syntheses on riverine delivery data to the ocean (involving hydrological modeling on land) have significantly improved our ability to quantify land-ocean carbon fluxes (Mayorga et al., 2010).

Due to the spatiotemporal heterogeneity of riverine carbon transport to the ocean, intermediate filtering processes (Borges, 2005) and associated release of $\mathrm{CO}_{2}$ to the at- mosphere by freshwaters and estuaries, to the complexity of the interaction between shelf-seas and the open ocean (Walsh, 1991), a quantification of land-ocean carbon transport is a substantial challenge (Regnier et al., 2013). A rough estimate of total land-ocean carbon transfer amounts to ca. $0.8 \mathrm{PgC} \mathrm{yr}^{-1}$, where $0.2 \mathrm{Pg} \mathrm{C} \mathrm{yr}^{-1}$ become buried in marine sediment (Liu et al., 2010). The state of current observation systems is as follows.

\section{River $\mathrm{CO}_{2}$ outgassing/carbon burial in reservoirs}

There is no coordinated observation network of river carbon fluxes. The Global River Chemistry (GloRiCh) database (Hartmann et al., 2009) provides measurements of $p \mathrm{CO}_{2}$ in rivers with $\sim 6000$ data, but incomplete spatial coverage. There is no global data set of carbon burial in lakes and reservoirs.

\section{Estuaries}

For estuarine carbon releases/burial, no global consistent observational data set exists as yet. A global synthesis taking into account spatially explicit typologies of estuaries and continental shelves estimated an estuarine $\mathrm{CO}_{2}$ flux to the atmosphere of $0.27 \pm 0.23 \mathrm{Pg} \mathrm{C} \mathrm{yr}^{-1}$ (Laruelle et al., 2010). Only for specific estuaries, regional observational carbon data sets are available (e.g. Frankignoulle et al., 1998; Green et al., 2006; Salisbury et al., 2008).

\section{River carbon fluxes to the ocean/carbon budget of coastal ocean}

Recent data syntheses (involving hydrological modeling on land) have improved our ability to quantify carbon delivery from land to estuaries and oceans (Mayorga et al., 2010). The CMTT (Continental Margins Task Team from the International Geosphere-Biosphere Programme (IGBP) core projects JGOFS, LOICZ and IMBER) synthesized carbon budgets from all major continental margins including the proximal as well as distal domains (Liu et al., 2010). The ongoing international Surface Ocean $\mathrm{CO}_{2}$ Atlas (SOCAT) project (see Sect. 2.4.1) includes a specific surface $\Delta p \mathrm{CO}_{2}$ data synthesis for coastal seas.

\subsubsection{Remote sensing of terrestrial carbon-cycle parameters}

Remote sensing is an essential component of current carbon observation assets, for detecting trends and variability in land components of the carbon cycle. Past studies in vegetation dynamics have had to rely on vegetation indices such as the normalized difference vegetation index (NDVI) using the Advanced Very High Resolution Radiometer (AVHRR) data since the 1980s (Tucker et al., 2005; Myneni et al., 1997), and MODIS, MERIS more recently. Since 1972, Landsat satellites have collected 
high-spatial-resolution data $(30 \mathrm{~m})$ at lower temporal frequency than AVHRR or MODIS (http://landsat.gsfc.nasa. gov/references/recent_pub.html). These data have been used in various applications (Vogelmann et al., 2009) but primarily for land cover, and cannot be used to quantify ecosystem state variables except by correlation. As satellite sensors have increased spectral and spatial resolution and stability of sensor calibration, biophysically based alternatives to vegetation indices have emerged (e.g. photosynthetic light-use efficiency; Hilker et al., 2011). In addition, new technologies (lidar, microwave, hyperspectral) instead of retrieving indices, can infer actual key ecosystem states such as leaf area, canopy architecture, foliar chemistry (nitrogen, photosynthetic pigments), and other properties that govern photosynthesis, growth, and decomposition.

Satellite radar data, both C-band and L-band, have been used over the past several decades to document land cover and disturbance. They have some sensitivity to canopy volume and have been used to estimate aboveground biomass in low to medium biomass ecosystems. Passive microwave measurements for freeze-thaw conditions have been used to estimate growing season length and infer GPP in northern high-latitude ecosystems. More recently, forest height and canopy profile metrics have been derived from Ice, Cloud, and Land Elevation Satellite (ICESat), Geoscience Laser Altimeter System (GLAS) measurements and then used to estimate above-ground biomass and carbon storage. Radar and lidar remote-sensing approaches hold great promise for reducing uncertainties in global carbon inventories, providing direct observations of the three-dimensional structure of above-ground vegetation that can be used to rather straight-forwardly calculate global terrestrial carbon storage in above-ground biomass. Remote-sensing techniques are, however, unable to measure below-ground biomass and carbon in soil.

\section{Biophysical and phenological parameters}

On the ground, photosynthetically active radiation (PAR) is monitored at many FLUXNET sites and fewer ecological research sites. In the AMERIFLUX eddy covariance flux tower network (http://public.ornl.gov/ameriflux/) PAR sensors are calibrated to quality assurance laboratory standards (Law et al., 2008a). The fraction of photosynthetically active radiation absorbed by vegetation (FAPAR) is an important parameter in land surface simulation of carbon (and water, energy) fluxes, especially in light-use efficiency models (Sellers et al., 1997; Running et al., 2004; Myneni et al., 2002) that estimate photosynthesis using this parameter. Many remotesensing products have been available for more than a decade (Gobron et al., 2010; Knyazikhin et al., 1998; Plummer et al., 2006; Pinty et al., 2007). The leaf area index (LAI) is the one-sided total area of green leaf material per $\mathrm{m}^{2}$ and is used to parameterize interception and photosynthesis models.
In addition, the land surface albedo is recognized as an important ancillary variable for terrestrial carbon studies. Albedo corresponds to the ratio of the radiant flux reflected from the Earth surface to the incident flux and controls the planetary radiative energy budget as well as the partitioning of radiative energy between the atmospheric and surface layers.

Many remote-sensing products have been available for more than a decade (Gobron et al., 2010; Knyazikhin et al., 1998; Plummer et al., 2006; Pinty et al., 2007). Various space remote-sensing albedo products derived from optical sensors are currently available at both regional and global scales (Schaaf et al., 2008).

LAI for only a relatively small number of vegetation classes and FAPAR are generated as global products by space agencies and other institutional providers as a global product at various spatial resolutions for daily to monthly periods, using optical space-borne sensors (Myneni et al., 2002; Gobron and Verstraete, 2009). When tested against local site measurements, there are large discrepancies between different LAI products, as shown, for instance, in Garrigues et al. (2008). Note that there are also uncertainties in measuring LAI on the ground - that is, it is largely an indirect measurement, with large uncertainty at field scale. New efforts with web-cams may provide a solution to monitoring canopies in the field for comparison to remote sensing. Surface albedo, transmittance, and FAPAR derived from remote-sensing observations are not spatially and temporally consistent with each other, limiting applications that use data assimilation techniques. The compatibility of LAI products with the specific requirements of models, especially in the context of data assimilation systems is not assessed. For instance, the fractions of scattered and absorbed radiant fluxes cannot be used together with the retrieved values of LAI, because this yields erroneous descriptions of the redistribution of energy within the vegetation layer (Pinty et al., 2007). Long time series of land remote-sensing parameters are relevant for monitoring the seasonality of vegetation, which is crucial to account for the seasonality of the atmospheric $\mathrm{CO}_{2}$ concentrations (Piao et al., 2008; Keeling et al., 1996) and the terrestrial component of the carbon cycle (White et al., 1999).

Recently, Joiner at al. (2011) and Frankenberg et al. (2011) succeeded in deriving plant fluorescence using high spectrally resolved solar Fraunhofer lines from earth radiance data measured with GOSAT. The data shows good correlation with GPP. Chlorophyll fluorescence provides therefore direct observational constraints on GPP which opens a new viewpoint on the global carbon cycle. Future missions which cover the spectral range of the $\mathrm{O}_{2}$ A-Band and includes solar Fraunhofer lines with sufficient high spectral resolution like OCO-2, GOSAT-2 or CarbonSat will also provide this information when launched. The cross validation or calibration of different data products may help to explore more uniformed vegetation traits and key satellite-based parameters of terrestrial productivity in the future. 


\section{Biomass}

Until recently, remote-sensing-based estimates of aboveground biomass and carbon storage have been limited to approximations based on (1) combining remotely sensed land cover type with biomass measurements derived from in situ inventory samples and (2) the sensitivity of radar scattering to biomass in low to medium biomass ecosystems. Radar sensitivity to canopy biomass ceases for moderate to dense canopies where the signal no longer penetrates through the entire canopy. This saturation level depends on the frequency, the polarization mode, incidence angle, the type of forest, foliage structure, and moisture conditions. As a result, a wide range of sensitivities has been reported, but rarely does the sensitivity exceed $100 \mathrm{Mg} \mathrm{ha}^{-1}$ for L-band polarimetric algorithms (Kasischke et al., 1997; Mitchard et al., 2012). The Phased Array type L-band Synthetic Aperture Radar (PALSAR) instrument on Advanced Land Observing Satellite (ALOS) builds on the Japanese Earth Resources Satellite (JERS-1) L-band Synthetic Aperture Radar (SAR) technology, provided the first systematic global observations for generating forest change and derived biomass maps, but failed in 2011. A replacement satellite is planned.

While there is currently no satellite instrument in space specifically designed to map global forest biomass, recent advances in active remote-sensing technologies demonstrate the possibility of high-resolution, globally consistent estimates of aboveground biomass and carbon stocks with significantly reduced uncertainties in the estimates. Remotesensing techniques integrating space-borne imaging and airborne lidar with pattern recognition methods (e.g. the Carnegie LANDSAT Analysis System Lite - CLASLITE; www.claslite.ciw.edu/) have demonstrated a strong capability for tracking and quantifying biomass and structural changes in forest undergoing deforestation at the national and county scale (Asner et al., 2010). Forest height and canopy profile metrics have been derived from the Geoscience Laser Altimeter System (GLAS) on the ICESat satellite and used to estimate aboveground biomass (Lefsky et al., 2005). ICESat height samples and MODIS data have been merged to create the first global canopy height product (Lefsky, 2010). ICESat, MODIS, QuikScat, and Shuttle Radar Topography Mission (SRTM) data have been used to spatially extrapolate ICESat observations and create a benchmark map of carbon storage, along with uncertainties, for tropical forests (Baccini et al., 2012; Saatchi et al., 2011). Comparison of these maps, however, shows significant differences indicating uncertainty in the data processing methods. Further, these maps are not temporally discrete (data from multiple years were used), and the main source of data, from ICEsat, no longer exists. A replacement mission may be launched in 2016. Preliminary results using polarimetric interferometric SAR (PolInSAR) approaches have demonstrated sensitivity to biomass in some high-biomass ecosystems (Treuhaft et al., 2003; Hajnsek and Papathannassiou, 2009).
Several research programs are underway to implement the use of Synthetic Aperture Radar (SAR) as well as airborne/spaceborne lidar, to derive estimates of vegetation aboveground biomass (e.g. Saatchi et al., 2007). Satellite missions such as the BIOMASS P-band radar of European Space Agency (ESA) (Le Toan et al., 2011) or a concept based upon the Deformation, Ecosystem Structure and Dynamics of Ice (DESDynI) mission of the National Aeronautics and Space Administration (NASA) (Hall et al., 2011; www.desdyni.jpl.nasa.gov/) are currently being considered for this purpose.

\section{Land cover and land cover change}

Several land cover data products based upon visible satellite data at a resolution of $1 \mathrm{~km}$ or better are available. For example, the ESA GLOBCOVER project has released a global map of $300 \mathrm{~m}$ spatial resolution using MERIS data (Arino et al., 2008) both for the year 2005 and recently 2009, and this is being comprehensively revisited in the ESA Climate Change Initiative (CCI) Program (www.esa-cci.org). MODIS land cover product provides maps at $1 \mathrm{~km}$ spatial resolution (Friedl et al., 2002). However these two products cannot be compared to detect land cover change. Global changes in forest cover have been derived from AVHRR at decadal increments (Hansen et al., 2003) and MODIS at five-year increments (Hansen et al., 2010). In some regions, particularly tropical forests of the Amazon basin, deforestation is monitored on a regular basis using the INPE PRODES (Instituto Nacional de Pesquisas Espaciais, Monitoramento Da Floresta Amazonica Brasilieira Por Satellite) system (www.obt.inpe.br/prodes/), though most tropical countries do not have operational forest monitoring systems in place (DeFries et al., 2007). Most land cover analysis to date has relied on low-resolution $(>300 \mathrm{~m}$ ) satellite-based optical data.

Satellite observations using Synthetic Aperture Radar (SAR) are also beginning to provide land-surface information, in particular over cloud-affected regions in the tropics and high latitudes, where optical data are sparse. A systematic acquisition strategy was developed for the ALOS L-band Synthetic Aperture Radar (PALSAR) for global tracking of land use change. Up to its failure in 2011, ALOS-PALSAR provided five years of systematic global forest (and wetland) observations and the first systematic global observations for generating forest change as well as derived biomass maps in low biomass zones (Saatchi et al., 2011). The GEO-initiated Global Forest Observation Initiative (GFOI) aims to provide better access to Landsat-resolution optical and imaging radar data worldwide in support of REDD+ projects and/or national Measurement, Reporting and Verification (MRV) programs. There is, however, no current capacity to generate repeated global biomass maps for determination of biomass change (Houghton et al., 2009). Such a capacity will better constrain the magnitude of land carbon storage changes, of 
biomass accumulation in forest and subsequent carbon sinks, and their locations.

New analyses using temporally dense time series (i.e. annual intervals) of Landsat imagery are beginning to be used to create continental-scale land cover maps over the Landsat data record (1972-present) that quantify the extent and recovery associated with forest disturbance (Masek et al., 2008). These products are providing new insights in to the carbon dynamics associated with disturbance and recovery processes (Goward et al., 2008). While currently limited to North America, it should be possible to extend this work globally. In related research, a first continental-scale forest age map of the United States and Canada was established by combining this Landsat disturbance record with forest inventory data, historical fire data, and other optical satellite data (Pan et al., 2011b). Forest age, related to time since disturbance, can be a useful surrogate in analyses of the impact of disturbance on the ability of forests to sequester and store carbon.

\section{Fires}

The AVHRR fire record goes back to 1982, providing the longest global record of fire but the data are sparse and incomplete. The European Space Agency (ESA) World Fire Atlas (Arino and Plummer, 2001; Arino et al., 2012), provides another long continuous global record of active fires using the Along-Track Scanning Radiometer (ATSR) instrument, and has recently been upgraded using a new nighttime algorithm and extended back to 1991. Other polar orbiting satellites, such as Advanced Very High Resolution Radiometer (NOAA-AVHRR), Visible and Infrared Scanner (VIRS) on board the Tropical Rainfall Measuring Mission (TRMM), and geostationary satellites (Meteosat Second Generation (MSG); Geostationary Operational Environmental Satellites (GOES)) extend these observations to better characterize the diurnal cycle of active fires (Pu et al., 2007; Ji and Stocker, 2002; Beaudoin et al., 2007). MODIS is currently the best polar orbiting sensor for this phenomenon, measuring both active fires and burned areas (Giglio et al., 2003). However, landscape analysis indicates that Landsat derived fire products (e.g. Monitoring Trends in Burn Severity - MTBS) are more reliable for burned area and severity, partly due to the spatial resolution of the data that is appropriate for the patchiness of fires (Meigs et al., 2011). For fire radiative energy (FRE), which can be used as a direct proxy of $\mathrm{CO}_{2}$ emissions (Freeborn et al., 2008; Roberts and Wooster, 2008; Wooster et al., 2003, 2005), Spinning Enhanced Visible and Infrared Imager (SEVIRI) onboard MSG and MODIS have demonstrated the capability to make measurements to the required specifications. FRE products from SEVIRI are generated every 15 min over Africa, Europe, and part of South America; with operational production at the European Organisation for the Exploitation of Meteorological Satellites (EUMETSAT) Land Satellite Applications Facility (Land-
SAF) (http://landsaf.meteo.pt/). Such products are already being used for fire emission calculations within the European Medium Range Weather Forecasting (ECMWF) system and steps are being taken to integrate FRE data from the constellation of geostationary meteorological satellites into the system (Kaiser et al., 2012).

Integrated fire emission products are based upon satellitebased fire data incorporated in ecosystem models. The Global Fire Emission Database, GFED (Van der Werf et al., 2003); www.globalfiredata.org), is an integrated product, combining MODIS, ATSR, and VIRS satellite products of fire activity with the Carnegie-Ames-Stanford Approach (CASA; http://geo.arc.nasa.gov/sge/casa/investg.html) terrestrial ecosystem model to estimate fire emissions of $\mathrm{CO}_{2}$, $\mathrm{CH}_{4}$, and other species from 1997 to the present (van der Werf et al., 2010). Other products also exist, but, even if the spatial and temporal pattern of fires is relatively well documented, the uncertainties in global fire emission estimates remain substantial (Csiszar et al., 2009). An assessment of emissions estimates from several fire emission products, including GFED, showed differences in model assumptions, including canopy consumption and changes in fuel moisture, were the main causes of uncertainties, and results varied by location, vegetation type, and fire weather (French et al., 2011).

\subsection{Generation of integrated data-products from current observations}

Integrated data products from the GLOBALVIEW (www.esrl.noaa.gov/gmd/ccgg/globalview/), GLOBCOLOUR (www.globcolour.info/), GLCN (www.glcn.org); GLOBCOVER (www.gofc-gold.uni-jena.de/), GLODAP (www.cdiac.ornl.gov/oceans/glodap/), SOCAT (www.socat.info/), Climate Change Initiative (http: //www.esa-cci.org/), FLUXNET (www.fluxnet.ornl.gov/) and FAO Global Forest Resources Assessments (www.fao.org/forestry/) have improved the quality and accessibility to carbon-cycle data, relative to the previous situation. Modeling projects such as CarbonTracker (Peters et al., 2007), TransCom (Baker et al., 2006; Law et al., 2008b); GEMS-MACC-MACC-II (www.gmes-atmosphere.eu/), CCDAS (Rayner et al., 2005), and CARBONES (www.carbones.eu/project.html/), and NASA Carbon Monitoring System (CMS, www.carbon.nasa.gov) have begun to integrate data across platforms and atmospheric, oceanic and land reservoirs. Most of this integrative effort has been placed on $\mathrm{CO}_{2}$, much less on $\mathrm{CH}_{4}$. The Global Carbon Project (GCP), an international research organization (www.globalcarbonproject.org/) has built a collaborative effort to update annually the global budget of anthropogenic $\mathrm{CO}_{2}$ (Le Quéré et al., 2009, 2010), and the uncertainty on each term (www.globalcarbonproject.org/carbonbudget/12/data.htm). The GCP has also established a first synthesis (RECCAP; 
www.globalcarbonproject.org/reccap/) of regional bottomup and top-down $\mathrm{CO}_{2}$ fluxes decadal-scale estimates over large regions of the globe, but there is no operational plan to revisit this effort periodically.

\subsection{Data delivery and archiving}

Currently, there is no single system for the operational dissemination and archiving of carbon-cycle observations and data products. But there are several systems in parallel areas on which one can draw. Both seismology and meteorology have operational networks for automatic data dissemination. These have evolved over decades in response to obvious needs, characterized by global cooperative governance, complete openness of data and no-cost access. Such global networks usually lag the state of the art in technology since global accessibility is a requirement. The meteorological network is currently undergoing a major upgrade to take account of contemporary networking technology (the existing system predated the internet). Such networks also require careful oversight and specification of standards for data interchange.

A parallel development has occurred as a by-product of the extension of numerical weather prediction schemes to include atmospheric tracers (including GHGs). The development of the Global Monitoring of Environment and Security (GMES) Atmospheric Service (Hollingsworth et al., 2008), now Copernicus (European Earth Observation Programme, http://www.copernicus.eu/pages-principales/ services/atmosphere-monitoring/) and land surface carbon modeling efforts (Boussetta et al., 2013), requires that the fields generated by the assimilation system be distributed to end-users and hence an extension of the list of variables carried on this network. This could serve as a point of departure for a carbon-cycle network.

Some properties of existing global networks may not carry over easily to a carbon-cycle system. Various trace gas observations are used in verifying compliance with air quality directives and these are governed by special confidentiality provisions in the data sharing agreements, usually involving delays (but not prevention) in public availability. Should any international enforcement of mitigation agreements come into play, the same arrangements may be necessary for carbon-cycle observations.

\section{Key elements required for a policy-relevant global carbon observing system}

This section outlines a set of needs/attributes for a global carbon monitoring system (or system of systems) that can be built in the next decade based on existing or known technology. It begins with a set of general system attributes/caveats. It is followed by a gap analysis and the formulation of specific requirements organized for anthropogenic emissions, atmosphere, oceans, terrestrial ecosystems, and "hot spots" such as vulnerable pools or fluxes in the natural cycle of $\mathrm{CO}_{2}$ and $\mathrm{CH}_{4}$.

Finally, the carbon cycle does not operate in isolation. It is intimately linked to other global cycles of water, nitrogen, phosphorus, oxygen, and also the global climate system, that must be studied to fully understand the carbon system. It is beyond the scope of this document to identify the aspects of these other cycles that are most critical, but it is anticipated that a wide field of related studies will need to be linked to a carbon observing system.

\subsection{General attributes}

A carbon observation and analysis system relevant for policy efficacy will need to differentiate (factor out) the large, relatively non-linear natural source and sink processes from the anthropogenic emissions. It should also monitor the short and long-term efficacy, or specific beneficial/negative impacts of climate mitigation policies and measures at global, national, provincial state, and perhaps down to city scales. It will need to identify the activities, types and sources of emissions (i.e. measure separately fossil fuel emissions, ocean and land biosphere fluxes). For the latter, it should be able to track the activities associated with agricultural and forest $\mathrm{CO}_{2}$ sources and sinks, and $\mathrm{CH}_{4}$ emissions, by detecting relatively small departures from reference levels.

First, an operational global carbon monitoring system will have to be grounded in observations that are sustained, and minimize gaps. Given the need to track long-term trends in carbon fluxes and pools over several decades, the observational ground and satellite networks must be designed and funded to offer continuity of critical data records. This robustness and sustainability has implications on reliability and redundancy of individual system elements, as well as contingency response options (particularly for long-turnaround satellites) in the form of spares and rapid re-deployment capability. These attributes are more common with contemporary weather observing systems than current exploratory carbon-cycle science assets.

Second, information products generated by such a system will have to obey a high standard of accuracy, with careful quantification of uncertainty (if possible, documentation of known biases and random errors), and be open to and able to withstand intense scrutiny. Rigorous and relentless attention to bias and other systematic errors introduced by observations, models, or interpretation must be a key feature of any global monitoring system. Provisions for sustained and regular intercomparison and calibration between observational assets and between models must be a core provision of the system. And thus, there needs to be substantial effort in quantifying (with adequate data accuracy reporting) what the reference levels are, especially if the anticipated deviations will be small. Representativeness error should also be the object of detailed case studies, given specific attributes (e.g. resolution) of models used to assimilate data. 
Third, in order to be useful in providing independent validation of policy efficacy, an integrated carbon observing system will have to incorporate mechanisms for comparing and reconciling the information produced by the observing and analysis system with other information sources used as primary policy instruments. For example, estimates of emissions derived from atmospheric inversions will only prove relevant as checks on reported emission inventories if the two estimates can be compared or combined within a consistent statistical framework/spatiotemporal resolution. A key attribute of the system must therefore be a comprehensive approach to uncertainty quantification and propagation. This requires end-to-end transparency and traceability in the form of open access to the raw observational data, calibration and validation data, core models and analysis software, intermediate and final data products, and documentation describing the processes and procedures for collecting, assimilating, and analyzing the data. All information products must include metadata to support traceability and independent reconstruction of the production process.

In addition to robust products, a policy-relevant carbon observing system will need to include services in the form of providing sustained end-user access to expert practitioners involved in data collection, modeling, data assimilation, and analysis. The observing system will have to meet the needs of operational agencies as well as those of research. Of these, operational requirements are probably more stringent or, at least, require more precise definition.

- All data must be associated with as much information as possible on their uncertainty (bias wherever possible and random errors). This goes beyond measures like precision since most types of data are subject to systematic errors. Thus, there must be enough metadata to assign each datum to a class for consistent bias correction.

- Metadata must be sufficient to allow automatic and valid comparison with model output. This means supplementing location information with descriptions of spacetime averaging, weighting functions, etc. Data must adhere precisely to standard formats. Most automatic systems for ingesting data include an error-checking component which rejects data that might be corrupted by instrument or transmission error and these can only work reliably when valid data is guaranteed to be correctly formatted. Given the heterogeneity of providers that will be required to fill the data requirements listed above this is a very large task in training and software development.

- The system must also serve the needs of researchers, so data must be globally catalogued with sufficient information for knowledge discovery and exploratory analysis.
- Where possible, information from the observing system should also support operational decisions for local carbon management trigged by more aggregate incentive schemes.

\subsection{Needs for effective interactions with the policy community}

An integrated global carbon observing system to support climate policies will only be relevant and adopted by end-users if the system developers make an early and sustained effort to engage those stakeholders (research councils, project developers, companies, policymakers, regional authorities and cities authorities). A critical precursor to developing detailed policy-relevant requirements for future observing and analysis systems is to craft well-posed questions to ensure the right issues are being addressed. One should expect the need to periodically re-evaluate end-user needs as policies are implemented and evaluated, and we learn more about the carbon cycle and the coupling between it and anthropogenic activity. This engagement between the science community, engineers, and end users has started, but at present a consensus set of requirements does not exist. This is particularly true for information needs associated with policy compliance assessments. These involve agreements with significant economic and political implications and the long-term forms of such agreements are not yet clear.

In the meantime, in order to help set the context/scope of a global carbon monitoring system, we present the following summary of anticipated requirements based on stakeholders involvement, and assessment of what will be needed to support policy efficacy assessments and climate adaptation assessments. Requirements for policy efficacy and climate adaptation assessments are perhaps more straightforward to define than compliance assessments. The former are strictly concerned with whether a given policy is meeting the intended end-objective of limiting greenhouse gas concentrations in the atmosphere, which is primarily a scientific question of "what are the carbon stocks and fluxes on spatiotemporal scales with sufficient resolution and precision to attribute their causes". This is quite distinct from verifying policy compliance with negotiated legal language from international agreements or national legislation. We acknowledge that the observational requirement for compliance monitoring must be revisited once we can frame it. In addition to policies informing observing strategies, ideally, more efficient future policies and mitigation strategies will be crafted, with knowledge of what is objectively quantifiable by a globally integrated observation system.

As a contribution towards national-level Measurement, Reporting and Verification (MRV) systems and policy, as well as reporting to the UNFCCC, a global carbon observing system will need to have the necessary spatial resolution to accommodate, where possible, the constraints that national governments have in terms of the scales and temporal 
aggregation of their emissions estimates (Baker et al., 2010). National governments also need to regularly provide access to dedicated United Nations (UN) review panels and build systems, which are sufficiently transparent in terms of models and observational data. This may complicate the interfacing between global/regional carbon assessments from an observing system and the bottom-up national emissions accounting approaches required by the UN review teams, hence the need of early/sustained stakeholders involvement.

\subsection{Spatiotemporal resolution of carbon flux products and pool products}

This section addresses the performance attributes of the products that would be delivered to decision-makers, rather than those of the observations from which they are inferred (covered in succeeding sections). The precision and space-time resolution needed for global observing system products depends on their intended end use. For example, as a short-term objective, generation of weekly $\mathrm{CO}_{2}$ and $\mathrm{CH}_{4}$ fluxes over the globe with spatial resolution of $100-500 \mathrm{~km}$ over land (i.e. covering the territory of large countries) and $1000 \mathrm{~km}$ over the ocean (i.e. the scale of gyres influenced by coherent circulation changes) would enable estimates of interannual, fluxes, and over time, to reduce uncertainty on decadal mean fluxes. Typical error reduction by a factor of two compared to current flux diagnostics seem to be achievable by atmospheric inversions using existing dense atmospheric networks in some regions (Broquet et al., 2013) for the ICOS network. This performance should be achievable in a first phase, in the next 5-10 years, if funding is provided to greatly increase the spatiotemporal density of coordinated groundbased and space-based observations and integrate them in data assimilation systems with rigorous attention to error propagation. Given uncertainty in the structure of carboncycle models, it is preferable that several data assimilation models can be applied to the problem.

In a second phase, within 10-15 years, depending upon the region considered, provision of weekly $\mathrm{CO}_{2}$ and $\mathrm{CH}_{4}$ fluxes over the globe with spatial resolution of $50-100 \mathrm{~km}$ over land and $500 \mathrm{~km}$ over the ocean should be a target. At these scales, flux uncertainties in the range of $20-50 \mathrm{~g} \mathrm{C} \mathrm{m}^{-2} \mathrm{yr}^{-1}$ for $\mathrm{CO}_{2}$ (1-sigma uncertainty) will be necessary to provide assessments of natural fluxes with a precision of 2 to 3 times greater than current estimates. Fossil fuel $\mathrm{CO}_{2}$ emissions will need to be measured at a smaller spatial scale $(1-10 \mathrm{~km})$ at a typical precision of $20-50 \mathrm{~g} \mathrm{C} \mathrm{m}^{-2} \mathrm{yr}^{-1}$. This scale is appropriate for high-resolution atmospheric models applied to, for example, urban emissions (McKain et al., 2012). Assessing emission trends will depend on the magnitude of local trends and variability and the time allowed for measuring changes. Maintaining long-term accuracy will be more important than reaching high precision with biases, in this context. It is likely that monitoring emission trends will require a higher accuracy than $10 \mathrm{~g} \mathrm{C} \mathrm{m}^{-2} \mathrm{yr}^{-1}$ in regions where those trends are small. The cost of a high-accuracy system will increase dramatically with increasing precision, so careful return on investment analysis is needed to evaluate the value of completeness and its dependence on sensitivity of the observing system (Fig. 9).

A consistent global framework will have to be implemented to include the different components and integrate them. This is needed to carry out internal consistency checks and assessments/attribution of greenhouse gas budgets and emission reductions. Finer spatial resolution will likely be needed for assessing emissions of individual cities or sites $(0.1$ to $10 \mathrm{~km})$, project-based carbon sequestration/conservation monitoring ( 0.1 to $1000 \mathrm{ha}$ ), mechanistic studies of disturbance events such as drought or fire impacts on carbon budgets ( 0.1 to 1000 ha). For urban flux estimates (at $\sim 1 \mathrm{~km}$ scale), random uncertainties of $100 \mathrm{~g} \mathrm{C} \mathrm{m}^{-2} \mathrm{yr}^{-1}$ should be sufficient to measure the instantaneous value of fluxes (typically $5-10000 \mathrm{~g} \mathrm{C} \mathrm{m}^{-2} \mathrm{yr}^{-1}$ ). These advances will require further major improvements in observational densities and advances in modeling, including flux up-scaling algorithms, small-scale atmospheric transport models and pertaining assimilation schemes. Such goals will warrant longer-term investments in observational and computing facilities as well as an expanded community of people trained with the necessary skill set. Alternatively and perhaps additionally, prioritized nested sampling in high-priority areas (e.g. megacities, industrial regions) may be necessary to accelerate and focus coverage.

In all cases, the complex interplay between spatiotemporal resolution and precision of an information product requires optimization to achieve the best fit with the desired end-use. Optimization requires the use of numerical analysis (e.g. Hungershoefer et al., 2010) to study the parameter space for each end-use scenario. In the following sections, we provide notional requirements for each component of a future global carbon observing system that could be assembled in the next decade. These requirements have been obtained by workshops and web-based consultation of an international community of more than 100 researchers and agency representatives, as part of the preparation of the GEO Carbon Observing Strategy Report (Ciais et al., 2010).

\subsection{Anthropogenic emissions information needs}

\subsubsection{Anthropogenic $\mathrm{CO}_{2}$ and $\mathrm{CH}_{4}$ emissions products, based upon inventories}

Emissions of $\mathrm{CO}_{2}$ from fossil fuel combustion occur at a variety of temporal and spatial scales. Temporally, some emitters (e.g., power plants) can be relatively constant over minutes to hours, while others are quite variable (e.g., buses) over the same timescales. All react to the rhythms of society and may increase or decrease emissions depending on if it is a workday, rest day, or holiday. These daily dependencies are a function of local/national customs and vary around the 
world. On top of all this, are the short-term variations from day-night cycles and weather, and longer-term perturbations brought on by the change in seasons. Spatially, some emitters are fixed (e.g., the tall stacks of power plants) and others are mobile (e.g., vehicles). Individual, fixed-location emitters are the largest single source of $\mathrm{CO}_{2}$ emissions to the atmosphere. Mobile sources collectively account for a significant fraction of fossil $\mathrm{CO}_{2}$ emissions (roughly one-quarter of the total) (EDGAR emission data set, http://edgar.jrc.ec.europa.eu). It will not be achievable in the next decade for cost and reporting reasons to put a sensor for $\mathrm{CO}_{2}$ and $\mathrm{CH}_{4}$ on every fossil fuel combustor. However, there are strong relationships between the types of fuel combusted, how they are combusted, and resulting $\mathrm{CO}_{2}$ and $\mathrm{CH}_{4}$ emissions. These relationships form the basis of the currently prevalent statistical basis for accounting emissions (as the Carbon Dioxide Information Analysis Center - CDIAC and the International Energy Agency - IEA do for national, annual $\mathrm{CO}_{2}$ emissions). This presently accepted methodology, however, is likely insufficient for approaching the temporal and spatial scales necessary for a global carbon observing system that would serve the policy and scientific goals of such a system. The reason for this insufficiency is the lack of statistical data at the relevant temporal and spatial scales for all emitters.

To improve estimates of global fossil fuel emissions and utilize those emissions estimates within forward and inverse carbon-cycle modeling, emissions estimation and uncertainties at a resolution of $1 \mathrm{~km}$, hourly over the globe, is needed. This scale is policy relevant in the context for instance of city-scale mitigation projects and/or trading mechanisms. It is also scientifically relevant since it is the typical scale at which meso-scale models can be run with inventories to be checked against independent atmospheric concentration measurements. Meeting this objective will require:

1. Comprehensive, consistent, national-level energy (fuel) consumption data of the best possible precision such as that achievable in some countries today (3-5\%), particularly from developing countries. Where possible, subnational fuel data (states; provinces; counties) energy consumption data will be desirable.

2. Sectorial details (residential, commercial, industrial, electricity production, on-road, non-road, air travel, cement) and fuel types details (different types of coal, oil, gas fuels) at the national level and at sub-national level.

3. Information on the spatial distribution of $\mathrm{CO}_{2}$ emissions from (bunker) fuels consumed in international commercial transport.

4. Improved estimation of the temporal variability of fossil fuel $\mathrm{CO}_{2}$ emissions. Generally, better quantification of the diurnal, weekly and seasonal cycles of emissions will allow for better interpretation of the fossil fuel signal in the atmosphere for specific economic sectors (e.g. diurnal and weekly on-road transportation).
5. Improved estimation of spatial variability of fossil fuel $\mathrm{CO}_{2}$ emissions from the transportation sector with fuel data (see 2.) and improved Geographic Information System (GIS) road networks and monitoring of traffic flows. This requirement could benefit from highresolution satellite imagery in the visible-infrared spectrum for evaluation against urban-scale modeling of fossil fuel consuming activity.

6. Improved spatiotemporal variability on ancillary combustion emissions tracers $\left(\mathrm{CO}, \mathrm{NO}_{\mathrm{x}}\right.$, aerosols, some volatile organic compounds - VOCs) consistent with the fossil fuel $\mathrm{CO}_{2}$ emissions data

7. Improved estimation of temporal variability of anthropogenic $\mathrm{CH}_{4}$ emissions, in particular fugitive emissions related to extraction, distribution and use of fossil fuels, of waste treatment systems (landfills, water processing plants), and agricultural activity (rice cultivation, ruminant densities and diet).

8. Estimation of sectorial emission factors fugitive emissions of $\mathrm{CH}_{4}$ from the fossil fuel upstream sector (gas production, coal mines, gas distribution).

9. Systematic monitoring of large point sources at the point of emissions (electricity production, metal manufacturing), including measurement of $\mathrm{CO}_{2}$ concentration and flow rate in the stack (Ackerman and Sundquist, 2008). Additionally, estimation of emission injection heights and exit velocities and temperatures will further improve atmospheric modeling of these large sources.

\subsubsection{Anthropogenic $\mathrm{CO}_{2}$ and $\mathrm{CH}_{4}$ emissions, data infrastructure}

A better data infrastructure for faster reporting and accessing anthropogenic $\mathrm{CO}_{2}$ and $\mathrm{CH}_{4}$ emission inventories data is a critical element to assemble a policy-relevant carbon observing system. The main needs are

1. Use of a consistent approach to inventory reporting and quantification of uncertainties. This approach will require reporting of accuracy estimates, including reporting of biases and random errors analyses and traceability in the elements used to construct fossil fuel $\mathrm{CO}_{2}$ emission maps such as geospatial economic activity information, land cover, emission factors and energy consumption statistics, with version documentation. This priority requirement includes access to census and other socio-demographic data, in developed and developing nations.

2. Data infrastructure and web-delivery systems to transfer data, format and present maps, and produce reports according to prescribed accounting methodologies of 
the United Nations Framework Convention on Climate Change (UNFCCC).

3. Regular reanalysis of past anthropogenic $\mathrm{CO}_{2}$ and $\mathrm{CH}_{4}$ emissions, using available information such as regional energy use and fuel use statistics, proxy data, complemented by research programs to improve fossil fuel emission mapping and integration.

\subsection{Atmospheric data}

There are two barriers to providing policy-relevant carbon flux estimates using atmospheric observations. First, the ability to reliably disentangle and attribute fossil fuel (vs. natural) sources of $\mathrm{CO}_{2}$ by limited quantities of ${ }^{14} \mathrm{C}-\mathrm{CO}_{2}$ (the even rarer ${ }^{14} \mathrm{C}-\mathrm{CH}_{4}$ can be used insofar only for a global constraint of fossil $\mathrm{CH}_{4}$ emissions (Lassey et al., 2007), and ${ }^{14} \mathrm{C}-\mathrm{CH}_{4}$ is contaminated by nuclear power plants emissions (Levin et al., 1992)) atmospheric measurements and the lack of systematic application of combustion tracers (e.g. $\mathrm{CO}$ and $\mathrm{NO}_{2}$ ) to separate fossil fuel $\mathrm{CO}_{2}$. Second, errors associated with atmospheric transport modeling dominate the inversion error budget. The first barrier can be overcome by increasing the number of ${ }^{14} \mathrm{C}$ observations (both in terms of collection and processing) and perhaps through concerted attention to data fusion and (regularly updated) calibration of $\mathrm{CO}$ and $\mathrm{NO}_{2}$ as proxies of fossil fuel $\mathrm{CO}_{2}$ in each region (Levin and Karstens, 2007; Berezin et al., 2013). The second problem is perhaps more challenging and will likely require a large increase in the density of atmospheric observations (both spatially and temporally) for in situ and satellite observations as well as focused attention on reducing errors associated with surface winds, planetary boundary layer height and atmospheric circulation in general. These two transformational changes warrant a systematic and quantitative study to determine the optimal mix of improvements to observations and models. Towards filling these gaps, the following general categories of improvements are warranted (see Sects. 3.3.1 to 3.3.4).

\subsubsection{Atmospheric in situ surface network and aircraft data}

To achieve homogeneous quality of flux diagnostics over the globe, a denser surface stations network complemented by aircraft vertical profiles is needed. Stations will need to be spaced typically apart from each other to be able to constrain fluxes at the scale of synoptic systems (Gloor et al., 2001; Broquet et al., 2011; Lauvaux et al., 2012) requiring 4000 surface continuous-measurement stations distributed according to flux heterogeneity across continents (Hungershoefer et al., 2010) and oceans, for the later using mobile platforms such as ships of opportunity. The biggest challenge will be to develop atmospheric measurements technology and methods to measure directly the variability of fossil fuel and other anthropogenic emissions of $\mathrm{CO}_{2}$ and $\mathrm{CH}_{4}$. In addition, $\mathrm{OH}$ rad- icals being the biggest sink of $\mathrm{CH}_{4}$, almost equal to the sum of all surface emissions. It is critical to quantify $\mathrm{OH}$, using proxy tracer measurements (e.g. Montzka et al., 2011). The transformational improvement of the surface network into a robust, operational system would require over the next 10 years the following developments:

1. Deployment of atmospheric $\mathrm{CO}_{2}$ and $\mathrm{CH}_{4}$ networks around mega-cities, calibrated to WMO dry air mole fraction scale, possibly taking stock of the existing air quality infrastructure. These data will have to be reported using formats consistent with atmospheric in situ data.

2. Development of surface atmospheric networks with synoptic density, in North America (North American Carbon Program - NACP, http://www.nacarbon. org/nacp/; National Ecological Observatory Network NEON, http://www.neoninc.org/), Western Europe (Integrated Carbon Observation System - ICOS, http:// www.icos-infrastructure.eu/) and China (China Meteorological Administration - CMA, http://www.cma.gov. $\mathrm{cn} / \mathrm{en} /$ ), accounting for private ventures and regional networks.

3. Improve rapidly the coverage of critically undersampled regions (Africa, South America, South and Southeast Asia, eastern Europe and Siberia, southern oceans).

4. Following up step (3), develop surface atmospheric networks over under-sampled regions with synoptic density, possibly by an international effort led by the World Meteorological Organization (WMO) Global Atmosphere Watch (GAW). The need would be of doubling the number of stations in under-sampled areas every 5 years until the required density is achieved.

5. During the expansion of surface networks, the collection of $\mathrm{CO}_{2}$ and $\mathrm{CH}_{4}$ vertical profile measurements will need to be pursued, and expanded over tropical regions using dedicated aircraft (Gloor et al., 2000; Gatti et al., 2010) and/or instrumented commercial aircraft (Machida el al., 2008; Matsueda et al., 2008) like Comprehensive Observation Network for trace gases by Airliner - CONTRAIL (http://www.cger.nies.go.jp/ contrail) and In-service Aircraft for a Global Observing System - Civil Aircraft for the Regular Investigation of the Atmosphere Based on an Instrument Container (IAGOS-CARIBIC) (www.iagos.org/).

In parallel with increasing the number of stations, measuring proxy tracers to separate either anthropogenic or natural emissions will be required on a regular basis, either by flask air samples or desirably by continuous measurements. 
1. Massive expansion of radiocarbon $\left({ }^{14} \mathrm{C}\right)$ sampling and analysis (cf. Box 4.2 in Pacala et al., 2010).

2. Measurement of proxy-tracers associated with anthropogenic emission processes: combustion tracers $\mathrm{CO}$, $\mathrm{NO}_{2}$ for fossil fuel $\mathrm{CO}_{2}$, halocarbon, $\mathrm{C}_{2} \mathrm{Cl}_{4}$ and hydrocarbon species, and $\mathrm{C}_{2} \mathrm{H}_{6}$ and $\mathrm{C}_{3} \mathrm{H}_{8}$ for fossil fuel $\mathrm{CH}_{4}$ (e.g. Levin and Karstens, 2007; Berezin et al., 2013).

3. Sustained and increased collection of tracers related to the identification/process attribution of natural fluxes: stable isotopes of $\mathrm{CO}_{2}$ and $\mathrm{CH}_{4}\left({ }^{13} \mathrm{C},{ }^{18} \mathrm{O}\right), \mathrm{OCS}$, $\mathrm{O}_{2} / \mathrm{N}_{2}$ ratio if possible using continuous in situ instruments.

4. Continuity of suitable tracers measurements will have to be ensured to assess atmospheric loss of $\mathrm{CH}_{4}$ through reaction with hydroxyl radical $(\mathrm{OH})$ (Prinn et al., 2001), especially because atmospheric methylchloroform (MCF) emissions are near zero and this tracer will no longer be useful for $\mathrm{OH}$ determination.

5. In parallel begin measurements of alternative tracers to MCF such as ${ }^{14} \mathrm{CO}$ (Krol et al., 2008) since MCF concentrations decline rapidly after the Montreal protocol.

\subsubsection{Atmospheric remote-sensing data}

The strategy is to exploit existing remote-sensing data of $\mathrm{XCO}_{2}$ and $\mathrm{XCH}_{4}$ to improve our knowledge, and invest into new instruments of spacecraft to empower capacity for global observations of greenhouse gases, according to the following steps:

1. Develop research programs to calibrate satellite greenhouse gases (GHG) observations to primary WMOscale international standards.

2. Guarantee the continuity and sustained measurements of the Total Carbon Column Observing Network (TC$\mathrm{CON}$ ) that is absolutely critical for validation of existing and future satellite missions and independent, continuous column-average observations. This is key to getting at the climate change timescale feedbacks on the GPP, R, and disturbance (Wunch et al., 2013). Its extension to regions that are critical to carbon-cycle science (e.g. tropics) as well as satellite validation (e.g. oceans, deserts). Strategically placed, it could cover a large region that is otherwise difficult to reach with in situ measurements.

3. Exploit existing SCanning Imaging Absorption spectroMeter for Atmospheric CHartographY (SCIAMACHY) and Greenhouse Gas Observing Satellite (GOSAT) data in inversions of fluxes. Assess biases and co-benefits of assimilating SCIAMACHY and GOSAT and/or in situ measurements in each region.
4. Keep GOSAT running as long as possible to provide a maximum overlap with Orbiting Carbon Observatory-2 (OCO-2), GOSAT-2, and other upcoming satellites.

5. Launch OCO-2. The smaller field of view of OCO-2 compared to GOSAT should offer higher measurement density in partially cloudy conditions ( $25 \mathrm{vs} .10 \%$ clearsounding probability), open the possibility to 10 -fold reduction in the uncertainty of sub-continental fluxes (Miller et al., 2007). Implement OCO-3 in a low inclination orbit with higher-density sampling of tropics, diurnal sampling of latitudes up to 57 degree, and "citymode" (high-density raster scan) at $\sim 3 \mathrm{~km}$ resolution for major urban areas.

6. Develop and begin to implement the next generation/constellation of GHG satellite measurements (Fig. 7a) from polar (low-earth) orbit to sustain and improve records of $\mathrm{XCO}_{2}$ and $\mathrm{XCH}_{4}$ established with first generation sounders. The target is to provide boundarylayer sensitivity $\mathrm{XCO}_{2}$ precisions of $1 \mathrm{ppm}$ and notional $\mathrm{XCH}_{4}$ precision of $9 \mathrm{ppb}$, for single observations (Buchwitz et al., 2011), with individual ground footprints adapted to minimize cloud contamination, and good global coverage at 1-4 day repeat pass intervals for resolving a fraction of emissions from strong local sources (e.g. urban areas or power plants) to provide policy-relevant flux estimations at regional- and cityscales (Bovensmann et al., 2010; Velazco et al., 2011). All of these column mixing ratio precisions should be "bias-corrected", single sounding retrieval error.

7. For $\mathrm{XCH}_{4}$, space-borne light detection and ranging (lidar) developments should be pursued for their ability to measure $\mathrm{XCH}_{4}$ during the winter season in boreal and arctic regions, where emissions may increase in the future (e.g. the Methane Remote Lidar (MERLIN) mission in Fig. 7).

8. Investigate the potential of geostationary platforms. For instance, instruments on commercial and other geostationary platforms offering hourly observations of $\mathrm{XCO}_{2}, \mathrm{XCH}_{4}$ at $1-5 \mathrm{~km}$ spatial resolution, with vertical profiling capability. Sampling areas from $60^{\circ} \mathrm{N}$ to $35^{\circ} \mathrm{S}$ will cover $>95 \%$ of anthropogenic $\mathrm{CO}_{2}$ and $\mathrm{CH}_{4}$ emissions (unless one needs to measure permafrost emissions).

9. Investigate the use of XCO (typical individual sounding precision of $15 \mathrm{ppb}$ ) and $\mathrm{XNO}_{2}$ as tracers of wildfires and fossil fuel/biofuel combustion measurements from satellites, possibly simultaneous observations with $\mathrm{XCO}_{2}$ and $\mathrm{XCH}_{4}$ sounders/imagers. 


\subsubsection{Atmospheric transport models and data infrastructure}

Improving atmospheric transport models is critical to best use of information expected from the massive data increase outlined in Sects. 4.5.1 and 4.5.2. The pertaining needs are

1. Improvement and frequent evaluation of transport models against observations, in particular for boundary layer mixing, vertical convective transport, largescale advection (including inter hemispheric exchange), and stratosphere-troposphere exchange by using tracer and meteorological measurements (e.g. boundary layer height data from lidar and Rawisond measurements, aircraft vertical profiles $\mathrm{CO}_{2}$ and tracers).

2. Pursue regular transport models inter-comparison and evaluation against measurements, for $\mathrm{CO}_{2}$ and $\mathrm{CH}_{4}$, and transport tracers $\left(\mathrm{SF}_{6}\right.$, Radon-222), under programs such as Atmospheric Tracer Transport Model Intercomparison Project (TRANSCOM) (www.transcom. project.asu.edu) (Denning et al., 1999; Taguchi et al., 2011). Benchmarking and inter-comparison exercises should be designed and carried out for a range of spatial scales and terrain, including at regional and cities scale.

3. Develop atmospheric transport models at higher than current resolution. A target in one decade would be a spatial resolution of $10-50 \mathrm{~km}$ over the globe for transport models used in inversions, and zooms of $1-10 \mathrm{~km}$ over regions/cities. Note that the forward model of the Monitoring Atmospheric Composition and Climate (MACC-II) system (http://www.gmes-atmosphere.eu/d/ services/gac/nrt/nrt_fields_co2/) is currently run with a resolution of $15 \mathrm{~km}$ over the globe.

4. Work cooperatively with weather forecast centers (National Center for Environmental Prediction - NCEP, European Centre for Medium-Range Weather Forecast ECMWF, Global Modeling and Assimilation Office GMAO, etc.) to improve atmospheric transport models and products best suited for accurate transport of longlived tracers like $\mathrm{CO}_{2}$ and $\mathrm{CH}_{4}$.

5. Possibly consider the utility and need for leveraging and expanding existing air-quality inversion systems employed by some regulatory agencies (e.g. Centre for Marine and Coastal Studies - CMACS) to include $\mathrm{CO}_{2}$ and $\mathrm{CH}_{4}$ regional inversions.

In terms of atmospheric data infrastructure, improving the current infrastructure to accommodate the required measurements will require to

1. Implement interoperable database tools, common formats, harmonized reporting of data uncertainties and calibration, for $\mathrm{CO}_{2}, \mathrm{CH}_{4}$, and above-listed tracers.
2. Statistically characterize and report errors on each information piece of atmospheric inversion models, including measurements, transport models, in terms of bias and random errors, the latter being desirable under the form of the space-time errors characterization (full error covariance matrices).

\subsection{Oceanic data needs}

\subsubsection{Ocean in situ data}

To observe the temporal evolution of the ocean $\mathrm{CO}_{2}$ sink as well as the chemical changes it induces, i.e., ocean acidification, the current observing system needs to be increased in sampling capacity and frequency. This can be achieved by combining existing programs and technology with new ones that take advantage of the emerging autonomous technology. The following notional requirements need to be considered:

1. Expansion of surface ocean $\Delta p \mathrm{CO}_{2}$ observing systems using Volunteer Observing Ship lines (VOS = voluntary observing ships; commercial ships equipped with autonomous measurement systems) and autonomous surface craft and moorings. For instance, to determine the regional air-sea flux of $\mathrm{CO}_{2}$ to within $\pm 0.2 \mathrm{Pg} \mathrm{C} \mathrm{yr}^{-1}$ requires evenly spaced and regular crossings in the northern North Atlantic of 5-9 crossings per year every $1500 \mathrm{~km}$ and 6 crossings per year every $1500 \mathrm{~km}$, in the temperate North Pacific - 9 crossings per year every 200 to $600 \mathrm{~km}$, in the equatorial Pacific - 15 crossings per year every $200 \mathrm{~km}$, and in the polar South Pacific every $300 \mathrm{~km}$ in summer to every $800 \mathrm{~km}$ in winter (Watson et al., 2009). Recent modeling approaches to optimize crossings suggest that in the Southern Ocean, the $\mathrm{CO}_{2}$ air-sea flux can be determined to within $\pm 0.1 \mathrm{Pg} \mathrm{C} \mathrm{yr}^{-1}$ with regular 3-monthly sampling at a spatial resolution of $3^{\circ}$ meridionally and $30^{\circ}$ zonally.

2. Continue and enhance time series moorings measurements of ocean surface $\Delta p \mathrm{CO}_{2}$ partial pressure and carbon parameters for long-term climate observations and for creating better process understanding. Ideally Eulerian time series will need to be constructed from arrays covering a wider area (dependent on the variability in the area of interest) in order to avoid aliasing due to slowly moving fronts. New technological development is needed to provide additional carbon sensors on moorings. As a first step, carbon sensors should be deployed on all of the OceanSITES (www.oceansites.org/) flux reference moorings. Most Eulerian ocean carbon time series stations (e.g. HOTS - Hawaii, BATS Bermuda/North Atlantic, ESTOC - eastern North Atlantic, DYFAMED - Mediterranean) are located in oligotrophic stable low variability regions, also in view of separating more easily long-term climate induced signals from higher frequency noise. It is highly desirable 
to also install Eulerian marine time series stations - and specifically time series arrays - in eutrophic and highvariability regions. These regions are currently undersampled when it comes to long time series. Naturally in these areas the potential aliasing of measurements through moving fronts becomes more serious. Nevertheless, also temporal developments of regions with high-marine-carbon turnover ecosystems must be assessed.

3. Pursue the collection of very-high accuracy threedimensional ocean interior carbon data (at least total dissolved inorganic carbon and alkalinity from the same cast) together with relevant physical and biogeochemical measurements (see GO-SHIP initiative http://www. go-ship.org and Roemmich et al. (2010). Ship-based hydrography is insofar the only method for obtaining high-quality, high spatial and vertical resolution measurements of a suite of physical, chemical, and biological variables over the full water column. More specifically, two types of survey are required: decadal surveys with full basin resampling of any basin over a less than 3 -year period, and a sub-set of the decadal surveys sampled at higher frequency (every 2-3 years).

4. Floats and gliders equipped with sensors for simultaneous measurements of two different inorganic carbon tracers (ideally of the two master tracers: dissolved inorganic carbon - DIC and total alkalinity - TAlk) need to be developed and applied to the ocean at large scale. In addition, floats that measure vertical particle fluxes must be refined and used. Such floats are currently under development (e.g., Bishop, 2009).

5. For coastal environments, design studies for a network of new hydrographic and ecological surveys, moorings and floats will be required to provide integrated observations.

6. Collect oxygen and nutrient measurements together with carbon, to help in detecting and diagnosing largescale changes in oceanic overturning, which cannot easily be monitored by physical techniques. In particular, develop and deploy sensors for a denser set of oxygen observations, especially on moorings and ARGO floats, to help differentiate between biologically dependent air-sea carbon fluxes and inorganic buffering of anthropogenic $\mathrm{CO}_{2}$. In particular over continental margins, where anthropogenic nutrient input and a potentially slower ocean overturning during global warming may lead to more oxygen depletion.

7. Coordinate carbon and ocean acidification sampling and requirements, given that many of the open-ocean research requirements of the ocean-acidification community could be met by future research plans of the ocean carbon and biological communities, and by adding sensors and moorings where needed (International Ocean Carbon Coordination Project - IOCCP, http://www. ioccp.org/).

\subsubsection{Ocean remote-sensing data}

Remote-sensing data complements and expands on ocean in situ sampling by providing information in regions that are under-sampled. To take full advantage of the remote-sensing technology (Fig. 7b), its data will need to be combined with in situ data and models. The following notional requirements are derived

1. Improvements in ocean color products from satellites, including ground-truth measurements to link satellite observations to chlorophyll, phytoplankton groups or primary production data (Fig. 7b).

2. Sediment traps (which are not "remote sensing", although that data would be useful for calibration of remote sensors) at more shallow depths in conjunction with measurements of dissolved quantities to derive a more precise quantification of changes in the biological carbon pumps.

3. Address potential gaps in future ocean color records. The MODerate-resolution Imaging Spectroradiometer (MODIS) instruments are currently in extended operational phases. Net primary production (NPP) and Joint Polar Satellite System (JPSS) Visible-Infrared Imaging Radiometer Suite (VIIRS) instruments, intended to provide a replacement for MODIS, will not have the necessary performance to fulfill this need; NASA is planning to expedite a follow-up capability - PreAerosol, Clouds, and ocean Ecosystem (PACE) but there is a risk of a 2-5 year data gap in the middle of this decade. For European Space Agency (ESA), Ocean Land Colour Instrument (OLCI) onboard Sentinel-3 will replace MERIS (see Fig. 7b).

4. Develop advanced multispectral/hyper-spectral satellite sensors with new channels for detecting dissolved organic carbon (DOC) and phytoplankton functional types.

\subsubsection{Ocean modeling and integration}

In terms of modeling and data integration tools development of systematic ocean carbon observations, notional requirements are

1. Homogenize data time series that cannot be used otherwise in interpretation. For inorganic ocean carbon variables (DIC, TAlk, $\mathrm{fCO}_{2}, \mathrm{pH}$ value, carbonate saturation state), standardized measurement and reporting methods exist, but will have to be continuously re-enforced. 
Standardization of particle flux measurements and a number of marine organic carbon measurements must be developed and put to use.

2. Pursue data synthesis activities and international data management activities, with task sharing between carbon and ocean acidification measurement programs.

3. Support the development of ocean carbon-cycle data assimilation systems that take advantage of the different data streams with the aim to estimate key ocean fluxes and carbon parameters.

4. Statistically characterize errors of all pieces of information that used in the data integration, including the ocean models, in terms of bias and random errors. Random errors should be described by space-time covariance matrices.

5. Develop integration activities for optimal sampling strategy with ship-based hydrography, time-series moorings, floats and gliders with carbon system, $\mathrm{pH}$ and oxygen sensors, and ecological and chemical surveys.

\subsection{Terrestrial data}

\subsubsection{Eddy covariance flux networks}

The priority to develop a robust, operational carbon monitoring system is to rationalize and harmonize the FLUXNET network to into core and supporting sites. The network of core sites should function in the long-term with standardized instrumentation as a reference network for model evaluation, satellite validation and calibration (e.g. leaf area index - LAI, fraction of photosynthetically active radiation FAPAR, gross primary production - GPP). Transforming the FLUXNET network as a component of a systematic global carbon monitoring system will require

1. Careful selection of core and supporting sites based on stratification by major biomes within eco-regions, for instance with a cluster of sites in each eco-region, with a core long-term site, and other towers capturing variation due to disturbance/management in that region (www.public.ornl.gov/ameriflux/).

2. Systematic sampling of carbon pool (soil and vegetation) inventories co-located at flux sites so that spatially extensive inventory and intensive, but sparse flux data can be used synergistically.

3. Harmonization of FLUXNET measurement, data processing and analysis protocols, and resulting data sets, including reporting of all sources of uncertainties in the data.

\subsubsection{Biomass and soil carbon pools inventories from in situ sampling}

Standardized inventory methods and data analyses, greater sampling density for non-living $\mathrm{C}$ pools and disturbed areas define the main needs/requirements to link results from observations like FLUXNET, from radar/lidar missions (e.g. Phased Array type L-band Synthetic Aperture Radar PALSAR) or atmospheric inversions that measure the variability of land-atmosphere fluxes, to the slowly changing carbon pools (e.g. forest biomass) representative of timeaccumulated fluxes and implicitly include lateral (horizontal) time-accumulated fluxes. Regarding non-forest biomes, soil carbon inventories that are extremely sparse in the current observing system, and priority needs are

1. Sampling of tropical and arctic regions that contain large soil carbon pools, including peat (tropical and northern), wetlands and mangroves, tundra and frozen soils.

2. Development of minimum soil carbon inventories under grassland and cropland by sampling representative climatic zones, agricultural practice/land use history (e.g. chrono-sequences).

3. Harmonize methodologies for soil carbon assessments, including optimal methods for organic soils, for assessing $\mathrm{C}$ in deep/frozen soils.

Regarding forest biomass and soil carbon stocks inventories, it is critical for global carbon observing system to have available high spatial resolution measurements, since the scale of disturbance is often of tens of meters, smaller than the grid of systematic forest inventories (which can pick up the signal of some disturbances through statistical sampling of large regions). Yet, at ca. $0.1 \mathrm{ha}$, biomass distribution is skewed to those plots with a large stem, and the error on biomass estimates for a single large stem is large. Instead, we need a few large stems in each plot (i.e. 1 ha minimum). A scale of $\sim 1$ to 4 ha defines the main spatial resolution requirement for satellite observations of biomass.

Transformational change in the current sampling scheme will require a high priority to develop forest inventories in tropical forests. It is recommended to repeat measurements typically every 5 years for trees while allowing 10 years for the soil compartment to track pool dynamics. Improved forest inventories systems as part of an observing system to quantify $\mathrm{CO}_{2}$ fluxes from pools changes will need to fill in the following gaps:

1. Increase the number of tropical inventories, both over intact and disturbed forest sites and over closed canopy and woodland.

2. Make more accessible the current forest inventory data (at present mostly proprietary), including a subset of 


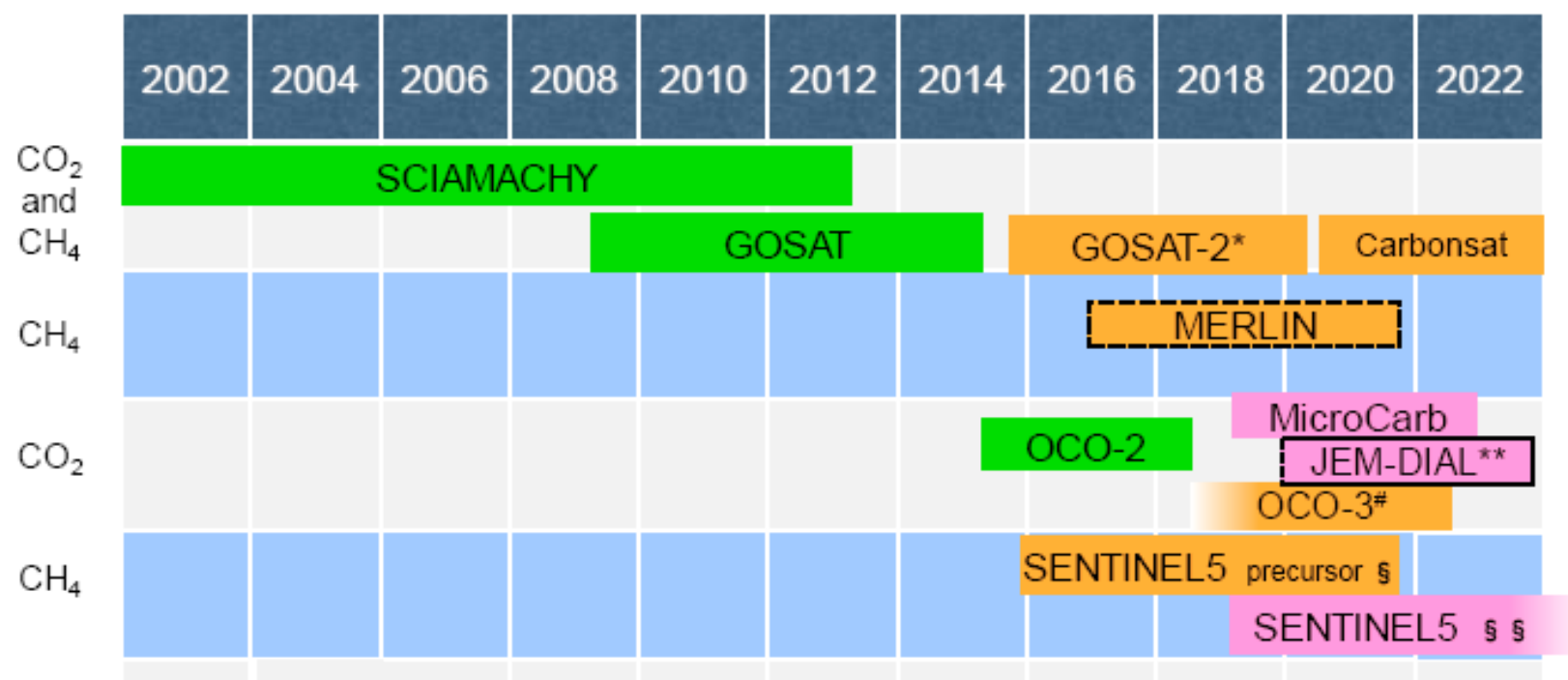

$\mathrm{CO}_{2}$

ASCENDS

* GOSAT-2 mission started pre-project in 2011.

** JEM-DIAL has been studying dedicated $\mathrm{CO} 2$ measurement to be aboard ISS -Japan Exposure Module

\# instrument will be assembled and ready for integration on to a flight of opportunity as soon as 2015

$\S \mathrm{CO}$ as a "by-product"

$\S \S 15$ years of continuity expected ; some $\mathrm{CO}_{2}$ but currently not prioritized

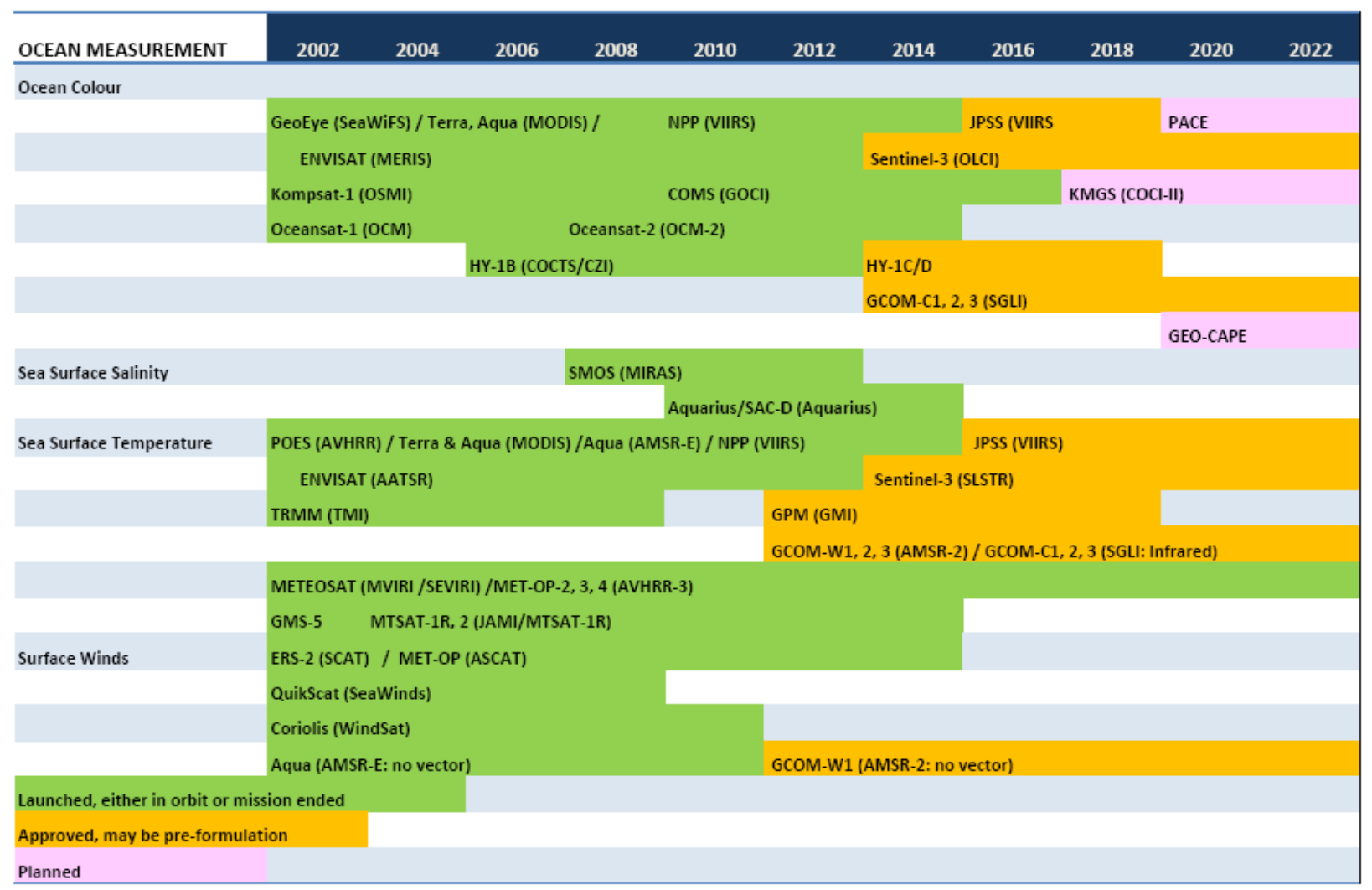

Figure 7. Satellite missions ongoing and planned. (A) Ffor $\mathrm{XCO}_{2}$ and $\mathrm{XCH}_{4}$ column mixing ratio observations with PBL sensitivity; launched or near-launched (green), approved - maybe at pre-formulation stage (tan), and planned missions (pink). Outlined dashed black are active sensors (lidar). (B) Same for ocean carbon-cycle satellite missions. (C) Same for terrestrial carbon cycle. 


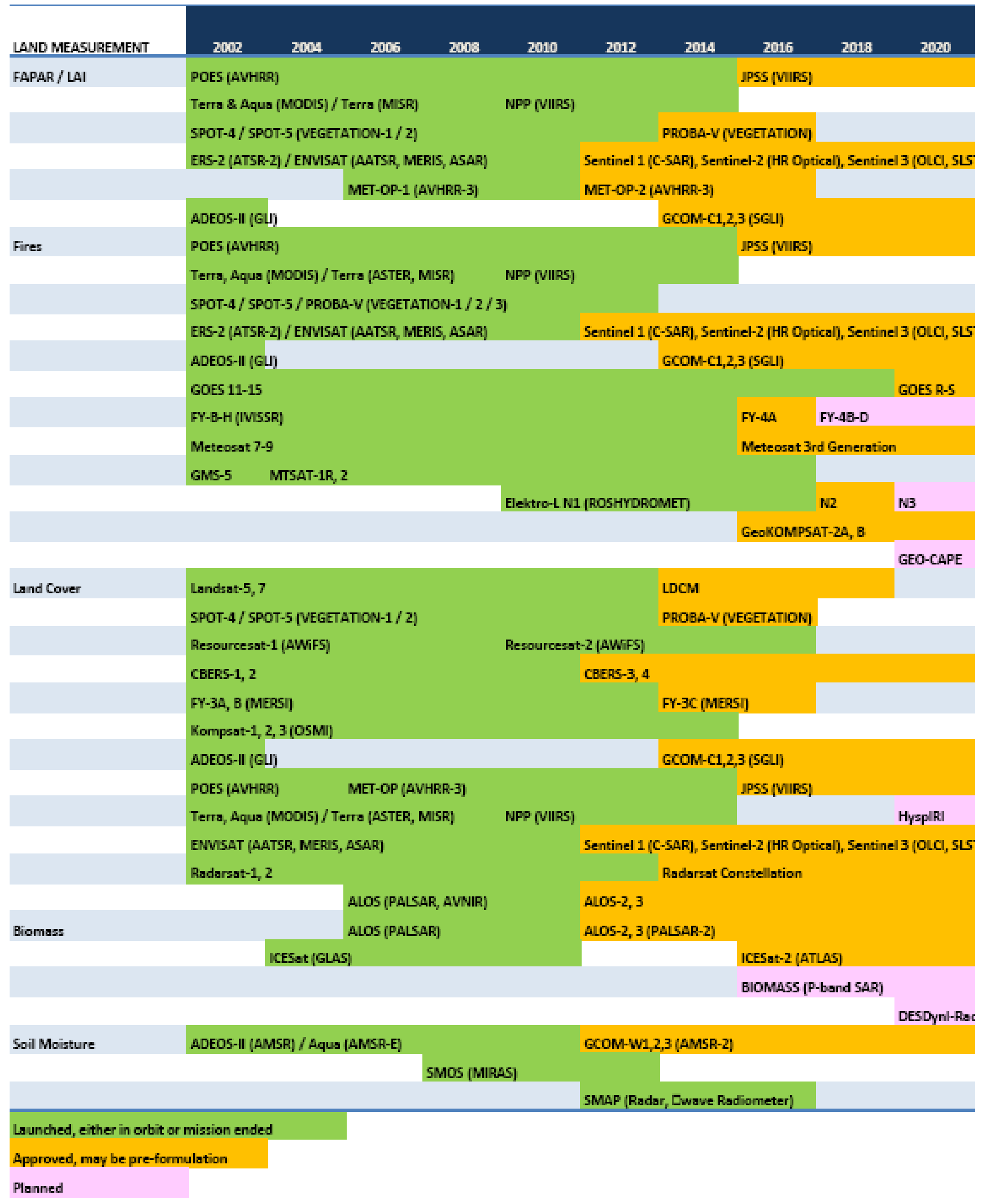

Figure 7. Continued. 
plot-level data or aggregated data at higher resolution than is presently available.

3. Harmonize the different methods for biomass inventory data collection to create continuous, standardized, georeferenced forest biomass data products.

4. Refine standard methodology for biomass values for use in grid cells to include probability-based sampling across regions (e.g. systematic grid design, variable radius subplots in forests adjusted to maximum coefficient of variation $<20 \%$ ).

5. Complement data from forest inventories by additional sampling of carbon in soils, dead wood, and woody debris.

6. Perform additional sampling of forest recently disturbed by events such as wind thrown, wildfires, and insects to assess impacts on carbon stock changes.

7. Develop allometric functions and use consistent biomass conversion method such as the method of continuous biomass expansion factor (BEF) to estimate biomass from inventory variables (diameter at breast height (DBH) and timber yield) for different vegetation types, climate zones, and fertility classes. Allometric functions are needed in a similar range of conditions to convert aboveground to total biomass. Accounting for biodiversity in tropical sites will be a major challenge.

8. Develop specific carbon conversion factors for foliage, root, and wood tissues and apply them to calculate carbon from biomass of different tree components.

\subsubsection{Terrestrial remote-sensing parameters}

To enhance the monitoring of terrestrial $\mathrm{CO}_{2}$ fluxes and their response to management and climate, increased accessibility, improvement, and regular updates of remote-sensing products are required, supported by cross-validations/calibrations campaigns and exercises, as well as continuity in current satellite observations. The continuity of such observations is expected to be enhanced by new Landsat-, and MODIScontinuity missions in the US, as well as the European Space Agency/European Commission constellation of Sentinels under the Global Monitoring of Environment and Security GMES program.

New "Imaging Spectrometers" (also known as hyperspectral imagers) that will be launched by various countries such as Germany, Italy, Japan, and the US in the coming 3-10 years, are expected to provide unprecedented fidelity in more direct measurement of various chemical and biochemical constituents of vegetation, water bodies, oceans, and soils, thus providing new opportunities for further refinement of $\mathrm{C}$ cycle models (see e.g. http://hyspiri.jpl.nasa.gov/science). In terms of continuity and update of remote-sensing products, the main needs are
1. Validated and regularly updated satellite LAI and FAPAR and remote-sensing based global GPP. NPP products will be required over the entire operation length of a carbon observing system, including reanalysis products using long-term records Advanced Very High Resolution Radiometer (AVHRR) to detect trends (Fig. 7c).

2. Validation campaigns to improve LAI, FAPAR and GPP, NPP remote-sensing products should be initiated over sites (e.g. FLUXNET, inventories) distributed globally to sample a large number of biomes, land use and canopy structural types. Optimal site distribution and benchmarking should capitalize on current 3-D radiation transfer modeling capabilities (e.g. Huang et al., 2008).

In terms of algorithm and products development, specific data products allowing regular assessment of carbon fluxes from land use/land cover change and disturbances will be required in the next decade (see Fig. 7c for existing and planned satellite measurements):

1. Annual validated land use/land cover mapping products. Validation and accuracy assessment of satellite-derived land cover will be needed against independent data collected in ground surveys or aerial photos. Accuracy assessments are critical for monitoring treaty agreement compliance (e.g. REDD+).

2. Global remote-sensing data products for mapping fire, harvest and degradation, forest regrowth, land clearing, and insect disturbance. Detection of partial disturbances or degradation such as high-grade harvest in the tropics, will require annual to sub-annual satellite data to detect changes before forest canopies fill in. Due to spatial heterogeneity of disturbance and biomass in forests, a spatial resolution of $50 \mathrm{~m}$ at minimum for deforestation detection will be required (e.g. the BIOMASS mission in Fig. 7c), and a 100-200 m resolution product for detection of forest degradation and regrowth.

3. Continuous programs to derive direct estimates of forest biomass and forest degradation through the use of optical technologies (hyperspectral) or Synthetic Aperture Radar (SAR) (multi-wavelength X-, C-, L-, P-band) linked to ground inventory plots at appropriate scales.

4. Develop improved global measures of ecosystem functional response to stress, including water, temperature and nutrient effects through new optical (hyperspectral) or other techniques.

In terms of satellite capabilities needed to sustain the terrestrial component of a global carbon monitoring system, the main requirements are

1. Reduce dependency on single satellite missions. Develop contingency planning in case of failure of Landsat Data Continuity Mission (LDCM) (NRC, 2010) and 
plan for a successor to LDCM (http://landsat.usgs.gov/ about_dcm.php), coordinated with European Sentinel2, the first of which should be launched in 2013 (see Fig. 7c) (http://www.esa.int/esaLP/SEMM4T4KXMF_ LPgmes_0.html). If the monitoring system is to rely solely on one mission and the launch fails, it would be virtually impossible to monitor land use change, which might significantly undermine the REDD component (Reducing Emissions from Deforestation and Forest Degradation in Developing Countries) of a future global treaty by limiting the capability of tropical countries to produce realistic national inventories.

2. Develop and deploy advanced lidar, SAR (multiwavelength X-, C-, L-, P-band and/or interferometric SAR), and new optical sensors (e.g. hyperspectral) to provide more direct estimates of forest biomass and forest degradation (Fig. 7c).

3. Deploy next generation satellites offering improved soil moisture data (e.g. Soil Moisture Active/Passive (SMAP) mission) and chlorophyll fluorescence data (e.g. from OCO-2, OCO-3, GOSAT-2, and either the FLuorescence Explorer (FLEX) or CarbonSat missions) towards improved or independent estimates of GPP, respectively. Explore options for detecting vegetation moisture from these sensors to inform analysis and modeling of plant stress.

\subsubsection{Lateral carbon transport in aquatic systems}

More systematic observations are needed to quantify/start to monitor lateral carbon fluxes in aquatic systems. Specific new surface water records are required to better map floods and the spatial extent of streams and rivers (floodobservatory. colorado.edu/) including

1. Remote-sensing and model-based data products to assess the temporal dynamics of inland water areas and water residence time in large lakes and fluvial systems.

2. New remote-sensing algorithms to use the color of water as a proxy for terrigeneous dissolved organic carbon (DOC), and studies of new sensors (ultraviolet) that could enable detection of dissolved organic matter.

In the next 10 years, increased sampling of carbon in aquatic systems is required to complete the terrestrial component of a global carbon monitoring system for boreal, temperate and tropical inland waters - including streams, rivers, and estuaries - to estimate ecosystem gross primary production and respiration, horizontal carbon transport fluxes (dissolved and particulate organic carbon, dissolved inorganic carbon, total alkalinity, $\mathrm{pH}, \mathrm{pCO}_{2}, p \mathrm{CH}_{4}$ (e.g. Global Lake Ecological Observatory Network - GLEON; www.gleon.org/)). Notional requirements are
1. Monitoring of the discharge of inorganic and organic river carbon to the ocean.

2. Monitoring of dissolved (DOC) and particulate organic carbon (POC) river flux of relevant rivers with the frequency of data acquisition capable of capturing the contribution of floods/extreme events, which usually make a dominant contribution to annual budgets.

3. Aquatic carbon parameters monitoring in regions particularly susceptible to climate change (e.g. permafrost). At aquatic stations, loads and ages of DOC and POC should be determined in addition to measurements of $p \mathrm{CO}_{2}, \mathrm{pH}$, DIC, total alkalinity, and $\mathrm{CH}_{4}$.

4. Local estimates of carbon burial in major lakes, impoundments, floodplains, for example, using sediment cores and traps sampled at 5-10-years interval.

5. Concentration in the soil of dissolved and particulate inorganic and organic carbon (DOC and POC) monitored at at least 100 stations located in different biomes and ecosystems. Stations may be equipped with erosion traps, wells or lysimeters and tensiometers to continuously monitor chemical composition and fluxes of carbon in groundwater.

In the longer term, over the next 20 years, production of DOC and POC should be monitored at stations located in different biomes and ecosystems (likely collocated with FLUXNET stations). These future stations should be equipped with wells, lysimeters and tensiometers that monitor chemical composition and fluxes of carbon in groundwater. Data could be disseminated through existing infrastructure (e.g. Glo$\mathrm{RiCh}$ - Global River Chemistry Database) for hydrochemical modeling.

\subsubsection{Terrestrial ecosystems management data}

Global geo-referenced information about harvest and use of carbon in food and wood products is required to close regional terrestrial carbon budgets, and integrate ecosystembased carbon budgets into regional budgets. Harvest information should be determined regularly from agricultural and forestry statistics, with the best geospatial resolution at which statistics are collected (for instance, counties). Basic notional requirements for management data are

1. Geospatial information on crop and wood biomass harvest updated each year, at resolution of at best $1 \mathrm{~km}$ to 1 county in regions with detailed agricultural and forestry statistics, and at worst $100 \mathrm{~km}$ in regions with less detailed statistics.

2. Conversion factors from harvested biomass to carbon for different crop and wood products. 
3. Geospatial information about the use of wood and food products, including burning for energy, cooking, consumption by the population and by animals in case of food products, and decay in landfills for wood products.

4. Information on carbon embedded into food and wood products in international trade circuits, including associated uncertainties.

Ancillary geo-referenced information will be required to drive the generation of ecosystem models expected to be run operationally in the next $\sim 10$ years for estimating carbon fluxes and stocks. This information should be determined regularly from agricultural statistics, with the best geospatial resolution at which statistics can be collected (e.g. counties) and wherever possible with historical reconstruction over at least the past 4 decades, and includes

1. Forest species growing and planted.

2. Forestry management practice (silvicultural techniques, and management of biotic and abiotic disturbances).

3. Estimates of carbon losses from forest degradation and subsequent recovery.

4. Crop varieties and rotations.

5. Cropland management practice: planting density, mineral fertilizers or manure additions, fate of crop residues, tillage, liming, irrigation, sowing, and harvest dates.

6. Pasture and rangelands management practice (grazing animal density and grazing season, rotational grazing systems, cutting, fertilization and pasture improvement, and rotation of grassland with other land use).

7. Farm-scale management information for a representative farm gate management in each region (production, non-marketed crops, and mechanization).

8. Georeferenced information on agricultural activities associated with $\mathrm{CH}_{4}$ emissions, rice cultivation and livestock production, and waste management.

\subsubsection{Terrestrial data integration and modeling}

In terms of modeling and data integration tools development of systematic terrestrial carbon observations, notional requirements are

1. Development of spatial flux and pools up-scaling algorithms for application over heterogeneous landscapes, for example, around flux tower footprints. In particular, work is needed on the effective integration of intensive plot biological measurements with remote-sensing data for spatial extrapolation of local data to the wider region (e.g. Hudiburg et al., 2011).
2. Continuous programs to improve ecosystem models and remote-sensing integration in models, to provide initial conditions, as well as quantification of change at global and regional scale. Development and evaluation are required for models to include land use and land use change (cohorts), forestry, fire/insect/wind throw disturbance (including the scale, frequency, and severity of each type of disturbance and subsequent lagged effects, forest growth and demography changes, and agricultural management. Models need to incorporate, in addition to water, energy, and carbon-cycle processes, the interactions between nutrients and carbon cycling (both limitations and fertilizations resulting from increased nutrient supply), export of dissolved/particulate carbon from ecosystems to river headstreams, and carbon fluxes transformation in aquatic systems. Ecosystem models used to calculate $\mathrm{CO}_{2}$ and $\mathrm{CH}_{4}$ fluxes and carbon stock change from observations will need to assimilate remote-sensing and in situ data at the scale where the data are collected.

3. Pursue ecosystem models inter-comparison, benchmarking and evaluation programs such as the International Land Model Benchmarking Project - ILAMB (www.ilamb.org) and dynamic global vegetation model projects - TRENDY (www.dgvm.ceh.ac.uk), and link to plant trait databases to exploit most up-to-date ecological information relating to biodiversity (Plant Trait - TRY database).

In terms of terrestrial carbon observation access and infrastructure, the needs include

1. Data access tools for operationally robust forest and carbon monitoring systems such as the GEO Forest Carbon Tracking Task (www.geo-fct.org) - spatial data infrastructure and web-delivery systems to transfer data holdings and present maps.

2. Closer working relationships with space agencies (e.g. through the Committee on Earth Observation Satellites (CEOS) to provide continuous supply of satellite data) to annually monitor areas of forest, deforestation and forest degradation, as well as afforestation, reforestation, and areas of rising biomass density. Because Monitoring Reporting and Verification (MRV) reports are required for both national and sub-national level (e.g. REDD+) scale, and to avoid "leakage", border-toborder remote-sensing data with a spatial resolution of $50 \mathrm{~m}$ as a minimum will be required.

3. Access to inventory data and accuracy assessment (e.g. web-based) including remote-sensing data products (e.g. aboveground biomass) and model input parameters and output (e.g. net carbon uptake, carbon stocks) with version documentation. 
4. Statistical characterization of errors of all information used in the data integration, including ecosystem models, and their forcing data, in terms of bias and random errors. Random errors should be described by spacetime covariance matrices.

\subsection{Notional attributes for detection of regional "hotspots" of the carbon cycle}

"Hotspots" are the regions with large carbon reservoirs whose stability is threatened by progressive climate and land use change, sites/areas with large emissions, such as megacities, highly variable fluxes, and/or climate or land use change sensitive fluxes or stocks. Two main hotspots for land are Arctic and tropical forest biomes. Examples for the oceans are the deep-water production areas of the North Atlantic and the Southern Ocean. The regions, where $\mathrm{CH}_{4}$ fluxes are sensitive to climate or land use change (wetlands, permafrost, landfills, fire-prone ecosystems, geological gas storage areas, and some dams) can also be considered as hotspots. The consequences of their destabilization will likely be increased natural emissions, loss of sink capacity, with positive feedback on climate change.

It is beyond the scope of this study to derive notional requirements for regional observing systems oriented to characterize carbon-cycle hotspots in the context of early warming systems. It is likely that a higher density of observations, with sampling strategies appropriate to specific observation types, will be required for monitoring hotspot carbon pools/fluxes, detect early changes and/or attribute abnormal flux measurements. These observations may include highresolution $\mathrm{CO}_{2}$ and $\mathrm{CH}_{4}$ concentrations with their isotopes, high-resolution land cover change, key ground-based measurements such as local ecosystem or reservoir flux measurements (e.g. flux towers and flux chambers) and ancillary data (e.g. permafrost active layer dynamics, peatland drainage depth, and carbon densities), and emission measurements (plume sampling, dual tracer release) for intense anthropogenic sources (e.g. power plants, some factories and industrial sites, landfills, and pipelines).

\section{Hurdles and cross-cutting issues in the deployment of a global carbon observing system}

Developing and operating an integrated global carbon observing system will require a coordinated effort, spanning many partner countries and organizations to support instrument development, data and model validation, sustained observations, quality assessment and control, data assimilation, database management, carbon-cycle modeling, fossil fuel inventories, high-performance computing resources, decisionsupport analyses, and systems engineering. Advanced dataintensive analysis and visualization methods will be required to evaluate the information collected in the integrated observ- ing system. The system will have to be built in successive steps. Figure 8 gives a notional vision of the different accuracy and sampling requirements that could be associated with each successive step over the next two decades.

\subsection{Integration of multiple data streams and model-data fusion}

The task of carbon data integration has several objectives:

1. Spatial integration, in which measurements from different regional programs are coherently combined, and databases interoperable.

2. Completeness, in which we try to ensure that important processes of the carbon cycle are observed with clear error assessment.

3. Temporal integration, to be able to use long-time series for improved model prediction, as well as evaluation of impacts associated with climate policy decisions.

4. Process integration, in which data are combined to form a consistent view of the carbon cycle given inferences from atmospheric, oceanic, terrestrial and socioeconomic data, and their uncertainties.

It is obvious that any coherent observing strategy must take account of how observations will be used. The process of integrating multiple streams of observations into carboncycle models requires assimilation techniques that modify model behavior to match observations within their uncertainty range. This approach is given many names such as model-data fusion, the multiple constraint approach, or carbon-cycle data assimilation. Such techniques were initially applied long ago to the tuning of the seasonal cycle of atmospheric $\mathrm{CO}_{2}$ concentration (Fung et al., 1987), but the use of formal data assimilation methods allowed rapid development in the field (Qualife et al., 2008). Examples of such applications are the estimation of phenology parameters from satellite observations (Picard et al., 2005; Stöckli et al., 2011), estimates of photosynthetic parameters using $\mathrm{CO}_{2}$ and heat fluxes (Santaren et al., 2007; Knorr and Kattge, 2005; Randerson et al., 2002; Wang and McGregor, 2003). Oceanographic examples are the optimal interpolation of VOS line data and respective upscaling to the basin-wide scale (Telszewski et al., 2009) and sensitivity estimates of carbon fluxes with respect to specific processes (Tjiputra et al., 2007). A conceptual representation of a global carbon data integration system is depicted in Fig. 9.

Applications can be divided into two broad categories: those that constrain the internal state of the model by optimizing state variables, and those that estimate the poorly known internal parameters of the model. Data assimilation for state variables can produce a closer fit to observations because it uses less hard constraints from the underlying imperfect model. It is therefore preferred when the best possible 


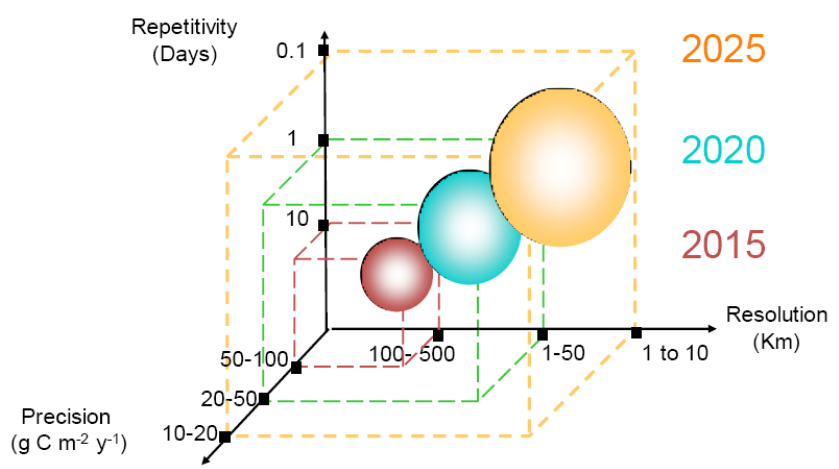

Figure 8. Notional deployment of a global carbon monitoring system in three phases with increasing sampling, resolution and accuracy. The resolution and target precision are expected to be reached in the best-sampled regions at first.

performance within the observing period is required (i.e. diagnostic applications), while assimilation to estimate parameters is intended to improve the underlying behavior of the model and targets prognostic applications.

Key elements needed for policy-relevant carbon observations that could be deployed with significant funding and coordination in the next decade have been set out in Sect. 4 . Most importantly, every observation must be associated with error statistics to properly weight its influence in the data assimilation system. The linkage of observations to accepted calibration scales (and any offsets) must also be clear so that scale differences between different observations are not mistakenly interpreted as arising from physical processes. Beyond this, the use of observations in a data assimilation system will require operators that can map the internal state of the model onto the observed variable. Here there are practical choices that will have to be made if the published data are themselves the result of a complex model, such as a radiative transfer model. Biases in calibration can generate coherent errors that will not be captured by point-wise descriptions of error. Experience with numerical weather prediction suggests that the generation of observation operators requires close collaboration between modelers and experts in the particular observed variable. As a scientific task, the generation of these observation operators is equally as important as the generation of data sets of observations using them.

\subsection{Quantitative network design and observing system simulation experiments}

Given knowledge of the error statistics of potential measurements, it is possible to quantify the value of a given data set in terms of the new information it brings. This always requires some kind of model of the underlying statistics, as well as the system dynamics. The approach is described in Kaminski et al. (2012) for network design. The approach has been used to quantify the value of in situ measurements of concentration for constraining surface fluxes and to assess the likely value of satellite measurements of $\mathrm{CO}_{2}$. One can even attempt to design an optimal network (e.g. Rayner et al., 1996), but the task of defining optimality and the assumptions of prior knowledge suggest that the more conservative option of testing potential networks is more reliable (Hungershoefer et al., 2010). Furthermore, experience has shown that "optimal" networks are often governed as much by the reality of logistical considerations (e.g. the development of a tall tower for atmospheric measurements where reliable transport, power and scientific collaborators are) as by quantitative theoretical considerations. Thus, both expert judgment and model analysis must be brought to bear in designing networks (e.g. the NEON approach to determination of eco-regions).

\subsection{Data management and processing}

Building a coordinated carbon monitoring system requires a highly integrated data and information management system. Key to such a system is the ability to synthesize and integrate carbon observations from a wide variety of platforms and techniques within a coherent modeling framework based on model-data fusion methods. To achieve these aims, a distributed data management system must enable access, understanding, use, integration, and analysis and visualization of large volume of diverse data at multiple scales. The data management and analysis systems for the entire data life cycle should deliver high-quality products that will be freely accessible to the scientific, resource management, and policy communities around the world. A lot will depend on the funding mechanisms to make this happen. In the numerical weather prediction world, individual countries are sometimes protective of their data. Prediction centers can have access to data of direct interest to, but for research activities it can be more complicated.

The challenge will be to manage high-quality, consistent, long-term data in a manner that directly supports the data assimilation models, while maintaining enough flexibility to respond to researcher's needs, new observations, and evolving information technology. This includes providing transparent access to the necessary data to implement sub-national and national mitigation activities and to support emission reduction policies. Currently, the data and information systems are not in place to support the data requirements of an integrated carbon monitoring system. It is thus key to the success of the data and information system to plan at an early stage for improved data calibration, harmonization, and quality assurance and quality control procedures that will ensure that observations produced by different networks and observing systems for a broad range of purposes and covering differing spatial and temporal domains are fully compatible and readily integrated in data assimilation systems. While harmonization and data quality control is definitely a good thing, current practice in numerical weather prediction is that the data assimilation centers do their own quality control and bias correction, on top of data provided by the data providers. With 


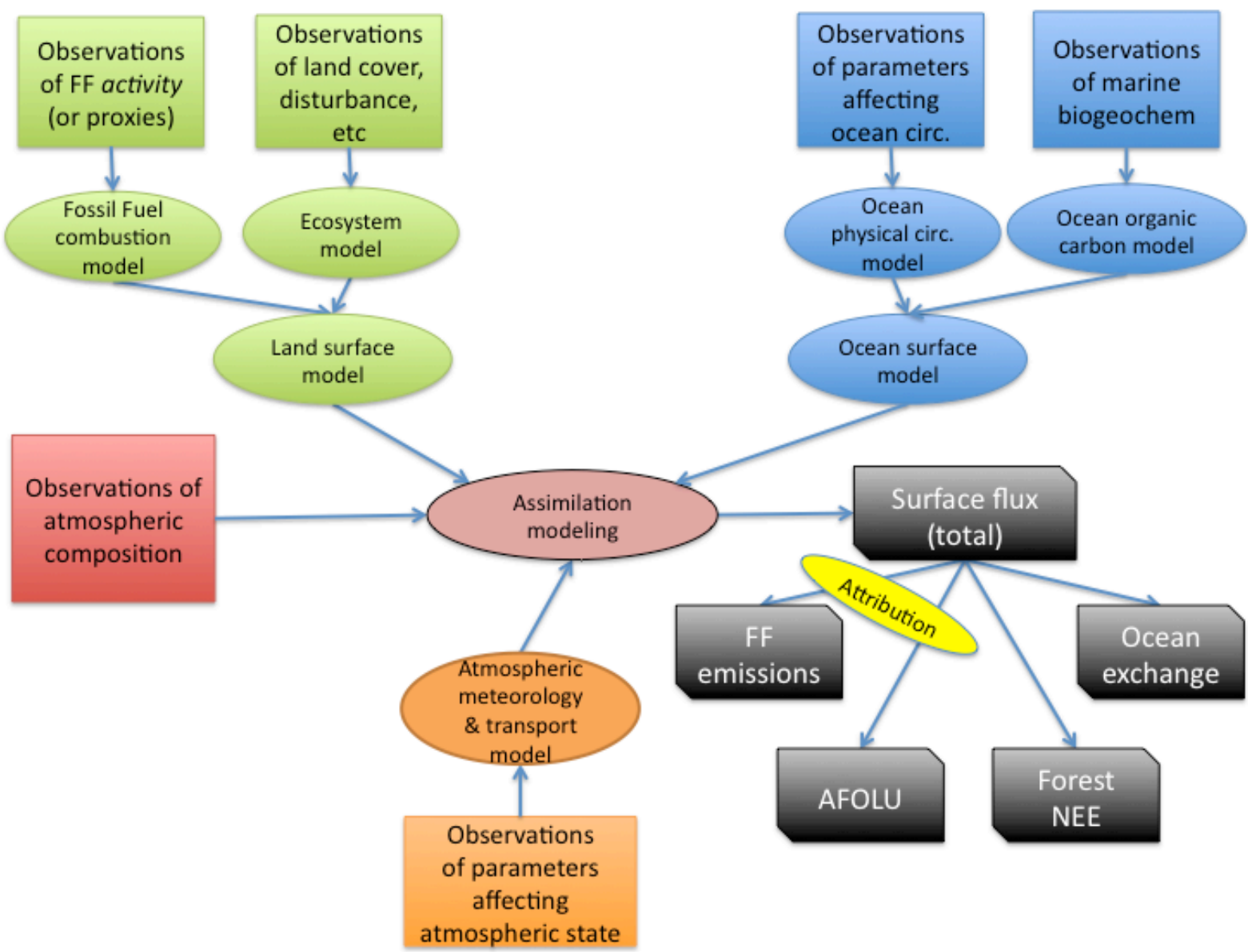

Figure 9. Conceptual illustration of a global carbon-cycle data assimilation system relying on operational carbon-cycle flux and pool measurements.

all input data streams available, data assimilation frameworks provide a useful tool to check the consistency of observations under the assumption of a good model constraint. How significant the last assumption is for carbon-cycle research (i.e. how good the model constraint is) is an open question.

Existing sets of well-calibrated, high-precision carbon stocks, $\mathrm{CO}_{2}$ and $\mathrm{CH}_{4}$ observations should be made available openly. Open access to data, metadata, and data products within a reasonable time after acquisition is the most efficient and cost-effective way to fill observational gaps. The following sections describe data management and processing actions required to establish and operate the proposed data system. Results from pilot projects to enable seamless interoperability (ability of information exchange and use of the information that has been exchanged) of carbon data sets and other data need to be exploited.

\subsection{Integrated data products and services}

The goal of a policy-relevant carbon observing system is to generate data products that are of value for the user communities. Raw observations are rarely adequate on their own.
To create usable products, in situ measurements from a variety of sources with the vastly different spatial, temporal, and process resolutions used in the modeling approach need to be integrated with remote-sensing observations within a modeling framework. To achieve this objective the following actions will be needed.

1. Ensure documentation and harmonization of in situ data from diverse sources. The current problems with in situ data include inconsistent parameter definitions of state variables, different data formats, incomplete data and missing estimates of realistic uncertainties, various spatial and temporal scales, and sampling bias in measurements.

2. Harmonize methods. Many core measurements of carbon pools and fluxes are nationally based, so the harmonization of existing data and the standardization of methodologies is a central issue for a global data system. Many pool and flux synthesis products exist only in research mode. Considerable further development is required before these products can be included in 
hind-casting, re-analysis, or regular carbon budget updates in the context of an operational system. Among other international initiatives, the Global Terrestrial Observing System (GTOS) program (www.fao.org/gtos/) has the specific goal of integrating in situ and spacebased observations, and can provide standards and harmonization guidelines for data integration (e.g. Law et al., 2008a).

3. Facilitate the combination of atmospheric observations with observations on the surface and subsurface, both on land and in the ocean, to include ancillary observations of ecosystem condition, and socioeconomic status.

4. Automate, as far as possible, the production and dissemination of data.

Table 2 shows the differences between current numerical weather prediction systems, current global carbon observing system, and a future (achievable) carbon observing system.

\subsubsection{Priority data products and services}

The integration of models and data needs strategies involving different algorithms and models. Using model-data fusion schemes, inverse modeling and data assimilation to place constraints on the fluxes of $\mathrm{CO}_{2}$ and $\mathrm{CH}_{4}$ between the Earth's surface and the atmosphere and on changes in carbon pools, requires reliable, quality assured, and well-calibrated measurements of both carbon stocks and $\mathrm{CO}_{2}$ and $\mathrm{CH}_{4}$ fluxes along with other measures of system properties and fluxes such as wind fields. In addition, there are a number of control parameter observations that are crucial to data assimilation and model-data fusion activities:

1. Acquire the priority data products identified earlier.

2. Implement model-data fusion techniques to routinely assimilate data streams of carbon measurements to produce consistent and accurate estimates of global $\mathrm{CO}_{2}$ flux fields. These products will need to be indexed and made available for assessment, policy, and resource management.

3. Merge, synthesize, and eventually fuse carbon observations within process oriented carbon models. Comprehensive advanced Carbon-Cycle Data Assimilation Systems (CCDAS) will be required, that are expected to analyze large amounts of data, routinely diagnose carbon quantities, and provide error diagnostics.

4. Implement a global data management system. This system should be based on open source collaboration principles in system development efforts (portal design, data filters, format conversion, web mapping services, or cross-platform compatibility).

5. Implement open and agreed protocols.
The specific functions required of the data management system to support innovative data assimilation methods need to be identified and plans made to provide that support. Several of the required data streams exist today, and systems are in place for handling many of these individual data streams. The data and information management system should build on these existing systems. However, some of the data streams are not produced consistently at the required time and space resolution and the data are not harmonized: as a result they cannot be readily assembled into an integrated set for data fusion.

Feedback and coordination about data requirements to the observing systems are needed to meet the ultimate information needs. Close coordination between data managers, those making the observations, modelers, and other data users is critical. Integration and dialogue will be required between the research teams and the data systems to define and implement data product requirements. It is almost impossible for large data users to communicate with each individual data provider. Frameworks like NOAA/ESRL/GMD, WMOWDCGG and ICOS are crucial as an intermediary.

The continuous improvement of a carbon observing system should periodically take stock of the data and information by documenting its character and quality in ways that are responsive to the needs of its end users, now, for both basic and applied uses, and into the future as they provide the climate-quality, long-term records of Earth system change. As the system provides information for policymakers (e.g., through the Intergovernmental Panel on Climate Change (IPCC) period assessments), the data products input to these analyses need to be evaluated and published in the peer-reviewed literature or in some equivalent, of documented quality.

\subsubsection{Component uncertainty}

Any modeling estimation of the global distribution of carbon fluxes and pools requires the uncertainty characteristics of all data-streams to be an integral component of the data system (Raupach et al., 2005). It is important that uncertainties of all information pieces that are used in data integration schemes, including observations, ocean models, ecosystem models, and atmospheric models, can be described in terms of random errors, and if possible, in terms of known biases. Random errors should be described as far as possible by space-time covariance matrices (Chevallier et al., 2006; Kuppel et al., 2013). Equally important, many of the final products of a global carbon monitoring system and their uncertainties must be presented in a format understandable by decision-makers (not necessarily the same audience as science user communities). Attention must be given to this nuance in the design of the system. 
Table 2. Comparison between numerical weather prediction systems and Carbon Observing system for atmospheric data (infrastructure, management, stewardship), system attributes, and algorithms used for delivering products to end users. For oceanic $\mathrm{CO}_{2}$ data for instance the data are already reported on standardized formats.

\begin{tabular}{|c|c|c|c|}
\hline & \multirow{2}{*}{$\begin{array}{l}\text { Numerical weather } \\
\text { prediction system (NWP) }\end{array}$} & \multicolumn{2}{|c|}{ Carbon observing system } \\
\hline & & Current: research based & $\begin{array}{l}\text { Future: policy-relevant system, } \\
\text { first version achievable in } 5 \mathrm{yr}\end{array}$ \\
\hline \multicolumn{4}{|l|}{ Data } \\
\hline $\begin{array}{l}\text { Data ownership } \\
\text { (in situ) }\end{array}$ & $\begin{array}{l}\text { National Member States coordinated by } \\
\text { WMO. WMO Resolution } 40 \text { defines } \\
\text { the governance; some data are publicly } \\
\text { available; some data are even commer- } \\
\text { cially available; other data are protected } \\
\text { (WMO essential, WMO additional, Na- } \\
\text { tional). The boundaries between pro- } \\
\text { tected and public data are changing, } \\
\text { most notably in the US. }\end{array}$ & $\begin{array}{l}\text { Research Institutes, sometimes } \\
\text { agencies }\end{array}$ & $\begin{array}{l}\text { Possibility of having a similar } \\
\text { setup as in NWP. } \\
\text { With governance by something } \\
\text { like WMO to have at least } \\
\text { recommendations to individual } \\
\text { countries }\end{array}$ \\
\hline $\begin{array}{l}\text { Data ownership } \\
\text { (space) }\end{array}$ & Space agencies & $\begin{array}{l}\text { Space agencies (L2 data are mostly } \\
\text { provided by research institutes, } \\
\text { which sometimes complicates the } \\
\text { data policy). }\end{array}$ & $\begin{array}{l}\text { Clearer organization between } \\
\text { space agencies and research } \\
\text { institutes. }\end{array}$ \\
\hline Data security & $\begin{array}{l}\text { Each member state makes it own deci- } \\
\text { sion based on available funding. Most } \\
\text { countries do realize, however, that } \\
\text { weather data is very important and } \\
\text { needs continuous funding. }\end{array}$ & $\begin{array}{l}\text { No security. Each country makes it } \\
\text { own decision to support or not } \\
\text { carbon observations }\end{array}$ & Security for backbone system. \\
\hline $\begin{array}{l}\text { Data processing } \\
\text { time (in situ) }\end{array}$ & Within a few hours & Month to years & Days - to months \\
\hline $\begin{array}{l}\text { Data processing } \\
\text { time (space) }\end{array}$ & Within a few hours & $\begin{array}{l}\text { Varies. Operational radiance data is } \\
\text { available in real-time, but } \mathrm{L} 2 \text { data } \\
\text { is generally not. Currently, there is } \\
\text { SCIAMACHY } \mathrm{CH}_{4} \text { and } \mathrm{CO}_{2} \text { data } \\
\text { available lagging a few months in } \\
\text { time. Data constraining land car- } \\
\text { bon might be more readily available } \\
\text { (e.g., NDVI)? }\end{array}$ & Within a few hours \\
\hline $\begin{array}{l}\text { Data } \\
\text { standardization }\end{array}$ & $\begin{array}{l}\text { High WMO BUFR format is the stan- } \\
\text { dard, although more and more satellite } \\
\text { data is also provided in HDF and simi- } \\
\text { lar formats. }\end{array}$ & Low & $\begin{array}{l}\text { Coordination with EU, Ameri- } \\
\text { can, Japanese, and other inter- } \\
\text { ested counterparts, in defining } \\
\text { common data standards }\end{array}$ \\
\hline Data Access & Easy & Difficult & \\
\hline $\begin{array}{l}\text { Data Dissemina- } \\
\text { tion channels }\end{array}$ & $\begin{array}{l}\text { WMO-GTS, EUMET-CAST, and FTP } \\
\text { in some cases. Development towards } \\
\text { WMO-WIS }\end{array}$ & $\begin{array}{l}\text { Various, sometimes individual } \\
\text { researchers }\end{array}$ & WMO-WIS could be used \\
\hline \multicolumn{4}{|l|}{ System } \\
\hline $\begin{array}{l}\text { Temporal conti- } \\
\text { nuity (in situ sys- } \\
\text { tem) }\end{array}$ & $\begin{array}{l}\text { Depends on type of observation. Ra- } \\
\text { diosondes are only launched once or } \\
\text { twice a day. Synoptic observations of- } \\
\text { ten only every } 6 \mathrm{~h} \text {. Commercial } \\
\text { aircraft observations only at take-off } \\
\text { and landing. More automatic continu- } \\
\text { ous systems are emerging. }\end{array}$ & Continuous, hourly & Continuous, hourly \\
\hline
\end{tabular}


Table 2. Continued.

\begin{tabular}{|c|c|c|c|}
\hline & \multirow{2}{*}{$\begin{array}{l}\text { Numerical Weather } \\
\text { Prediction system (NWP) } \\
\text { Current }\end{array}$} & \multicolumn{2}{|c|}{ Carbon Observing System } \\
\hline & & Current: research based & $\begin{array}{l}\text { Future: policy-relevant system, } \\
\text { first version achievable in } 5 \mathrm{yr}\end{array}$ \\
\hline $\begin{array}{l}\text { Robustness of in } \\
\text { situ system (redun- } \\
\text { dancy, sensitivity to } \\
\text { stations failure) }\end{array}$ & $\begin{array}{l}\text { Still high in densely populated areas, } \\
\text { but sparse in less developed parts of } \\
\text { the world. Many basic observations are } \\
\text { still done by hand, which provides high } \\
\text { robustness. Oceans are reasonably } \\
\text { covered by buoys for (for instance) } \\
\text { temperature and surface pressure. }\end{array}$ & Very Low & $\begin{array}{l}\text { Will remain low. Depend on } \\
\text { funding decisions. }\end{array}$ \\
\hline $\begin{array}{l}\text { Robustness of } \\
\text { space system } \\
\text { (continuity, } \\
\text { redundancy) }\end{array}$ & $\begin{array}{l}\text { High, but declining. Less funding avail- } \\
\text { able for development of new satellites. }\end{array}$ & $\begin{array}{l}\text { Low, except for carbon variables } \\
\text { retrieved from meteorological } \\
\text { satellites }\end{array}$ & $\begin{array}{l}\text { Depends on funding deci- } \\
\text { sions. Many instruments in the } \\
\text { pipeline, in principle: GOSAT, } \\
\text { OCO-2, CarbonSat, MERLIN, } \\
\text { MicroCarb (see Fig. 7). }\end{array}$ \\
\hline $\begin{array}{l}\text { Completeness of } \\
\text { in situ system }\end{array}$ & High to low in some regions & Low in most regions & $\begin{array}{l}\text { Medium in some regions (US, } \\
\text { Canada, EU, China, Japan) and } \\
\text { low in most others. }\end{array}$ \\
\hline $\begin{array}{l}\text { Completeness of } \\
\text { space system }\end{array}$ & $\begin{array}{l}\text { High in most regions, especially for } \\
\text { temperature and humidity. Observa- } \\
\text { tions of wind, precipitation, clouds, } \\
\text { etc., can still be improved. }\end{array}$ & $\begin{array}{l}\text { High for some variables } \\
\text { Low for some variables }\end{array}$ & Low \\
\hline \multicolumn{4}{|l|}{ Algorithm } \\
\hline $\begin{array}{l}\text { Algorithm } \\
\text { sophistication }\end{array}$ & $\begin{array}{l}\text { Long record under governance of } \\
\text { WMO. Use of satellite data has evolved } \\
\text { over many years and the larger NWP } \\
\text { centres now mostly use radiance data } \\
\text { directly. }\end{array}$ & High & High \\
\hline $\begin{array}{l}\text { Algorithm perfor- } \\
\text { mance evaluation }\end{array}$ & High for operational systems & $\begin{array}{l}\text { Moderate. Again, ESA-CCI might } \\
\text { contribute here. }\end{array}$ & Moderate \\
\hline
\end{tabular}

\subsubsection{Data policy}

Managing and integrating data requires an overarching global data policy that provides full and open access to global and regional observational data, and ensures interoperability of the system and gives due credit to the data providers. An open and transparent data policy will provide a continuing commitment to the establishment, maintenance, description, accessibility and long-term stewardship and availability of high-quality data and information. The data policy should build on the GEO Data Sharing Principles (www.earthobservations.org/geoss_dsp.shtml) that provide a set of widely internationally approved principles for full and open exchange of data, metadata, and products, in the frame of GEO.

\subsubsection{Metadata standards}

The envisioned carbon observing system will need to follow interoperability principles and metadata standards to facilitate cooperation and effective use of collected data and information. The WMO Information System (WMO WIS), http: //www.wmo.int/pages/prog/www/WIS/ developments could be followed for carbon data. Metadata enables users to 
discover data products and understand the content of those products. In addition, the systems and tools rely on consistent and interoperable metadata as a means to enable automatic processing, including analysis, visualization, and subsetting. Contributors will have to promote the development and use of flexible, open, and easy-to-use community standards for metadata (e.g., the Climate and Forecast (CF-1) standards for the Network Common Data Form - netCDF). These standards should be interoperable and independent of specific hardware and software platforms. Guidelines for their use should be widely circulated and incorporated into data management training courses.

\subsubsection{Data preservation}

Data products, including value-added products and the algorithms used to produce them, need to be archived when the data sets are finalized. A data archive plan is critical, because of the distributed nature of the data management system with individual agencies holding active data products. Archiving procedures must take data security, integrity, and routine technological updating into account, and archives should support data discovery and access. Many carbon data products are currently being archived by agency or national data centers, and a new system should not duplicate those efforts. However, centers participating in the distributed archive should meet a range of standards of accessibility, security and should follow agreed protocols. Accuracy estimates need to be put on existing/historical data sets (e.g. stored in the WDCGG for atmospheric in situ data). The planning team should identify agency roles and responsibilities, commitment, and the issues/concerns of international collaborators associated with long-term data archival. Such a long-term archiving is essential to create "heritage data sets" which must be accessible even several decades after their creation for future generations to come. These must be able to optimally use data sets created today in order to critically calibrate their prediction and adaptation models in a future world where human-induced climate change has much further progressed than at present. Going back to previous "working points" of the climate system will be essential for these future generations in order to optimize the sensitivity of the then existing Earth system models.

\subsubsection{Data hierarchies}

Not all data is of equal quality. Data assimilation systems deal with this by assigning different data uncertainties, effectively giving different weight to different observations. All data, however, is potentially useful provided that its uncertainties are properly characterized. However different tasks require different characteristics because the signals are different. For example data to detect early changes in the growth rate of atmospheric $\mathrm{CO}_{2}$ demands much higher temporal stability in its calibration than data used to calculate instanta- neous fluxes (which may in turn demand precise regional calibration). Care must be taken in the design of the system that it can answer both types of question.

\subsubsection{Implications for researchers}

Serious progress towards the system described above would mean large changes to the conduct of research, both data provision and use. Questions of data ownership would become less relevant, in the same way as no one attaches a researcher name to a given automatic weather station. The compromises between robust and timely delivery and the absolute best quality, always evident in meteorological data, would also enter carbon-cycle research. On the other hand the close relationship between data users and providers that has characterized much of the best research in this domain would, on average, weaken. This is an inevitable consequence of the arrival of orders of magnitude more data. Of course focused research on regions or questions would continue and here the main task would be enabling the distribution of gathered data.

\section{Conclusions}

A policy-relevant carbon monitoring system consisted of a multi-scale, coordinated suite of global carbon observations and supporting data integration with a model-data fusion and data distribution system will contribute to answering critical scientific and socio-economic questions formulated in Section 2. Such monitoring system needs to provide observationally derived estimates of key carbon-cycle quantities in the atmosphere, ocean, and terrestrial ecosystems. That requires observations offering the possibility to derive flux and stocks products on a range of spatial scales, starting from $100 \mathrm{~m}$ for "bottom-up" emissions and ecosystem carbon stocks, which can then be verified at larger scales using independent atmospheric concentration measurements and inversions. Continuous sampling at appropriate frequency (e.g. minutes for atmospheric concentrations, and several years for soil carbon stocks) are needed for (1) fluxes of $\mathrm{CO}_{2}$ and $\mathrm{CH}_{4}$ over ocean and land surfaces, with denser sampling in regions of high emissions, of large sinks and sinks variability, and where $\mathrm{CH}_{4}$ and $\mathrm{CO}_{2}$ abnormal losses could occur in the coming decade; (2) estimates of biomass and biomass change for all land surfaces and coverage with soil carbon sampling, wherever possible repeated over time; (3) biophysical parameters for terrestrial ecosystems are needed globally to help constrain atmospheric flux estimates and/or validate claimed carbon offset credits, in particular LAI and FAPAR; and (4) ocean carbon parameters (both biogenic and chemical) require measurement of surface and 3-D properties including air-sea $\Delta p \mathrm{CO}_{2}, \mathrm{DIC}, \mathrm{DOC}, \mathrm{pH}, \mathrm{O}_{2}$, and other state variables.

The above data needs can be best achieved with a well-balanced portfolio of observational techniques and 
observational strategies, particularly those that leverage the strengths of each technique to offset the weaknesses of another. An example of this is the complementary use of surface-based in situ observations along with satellite remote sensing. In situ observations represent the "gold standard" for most data types in terms of their high accuracy and ability to calibrate biases and establish robust links to reference standards where appropriate. Furthermore, in situ data establish the link to structural activity data needed to approximate points of departure to measure effort levels of mitigation actions. In situ observations also offer visibility into processes or chemical species that cannot be remotely sensed with available technology. Satellite observations offer nearglobal, high-density observations that fill in the gaps between sparse in situ observations and enable spatial extrapolation. The global coverage provided by satellites enables a truly synoptic view of the global carbon cycle. Satellite observational data that are disseminated in an open fashion can also play an important role in meeting the critical requirement for transparency that a policy-relevant monitoring system needs. Through global observation, satellites encourage a fair and transparent playing field for carbon policy - at least in terms of global reporting.

Increasing the number of observations is necessary, but not sufficient to achieve the required improvements in spatiotemporal resolution and precision of the final data products. Significant progress is needed in key model components such as atmospheric transport models and land/ocean carbon models, including relevant processes of inorganic and organic carbon cycling (physical, chemical, biological/ecological, and geological aspects). Additionally, improvements in biogeophysical data alone will not yield the desired reduction in uncertainty in policy-relevant information, unless these data can be effectively reconciled with inventory-based estimates in a statistically consistent framework for quantifying uncertainties. This suggests a need for both improvements in inventory processes (increasing their spatiotemporal resolution to scales comparable with the improved observations) and development of integration systems that allow intercomparison and reconciliation between inventories and biogeophysical data in a sustained and operational fashion. This requires development of a common data processing, analysis, archival, and distribution system, with careful attention to user-friendly protocols for end-product formats, delivery protocols, and metadata.

Implementation of a global carbon monitoring system will need to be a collaborative effort on an international scale. This is necessary both to satisfy the requirement for transparency (any system deployed unilaterally will not enjoy widespread credibility), as well as the very practical need to pool resources in the form of physical infrastructure, and scientific and engineering expertise.

While the requirements and scope of collaboration for the proposed monitoring system may seem daunting, there are two factors that indicate this problem is eminently tractable.
First, many elements of a global carbon monitoring system exist today in the form of various surface observing networks, data synthesis, community models, and dataassimilation systems, and coordinated use of ground and satellite observations. Indeed, the carbon-cycle science community has for some time been executing these kind of coordinated observations, data-model integration, and topdown/bottom-up reconciliation, albeit in a research mode with limited persistence or geospatial coverage and/or resolution. Second, at scales larger than $\sim 10 \mathrm{~km}$, the relationship between monitoring system performance and policy-support value may be monotonic (i.e. there does not exist a sharp breaking point between a flux map with $100 \mathrm{~km}$ resolution and one with $200 \mathrm{~km}$ resolution). This suggests that an incremental or phased deployment process can be employed. Such an approach would allow a first generation system to be deployed based strictly on existing observational assets, and therefore focus the initial investment on the development of the necessary data integration system. However, there certainly is a strong break towards increased policy support if the scales addressed can be of less $10 \mathrm{~km}$, the scale at which emissions can begin to be monitored (Duren and Miller, 2012). Given the uncertainties in both the carbon-cycle and socio-economic drivers, it is very likely that climate policies will continue to evolve in an organic fashion over the next decades. A monitoring system put in place sooner rather than later can provide baseline information for comparisons, and both inform and grow with new policy developments.

The cost of an adequately funded monitoring system with current technology will be assessed in a future study. Such a system supported by the contributing organizations could be deployed by 2020 with performance capabilities based on reasonable extrapolations in available technology and scientific understanding of key processes. A first generation demonstration-quality system could be deployed within 3 years from the time the initial investment is made, and based strictly on observing assets that exist today.

We close with a summary of threats to this concept. At the time of this writing, some of the existing observational assets described here are at risk of being canceled due to funding constraints or failing due to age. For example, several satellites in use today are either approaching or well beyond their design lifetimes. Delays in the replacement satellites present a discontinuation risk. These risks are manageable, but careful attention is required to preserve critical data continuity while moving forward with deploying new capabilities. In addition, commercialization of satellite data products is constraining overall scientific use and regular global monitoring analyses due to unaffordable high costs of accessing the data. Finally, planning for future monitoring systems needs to consider sustainability and maintainability through at least 2050 to provide assured support for GHG mitigation and adaptation policies expected to remain in effect through that time. 
Table 3. Acronyms.

\begin{tabular}{|c|c|}
\hline AFOLU & agriculture and forestry projects \\
\hline AIRS & Atmospheric Infrared Sounder \\
\hline ALOS & Advanced Land Observing Satellite \\
\hline PALSAR & $\begin{array}{l}\text { Phased Array type L-band Synthetic Aperture } \\
\text { Radar }\end{array}$ \\
\hline ATSR & Along-Track Scanning Radiometer \\
\hline AVHRR & Advanced Very High Resolution Radiometer \\
\hline BUFR & $\begin{array}{l}\text { binary universal form for the representation } \\
\text { of meteorological data }\end{array}$ \\
\hline CarbonSat & Carbon Monitoring Satellite \\
\hline CARIBIC & $\begin{array}{l}\text { Civil Aircraft for the Regular Investigation of } \\
\text { the atmosphere based on an instrument } \\
\text { container }\end{array}$ \\
\hline CCDAS & carbon-cycle data assimilation systems \\
\hline CDIAC & Carbon Dioxide Information Analysis Center \\
\hline CONTRAIL & $\begin{array}{l}\text { Comprehensive Observation Network for trace } \\
\text { gases by Airliner }\end{array}$ \\
\hline DIC & dissolved inorganic carbon \\
\hline DOC & dissolved organic carbon \\
\hline ECMWF & $\begin{array}{l}\text { European Centre for Medium-Range Weather } \\
\text { Forecast }\end{array}$ \\
\hline EDGAR & $\begin{array}{l}\text { Emission Database for Global Atmospheric } \\
\text { Research }\end{array}$ \\
\hline EOS & Earth Observing System \\
\hline ESA & European Space Agency \\
\hline $\mathrm{CCI}$ & Climate Change Initiative \\
\hline EUMETCast & $\begin{array}{l}\text { a scheme for dissemination of various (mainly } \\
\text { satellite based) meteorological data operated by } \\
\text { EUMETSAT, the European Organisation for the } \\
\text { Exploitation of Meteorological Satellites }\end{array}$ \\
\hline FAO & Food and Agriculture Organization \\
\hline FAPAR & $\begin{array}{l}\text { photosynthetically active radiation absorbed by } \\
\text { vegetation }\end{array}$ \\
\hline FRE & fire radiative energy \\
\hline GEO & Group on Earth Observations \\
\hline GFED & Global Fire Emission Database \\
\hline GHG & greenhouse gas \\
\hline GLODAP & Global Ocean Data Analysis Project \\
\hline GMD & Global Monitoring Division \\
\hline GMES & $\begin{array}{l}\text { Global Monitoring of Environment and } \\
\text { Security }\end{array}$ \\
\hline GOSAT & Greenhouse gases Observing SATellite \\
\hline GPP & gross primary production \\
\hline HDF & hierarchical data format \\
\hline IASI & infrared atmospheric sounding interferometer \\
\hline ICESat & Ice, Cloud, and Land Elevation Satellite \\
\hline ICOS & Integrated Carbon Observation System \\
\hline ISS & International Space Station \\
\hline JGOFS & Joint Global Ocean Flux Study \\
\hline JRC & $\begin{array}{l}\text { Joint Research Center of the European } \\
\text { Commission }\end{array}$ \\
\hline LAI & leaf area index \\
\hline Lidar & light detection and ranging \\
\hline
\end{tabular}

Table 3. Acronyms.

\begin{tabular}{|c|c|}
\hline MACC-II & $\begin{array}{l}\text { The Project for Monitoring Atmospheric } \\
\text { Composition and Climate-II }\end{array}$ \\
\hline MAMAP & Methane Airborne Mapper \\
\hline $\mathrm{MCF}$ & methyl-chloroform \\
\hline MERIS & MEdium-Resolution Imaging Spectrometer \\
\hline MERLIN & Methane Remote Lidar \\
\hline MODIS & $\begin{array}{l}\text { MODerate-resolution Imaging } \\
\text { Spectroradiometer }\end{array}$ \\
\hline NASA & National Aeronautics and Space Administration \\
\hline NDVI & normalized difference vegetation index \\
\hline NEE & net ecosystem exchange \\
\hline NEON & National Ecological Observatory Network \\
\hline NOAA & $\begin{array}{l}\text { National Oceanic and Atmospheric } \\
\text { Administration }\end{array}$ \\
\hline ESRL & $\begin{array}{l}\text { National Oceanic and Atmospheric } \\
\text { Administration - Earth System Research Labo- } \\
\text { ratory }\end{array}$ \\
\hline GMD & National Oceanic and Atmospheric \\
\hline NPP & $\begin{array}{l}\text { Administration - Global Monitoring Division } \\
\text { net primary production }\end{array}$ \\
\hline NRC & National Research Council \\
\hline NWP & numerical weather prediction system \\
\hline $\mathrm{OCO}$ & Orbiting Carbon Observatory \\
\hline PACIFICA & PACIFic ocean Interior CArbon \\
\hline PBL & $\begin{array}{l}\text { Netherlands Environmental Assessment } \\
\text { Agency }\end{array}$ \\
\hline POC & particulate organic carbon \\
\hline QuikSCAT & Quick Scatterometer \\
\hline RECCAP & $\begin{array}{l}\text { REgional Carbon Cycle Assessment and } \\
\text { Processes }\end{array}$ \\
\hline REDD & $\begin{array}{l}\text { reducing emissions from deforestation and } \\
\text { forest degradation in developing countries }\end{array}$ \\
\hline RTTOV & Radiative Transfer Code \\
\hline SAR & Synthetic Aperture Radar \\
\hline SCIAMACHY & $\begin{array}{l}\text { SCanning Imaging Absorption spectroMeter } \\
\text { for Atmospheric CHartographY }\end{array}$ \\
\hline SOCAT & Surface Ocean $\mathrm{CO}_{2}$ Atlas \\
\hline SSS & sea surface salinity \\
\hline SST & sea surface temperature \\
\hline TAlk & total alkalinity \\
\hline TCCON & Total Carbon Column Observing Network \\
\hline TES & Thermal Emission Spectrometer \\
\hline TransCom & $\begin{array}{l}\text { Atmospheric Tracer Transport Model } \\
\text { Intercomparison Project }\end{array}$ \\
\hline UN & United Nations \\
\hline UNFCCC & $\begin{array}{l}\text { United Nations Framework Convention on } \\
\text { Climate Change }\end{array}$ \\
\hline VOS & voluntary observing ships \\
\hline WDCGG & World Data Center for Greenhouse Gases \\
\hline WMO & World Meteorological Organization \\
\hline WIS & WMO Information System \\
\hline GAW & $\begin{array}{l}\text { World Meteorological Organization, Global } \\
\text { Atmosphere Watch }\end{array}$ \\
\hline GTS & Global Telecommunication System \\
\hline
\end{tabular}


Acknowledgements. This study was carried out as part of the GEO task on integrated carbon observations (GEO Carbon Strategy Report; available for download at http://www.falw.vu/ dola/downloads.html coordinated by H. Dolman and P. Ciais), and the FP7 European Commission funded project GEOCARBON (www.geocarbon.net). The writing of the manuscript is sponsored by Climate-KIC/European Institute of Technology (www.climate-kic.org/) through the Carbocount project. RJA was sponsored by US Department of Energy, Office of Science, Biological and Environmental Research (BER) programs and performed at Oak Ridge National Laboratory (ORNL) under U.S. Department of Energy contract DE-AC05-00OR22725. P. Rayner is in receipt of an Australian Professorial Fellowship (DP1096309).

Edited by: F. Joos

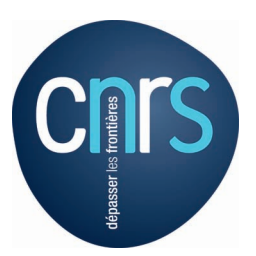

The publication of this article is financed by CNRS-INSU.

\section{References}

Ackerman, K. V. and Sundquist, E. T.: Comparison of two U.S. power-plant carbon dioxide emissions data sets, Environ. Sci. Technol., 42, 5688-5693, 2008.

Alden, C. B., Miller, J. B., and White, J. W. C.: Can bottomup ocean $\mathrm{CO}_{2}$ fluxes be reconciled with atmospheric ${ }^{13} \mathrm{C}$ observations?, Tellus B, 62, 369-388, doi:10.1111/j.16000889.2010.00481.x, 2010.

Alvain, S., Moulin, C., Dandonneau, Y., and Breon, F.-M.: Remote sensing of phytoplankton groups in case 1 waters from global SeaWiFS imagery, Deep-Sea Res. Pt. I, 52, 1989-2004, doi:10.1016/j.dsr.2005.06.015, 2005.

Andres, R. J., Marland, G., Fung, I., and Matthews, E.: A $1^{\circ} \times 1^{\circ}$ distribution of carbon dioxide emissions from fossil fuel consumption and cement manufacture, 1950-1990, Global Biogeochem. Cy., 10, 419-429, doi:10.1029/96gb01523, 1996.

Andres, R. J., Gregg, J. S., Losey, L., Marland, G., and Boden, T. A.: Monthly, global emissions of carbon dioxide from fossil fuel consumption, Tellus B, 63, 309-327, doi:10.1111/j.16000889.2011.00530.x, 2011.

Andres, R. J., Boden, T. A., Bréon, F.-M., Ciais, P., Davis, S., Erickson, D., Gregg, J. S., Jacobson, A., Marland, G., Miller, J., Oda, T., Olivier, J. G. J., Raupach, M. R., Rayner, P., and Treanton, K.: A synthesis of carbon dioxide emissions from fossil-fuel combustion, Biogeosciences, 9, 1845-1871, doi:10.5194/bg-9-18452012, 2012.

Arino, O. and Plummer, S.: Along Track Scanning Radiometer World Fire Atlas: validation of the 1997-98 active fire product. Validation report, IGBP-DIS Working Pap., Int. Geosph. Biosph. Progr., Stockholm, 23, 2001.

Arino, O., Ranera, F., Bicheron, P., Leroy, M., Brockmann, C., Defourny, P., Bontemps, S., Schouten, L., Achard, F., Eva, H., Stiebig, H. J., Weber, J. L., Meiner, A., Latham, J., Di Grego- rio, A., Witt, R., Van Woerden, J., Schmullius, C., Herold, M., Plummer, S., Bourg, L., Houghton, N., and Goryl, P.: Globcover, MERIS-AATSR Workshop, Frascati, Italy, 2008.

Arino, O., Casadio, S., and Serpe, D.: Global night-time fire season timing and fire count trends using the ATSR Instrument Series, Remote Sens. Environ., 116, 226-238, doi:10.1016/j.rse.2011.05.025, 2012.

Asner, G. P., Powell, G. V. N., Mascaro, J., Knapp, D. E., Clark, J. K., Jacobson, J., Kennedy-Bowdoin, T., Balaji, A., PaezAcosta, G., Victoria, E., Secada, L., Valqui, M., and Hughes, R. F.: High-resolution forest carbon stocks and emissions in the Amazon, P. Natl. Acad. Sci. USA, 107, 16738-16742, doi:10.1073/pnas.1004875107, 2010.

Aufdenkampe, A. K., Mayorga, E., Raymond, P. A., Melack, J. M., Doney, S. C., Alin, S. R., Aalto, R. E., and Yoo, K.: Riverine coupling of biogeochemical cycles between land, oceans, and atmosphere, Front. Ecol. Environ., 9, 53-60, doi:10.1890/100014, 2011.

Baccini, A., Goetz, S. J., Walker, W. S., Laporte, N. T., Sun, M., Sulla-Menashe, D., Hackler, J., Beck, P. S. A., Dubayah, R., Friedl, M. A., Samanta, S., and Houghton, R. A.: Estimated carbon dioxide emissions from tropical deforestation improved by carbon-density maps, Nat. Clim. Change, 2, 182-185, doi:10.1038/nclimate1354, 2012.

Baker, D. F., Law, R. M., Gurney, K. R., Rayner, P., Peylin, P., Denning, A. S., Bousquet, P., Bruhwiler, L., Chen, Y. H., Ciais, P., Fung, I. Y., Heimann, M., John, J., Maki, T., Maksyutov, S., Masarie, K., Prather, M., Pak, B., Taguchi, S., and Zhu, Z.: TransCom3 inversion intercomparison: Impact of transport model errors on the interannual variability of regional $\mathrm{CO}_{2}$ fluxes, 1988-2003, Global Biogeochem. Cy., 20, GB1002, doi:10.1029/2004gb002439, 2006.

Baker, D. J., Richards, G., Grainger, A., Gonzalez, P., Brown, S., DeFries, R., Held, A., Kellndorfer, P., Ndunda, P., Ojima, D., Skrovseth, P.-E., Souza, C., and Stolle, F.: Achieving forest carbon information with higher certainty: A five-part plan, J. Environ. Sci. Polic., 13, 249-260, 2010.

Baldocchi, D., Falge, E., Gu, L., Olson, R., Hollinger, D., Running, S. W., Anthoni, P., Bernhofer, C., Davis, K. J., Evans, R., Fuentes, J., Goldstein, A., Katul, G., Law, B., Lee, X., Malhi, Y., Meyers, T., Munger, W., Oechel, W., Paw, U. K. T., Pilegaard, K., Schmid, H. P., Valentini, R., Verma, S., Vesala, T., Wilson, K., and Wofsy, S.: FLUXNET: A new tool to study the temporal and spatial variability of ecosystem-scale carbon dioxide, water Vapor, and energy flux densities, B. Am. Meteorol. Soc., 82, 2415-2434, 2001.

Baldocchi, D.: Breathing of the terrestrial biosphere: lessons learned from a global network of carbon dioxide flux measurement systems, Austr. J. Bot., 56, 1-26, 2008.

Bange, H. W.: Nitrous oxide and methane in European coastal waters, Estuarine, Coastal Shelf Sci., 70, 361-374, doi:10.1016/j.ecss.2006.05.042, 2006.

Bastviken, D., Tranvik, L. J., Downing, J. A., Crill, P. M., and Enrich-Prast, A.: Freshwater methane emissions offset the continental carbon sink, Science, 331, 50, doi:10.1126/science.1196808, 2011.

Basu, S., Guerlet, S., Butz, A., Houweling, S., Hasekamp, O., Aben, I., Krummel, P., Steele, P., Langenfelds, R., Torn, M., Biraud, S., Stephens, B., Andrews, A., and Worthy, D.: Global $\mathrm{CO}_{2}$ 
fluxes estimated from GOSAT retrievals of total column $\mathrm{CO}_{2}$, Atmos. Chem. Phys., 13, 8695-8717, doi:10.5194/acp-13-86952013, 2013.

Battin, T. J., Luyssaert, S., Kaplan, L. A., Aufdenkampe, A. K., Richter, A., and Tranvik, L. J.: The boundless carbon cycle, Nat. Geosci., 2, 598-600, 2009.

Beaudoin, L., Gademer, A., Amir, A., Avanthey, L., Germain, V., and Pocheau, A.: Near real time detection of hot spots on Meteosat Second Generation images: from forest fires to volcanic eruptions, Geoscience and Remote Sensing Symposium, IGARSS, 23-28 July 2007, 2007.

Beer, C., Reichstein, M., Tomelleri, E., Ciais, P., Jung, M., Carvalhais, N., Rodenbeck, C., Arain, M. A., Baldocchi, D., Bonan, G. B., Bondeau, A., Cescatti, A., Lasslop, G., Lindroth, A., Lomas, M., Luyssaert, S., Margolis, H., Oleson, K. W., Roupsard, O., Veenendaal, E., Viovy, N., Williams, C., Woodward, F. I., and Papale, D.: Terrestrial gross carbon dioxide uptake: Global distribution and covariation with climate, Science, 329, 834-838, doi:10.1126/science.1184984, 2010.

Bellamy, P. H., Loveland, P. J., Bradley, R. I., Lark, R. M., and Kirk, G. J. D.: Carbon losses from all soils across England and Wales 1978-2003, Nature, 437, 245-248, doi:10.1038/nature04038, 2005.

Berezin, E. V., Konovalov, I. B., Ciais, P., Richter, A., Tao, S., Janssens-Maenhout, G., Beekmann, M., and Schulze, E.-D.: Multiannual changes of $\mathrm{CO}_{2}$ emissions in China: indirect estimates derived from satellite measurements of tropospheric $\mathrm{NO}_{2}$ columns, Atmos. Chem. Phys., 13, 9415-9438, doi:10.5194/acp13-9415-2013, 2013.

Bergamaschi, P., Frankenberg, C., Meirink, J. F., Krol, M., Villani, M. G., Houweling, S., Dentener, F., Dlugokencky, E. J., Miller, J. B., Gatti, L. V., Engel, A., and Levin, I.: Inverse modeling of global and regional $\mathrm{CH}_{4}$ emissions using SCIAMACHY satellite retrievals, J. Geophys. Res., 114, D22301, doi:10.1029/2009jd012287, 2009.

Bergamaschi, P., Krol, M., Meirink, J. F., Dentener, F., Segers, A., van Aardenne, J., Monni, S., Vermeulen, A. T., Schmidt, M., Ramonet, M., Yver, C., Meinhardt, F., Nisbet, E. G., Fisher, R. E., O'Doherty, S., and Dlugokencky, E. J.: Inverse modeling of European $\mathrm{CH}_{4}$ emissions 2001-2006, J. Geophys. Res., 115, D22309, doi:10.1029/2010JD014180, 2010.

Biastoch, A., Treude, T., Rupke, L., Riebesell, U., Roth, C., Burwicz, E., Park, W., Latif, M., Boning, C., Madec, G., and Wallmann, K.: Rising Arctic Ocean temperatures cause gas hydrate destabilization and ocean acidification, Geophys. Res. Lett., 38, L08602, doi:10.1029/2011GL047222, 2011.

Bishop, J. K. B.: Autonomous Observations of the Ocean Biological Carbon Pump, Oceanography, 22, 182-193, 2009.

Boden, T. A., Andres, R. J., and Marland, G.: Global, Regional, and National Fossil-Fuel $\mathrm{CO}_{2}$ Emissions: 1751-2009, ORNL/CDIAC, eclectronic database, doi:10.3334/CDIAC/00001_V2012, 2012.

Borges, A. V.: Do we have enough pieces of the Jigsaw to integrate $\mathrm{CO}_{2}$ fluxes in the coasteal ocean, Estuaries, 28, 3-27, 2005.

Borges, A. V.: Present day carbon dioxide fluxes in the coastal ocean and possible feedbacks under global change, in: Ocean and the Atmospheric carbon content, edited by: Duarte, P. and SantanaCasiano, J. M., Springer Science + Business Media B. V. 2011, 2011.
Böttcher, H., Eisbrenner, K., Fritz, S., Kindermann, G., Kraxner, F., McCallum, I., and Obersteiner, M.: An assessment of monitoring requirements and costs of "Reduced Emissions from Deforestation and Degradation", Carbon Balance Manage., 4, 7, doi:10.1186/1750-0680-4-7, 2009.

Boussetta, S., Balsamo, G., Beljaars, A., Panareda, A.-A., Calvet, J.C., Jacobs, C., van den Hurk, B., Viterbo, P., Lafont, S., Dutra, E., Jarlan, L., Balzarolo, M., Papale, D., and van der Werf, G.: Natural land carbon dioxide exchanges in the ECMWF Integrated Forecasting System: Implementation and offline validation, J. Geophys. Res.-Atmos., 118, 5923-5946 doi:10.1002/jgrd.50488, 2013.

Bovensmann, H., Buchwitz, M., Burrows, J. P., Reuter, M., Krings, T., Gerilowski, K., Schneising, O., Heymann, J., Tretner, A., and Erzinger, J.: A remote sensing technique for global monitoring of power plant $\mathrm{CO}_{2}$ emissions from space and related applications, Atmos. Meas. Tech., 3, 781-811, doi:10.5194/amt-3-781-2010, 2010.

Bréon, F.-M. and Ciais, P.: Spaceborne remote sensing of greenhouse gas concentrations, C. R. Geosci., 342, 412-424, 2009.

Bridgham, S. D., Megonigal, J. P., Keller, J. K., Bliss, N. B., and Trettin, C.: Wetlands, in: The First State of the Carbon Cycle Report (SOCCR): The North American Carbon Budget and Implications for the Global Carbon Cycle, A Report by the U.S. Climate Change Science Program and the Subcommittee on Global Change Research edited by: King, A. W., Dilling, L., Zimmerman, G. P., Fairman, D. M., Houghton, R. A. Marland, G., Rose, A. Z., and Wilbanks, T. J., National Oceanic and Atmospheric Administration, National Climatic Data Center, Asheville, NC, USA, 139-148, 2007.

Broquet, G., Chevallier, F., Rayner, P., Aulagnier, C., Pison, I., Ramonet, M., Schmidt, M., Vermeulen, A. T., and Ciais, P.: A European summertime $\mathrm{CO}_{2}$ biogenic flux inversion at mesoscale from continuous in situ mixing ratio measurements, J. Geophys. Res., 116, D23303, doi:10.1029/2011jd016202, 2011.

Broquet, G., Chevallier, F., Bréon, F.-M., Kadygrov, N., Alemanno, M., Apadula, F., Hammer, S., Haszpra, L., Meinhardt, F., Morguí, J. A., Necki, J., Piacentino, S., Ramonet, M., Schmidt, M., Thompson, R. L., Vermeulen, A. T., Yver, C., and Ciais, P.: Regional inversion of $\mathrm{CO}_{2}$ ecosystem fluxes from atmospheric measurements: reliability of the uncertainty estimates, Atmos. Chem. Phys., 13, 9039-9056, doi:10.5194/acp-13-9039-2013, 2013

Buchwitz, M., Chevallier, F., Bergamaschi, P., Aben, I., Bösch, H., Hasekamp, O., Notholt, J., Reuter, M. et al.: User Requirements Document for the GHG-CCI project of ESA's Climate Change Initiative, 45 pp., version 1, 3 February 2011, 2011.

Byrne, K. A., Chojnicki, B., Christensen, T. R., Drösler, M., Freibauer, A., Friborg, T., Frolking, S., Lindroth, A., Mailhammer, J., Malmer, N., Selin, P., Turunen, J., Valentini, R., and Zetterberg, L.: Current carbon stocks and trace gas fluxes, in: Carboeurope GHG, edited by: Christensen, R. T. and Friborg, T., Viserbo, Italy, 2004.

Canadell, J. G., Ciais, P., Gurney, K., Le Quéré, C., Piao, S., Raupach, M. R., and Sabine, C. L.: An international effort to quantify regional carbon fluxes, EOS Trans. AGU, 92, 81-82, 2011.

Chahine, M. T., Chen, L., Dimotakis, P., Jiang, X., Li, Q., Olsen, E. T., Pagano, T., Randerson, J., and Yung, Y. L.: Satellite remote sounding of mid-tropospheric $\mathrm{CO}_{2}$, Geophys. Res. Lett., 35, L17807, doi:10.1029/2008g1035022, 2008. 
Chevallier, F., Engelen, R. J., and Peylin, P.: The contribution of AIRS data to the estimation of $\mathrm{CO}_{2}$ sources and sinks, Geophys. Res. Lett., 32, L23801, doi:10.1029/2005g1024229, 2005.

Chevallier, F., Viovy, N., Reichstein, M., and Ciais, P.: On the assignment of prior errors in Bayesian inversions of $\mathrm{CO}_{2}$ surface fluxes, Geophys. Res. Lett., 33, L13802, doi:10.1029/2006GL026496, 2006.

Chevallier, F., Engelen, R. J., Carouge, C., Conway, T. J., Peylin, P., Pickett-Heaps, C., Ramonet, M., Rayner, P. J., and Xueref-Remy, I.: AIRS-based versus flask-based estimation of carbon surface fluxes, J. Geophys. Res., 114, D20303, doi:10.1029/2009jd012311, 2009a.

Chevallier, F., Maksyutov, S., Bousquet, P., Bréon, F.-M., Saito, R., Yoshida, Y., and Yokota, T.: On the accuracy of the $\mathrm{CO}_{2}$ surface fluxes to be estimated from the GOSAT observations, Geophys. Res. Lett., 36, L19807, doi:10.1029/2009g1040108, 2009b.

Chevallier, F., Ciais, P., Conway, T. J., Aalto, T., Anderson, B. E., Bousquet, P., Brunke, E. G., Ciattaglia, L., Esaki, Y., Fröhlich, M., Gomez, A., Gomez-Pelaez, A. J., Haszpra, L., Krummel, P. B., Langenfelds, R. L., Leuenberger, M., Machida, T., Maignan, F., Matsueda, H., Morguí, J. A., Mukai, H., Nakazawa, T., Peylin, P., Ramonet, M., Rivier, L., Sawa, Y., Schmidt, M., Steele, L. P., Vay, S. A., Vermeulen, A. T., Wofsy, S., and Worthy, D.: $\mathrm{CO}_{2}$ surface fluxes at grid point scale estimated from a global 21 year reanalysis of atmospheric measurements, J. Geophys. Res., 115, D21307, doi:10.1029/2010JD013887, 2010.

Chevallier, F., Deutscher, N. M., Conway, T. J., Ciais, P., Ciattaglia, L., Dohe, S., Fröhlich, M., Gomez-Pelaez, A. J., Griffith, D., Hase, F., Haszpra, L., Krummel, P., Kyrö, E., Labuschagne, C., Langenfelds, R., Machida, T., Maignan, F., Matsueda, H., Morino, I., Notholt, J., Ramonet, M., Sawa, Y., Schmidt, M., Sherlock, V., Steele, P., Strong, K., Sussmann, R., Wennberg, P., Wofsy, S., Worthy, D., Wunch, D., and Zimnoch, M.: Global $\mathrm{CO}_{2}$ fluxes inferred from surface air-sample measurements and from TCCON retrievals of the $\mathrm{CO}_{2}$ total column, Geophys. Res. Lett., 38, L24810, doi:10.1029/2011g1049899, 2011.

Ciais, P., Moore, B., Steffen, W., Hood, M., Quegan, S., Cihlar, J., Raupach, M., Tschirley, J., Inoue, G., Doney, S. C., Heinze, C., Sabine, C., Hibbard, K., Schulze, D., Heimann, M., Chedin, A., Monfray, P., Watson, A., LeQuere, C., Tans, P., Dolman, H., Valentini, R., Arino, O., Townshend, J., Seufert, G., Field, C., Igarashi, T., Goodale, C., Norbe, A., Crisp, D., Baldocchi, D., Denning, S., Rasool, I., Cramer, W., Francey, R. J., and Wickland, D.: Integrated Global Carbon Observation Theme. A Strategy to Realise a Coordinated System of Integrated Global Carbon Cycle Observations, Carbon theme team report, IGOS-P, 56 pp., 2004.

Ciais, P., Bousquet, P., Freibauer, A., and Naegler, T.: Horizontal displacement of carbon associated with agriculture and its impacts on atmospheric $\mathrm{CO}_{2}$, Global Biogeochem. Cy., 21, GB2014, doi:10.1029/2006gb002741, 2007.

Ciais, P., Schelhaas, M. J., Zaehle, S., Piao, S. L., Cescatti, A., Liski, J., Luyssaert, S., Le-Maire, G., Schulze, E. D., Bouriaud, O., Freibauer, A., Valentini, R., and Nabuurs, G. J.: Carbon accumulation in European forests, Nat. Geosci., 1, 425-429, doi:10.1038/ngeo233, 2008.

Ciais, P., Dolman, A. J., Dargaville, R., Barrie, L., Bombelli, A., Butler, J., Canadell, P., and Moriyama, T.: Geo Carbon Strategy, GEO Secretariat, Geneva/FAO, Rome, 48 pp., 2010.
Ciais, P., Sabine, C., Bala, G., Bopp, L., Brovkin, V., Canadell, J., Chhabra, A., DeFries, R., Galloway, J., Heimann, M., Jones, C., Le Quéré, C., Myneni, R. B., Piao, S., and Thornton, P.: Carbon and Other Biogeochem. Cy., in: Climate Change 2013: The Physical Science Basis. Contribution of Working Group I to the Fifth Assessment Report of the Intergovernmental Panel on Climate Change, edited by: Stocker, T. F., Qin, D., Plattner, G.-K., Tignor, M., Allen, S. K., Boschung, J., Nauels, A., Xia, Y., Bex, V., and Midgley, P. M., Cambridge University Press, Cambridge, United Kingdom and New York, NY, USA, 2013.

Claustre, H., Bishop, J., Boss, E., Bernard, S., Berthon, J.-F., Coatanoan, C., Johnson, K., Lotiker, A., Ulloa, O., Perry, M.J., D'Ortenzio, F., Hembise Fanton D'Andon, O., and Uitz, J.: Bio-optical profiling floats as new observational tools for biogeochemical and ecosystem studies: potential synergies with ocean color remote sensing, Lawrence Berkeley National Laboratory, LBNL paper, LBNL-3108E, OceanObs'09, Venice, Italy, 21-25 September 2009, 2010.

Cole, J. J., Prairie, Y. T., Caraco, N. F., McDowell, W. H., Tranvik, L. J., Striegl, R. G., Duarte, C. M., Kortelainen, P., Downing, J. A., Middelburg, J. J., and Melack, J. M.: Plumbing the global carbon cycle: Integrating inland waters into the terrestrial carbon budget, Ecosystems, 10, 171-184, 2007.

Corazza, M., Bergamaschi, P., Vermeulen, A. T., Aalto, T., Haszpra, L., Meinhardt, F., O’Doherty, S., Thompson, R., Moncrieff, J., Popa, E., Steinbacher, M., Jordan, A., Dlugokencky, E. J., Brühl, C., Krol, M., and Dentener, F.: Inverse modelling of European $\mathrm{N}_{2} \mathrm{O}$ emissions: Assimilating observations from different networks, Atmos. Chem. Phys., 11, 2381-2398, doi:10.5194/acp11-2381-2011, 2011.

Crevoisier, C., Heilliette, S., Chédin, A., Serrar, S., Armante, R., and Scott, N. A.: Midtropospheric $\mathrm{CO}_{2}$ concentration retrieval from AIRS observations in the tropics, Geophys. Res. Lett., 31, L17106, doi:10.1029/2004g1020141, 2004.

Crevoisier, C., Chédin, A., Matsueda, H., Machida, T., Armante, R., and Scott, N. A.: First year of upper tropospheric integrated content of $\mathrm{CO}_{2}$ from IASI hyperspectral infrared observations, Atmos. Chem. Phys., 9, 4797-4810, doi:10.5194/acp-9-4797-2009, 2009a.

Crevoisier, C., Nobileau, D., Fiore, A. M., Armante, R., Chédin, A., and Scott, N. A.: Tropospheric methane in the tropics - first year from IASI hyperspectral infrared observations, Atmos. Chem. Phys., 9, 6337-6350, doi:10.5194/acp-9-6337-2009, 2009b.

Crevoisier, C., Sweeney, C., Gloor, M., Sarmiento, J. L., and Tans, P. P.: Regional US carbon sinks from three-dimensional atmospheric $\mathrm{CO}_{2}$ sampling, P. Natl. Acad. Sci. USA, 107, 1834818353, doi:10.1073/pnas.0900062107, 2010.

Csiszar, I. A., Arino, O., Geraci, R., Giglio, L., Goldammer, J. G., de Groot, W., Justice, C. O., Kondragunta, S., Prins, E., Sessa, R., and Tansey, K.: Fire, Fire Disturbance, Essential climate Variables, T13, Assessment of the status of the development of the standards for the terrestrial essential climate variables, Global Terrestrial Observing System (GTOS68), Rome, 2009.

De La Paz, M., Padin, X. A., Rios, A. F., and Perez, F. F.: Surface $\mathrm{fCO}_{2}$ variability in the Loire plume and adjacent shelf waters: High spatio-temporal resolution study using ships of opportunity, Mar. Chem., 118, 108-118, doi:10.1016/j.marchem.2009.11.004, 2010. 
de Richter, R. and Caillol, S.: Fighting global warming: The potential of photocatalysis against $\mathrm{CO}_{2}, \mathrm{CH}_{4}, \mathrm{~N}_{2} \mathrm{O}$, $\mathrm{CFCs}$, tropospheric $\mathrm{O}-3, \mathrm{BC}$ and other major contributors to climate change, J. Photoch. Photobio. C, 12, 1-19, doi:10.1016/j.photochemrev.2011.05.002, 2011.

DeFries, R., Achard, F., Brown, S., Herold, M., Murdiyarso, D., Schlamadinger, B., and de Souza, C.: Earth observations for estimating greenhouse gas emissions from deforestation in developing countries, Environ. Sci. Polic., 10, 385-394, doi:10.1016/j.envsci.2007.01.010, 2007.

Denning, A. S., Holzer, M., Gurney, K. R., Heimann, M., Law, R. M., Rayner P. J., Fung, I. Y., Fan, S.-M., Taguchi S., Friedlingstein, P., Balkanski, Y., Taylor, J., Maiss, M., and Levin, I.: Threedimentional transport and concentration of SF6: A model intercomparison study (TransCom 2), Tellus B, 51, 266-297, 1999.

Denman, K. L., Brasseur, G., Heinze, C., Holland, E., Jacob, D., Lohmann, U., Ramachandran, S., da Silva Dias, P. L., Wofsy, S. C., and Zhang, X.: Couplings Between Changes in the Climate System and Biogeochemistry, Cambridge University Press, Cambridge, United Kingdom and New York, NY, USA, 2007.

Desai, A. R., Richardson, A. D., Moffat, A. M., Kattge, J., Hollinger, D. Y., Barr, A., Falge, E., Noormets, A., Papale, D., Reichstein, M., and Stauch, V. J.: Cross site evaluation of eddy covariance GPP and RE decomposition techniques, Agr. Forest Meteorol., 148, 821-838, doi:10.1016/j.agrformet.2007.11.012, 2008.

Dlugokencky, E. and Tans, P.: Recent Global $\mathrm{CO}_{2}, \mathrm{NOAA}$, ESRL, available at: www.esrl.noaa.gov/gmd/ccgg/trends/global. html, 2012.

Duren, R. M. and Miller, C. E.: Measuring the carbon emissions of megacities, Nat. Clim. Change, 2, 560-562, doi:10.1038/nclimate1629, 2012.

EEA (European Environment Agency): EEA Report \# 9/2009, Greenhouse gas emission trends and projections in Europe 2009: Tracking progress towards Kyoto targets, European Environment Agency website, retrieved 1 May 2010.

Emission Database for Global Atmospheric Research (EDGAR): release version 4.0., available at: http://edgar.jrc.ec.europa.eu, 2009.

Etheridge, D. M., Steele, L. P., Langenfelds, R. L., Francey, R. J., Barnola, J.-M., and Morgan, V. I.: Natural and anthropogenic changes in atmospheric $\mathrm{CO}_{2}$ over the last 1000 years from air in Antarctic ice and firn, J. Geophys. Res., 101, 4115-4128, doi:10.1029/95JD03410, 1996.

FAO: State of the World's Forests 2009, Food and Agriculture Organization of the United Nations (FAO), Rome, 152 pp., 2009.

FAO: Global Forest Resources Assessment 2010, Food and Agriculture Organization of the United Nations (FAO), Forestry Paper 163, 340 pp., 2010.

FAO/IIASA/ISRIC/ISSCAS/JRC: Harmonized World Soil Database (version 1.1), FAO, Rome, Italy and IIASA, Laxenburg, Austria, 2009.

Feely, R., Sabine, C. L., Byrne, R. H., Millero, F. J., Dickson, A. G., Wanninkhof, R., Murata, A., Miller, L. A., and Greeley, D.: Decadal changes in the aragonite and calcite saturation state of the Pacific Ocean, Global Biogeochem. Cy., 26, GB3001, doi:10.1029/2011GB004157, 2012.
Feely, R. A., Wanninkhof, R., Takahashi, T., and Tans, P.: Influence of El Niño on the Equatorial Pacific contribution to atmospheric $\mathrm{CO}_{2}$ accumulation, Nature, 398, 597-601, 1999.

Frankenberg, C., Meirink, J. F., Bergamaschi, P., Goede, A. P. H., Heimann, M., Körner, S., Platt, U., van Weele, M., and Wagner, T.: Satellite chartography of atmospheric methane from SCIAMACHY on board ENVISAT: Analysis of the years 2003 and 2004, J. Geophys. Res., 111, D07303, doi:10.1029/2005jd006235, 2006.

Frankenberg, C., Fisher, J. B., Worden, J., Badgley, G., Saatchi, S. S., Lee, J.-E., Toon, G. C., Butz, A., Jung, M., Kuze, A., and Yokota, T.: New global observations of the terrestrial carbon cycle from GOSAT: Patterns of plant fluorescence with gross primary productivity, Geophys. Res. Lett., 38, L17706, doi:10.1029/2011g1048738, 2011.

Frankignoulle, M., Abril, G., Borges, A. V., Bourge, I., Canon, C., Delille, B., Libert, E., and Theate, J.-M.: Carbon dioxide emission from european estuaries, Science, 282, 434-436, 1998.

Franz, B. A., Werdell, P. J., Meister, G., Kwiatkowska, E. J., Bailey, S. W., Ahmad, Z., and McClain, C. R.: MODIS Land Bands for Ocean Remote Sensing Applications, Proc. Ocean Optics XVIII, Montreal, Canada, 9-13 October 2006, 2006,

Freeborn, P. H., Wooster, M. J., Hao, W. M., Ryan, C. A., Nordgren, B. L., Baker, S. P., and Ichoku, C.: Relationships between energy release, fuel mass loss, and trace gas and aerosol emissions during laboratory biomass fires, J. Geophys. Res., 113, D01301, doi:10.1029/2007JD008679, 2008.

French, N. H. F., de Groot, W. J., Jenkins, L. K., Rogers, B. M., Alvarado, E., Amiro, B., de Jong, B., Goetz, S., Hoy, E., Hyer, E., Keane, R., Law, B. E., McKenzie, D., McNulty, S. G., Ottmar, R., Pérez-Salicrup, D. R., Randerson, J., Robertson, K. M., and Turetsky, M.: Model comparisons for estimating carbon emissions from North American wildland fire, J. Geophys. Res., 116, G00K05, doi:10.1029/2010JG001469, 2011.

Friedl, M. A., McIver, D. K., Hodges, J. C. F., Zhang, X. Y., Muchoney, D., Strahler, A. H., Woodcock, C. E., Gopal, S., Schneider, A., Cooper, A., Baccini, A., Gao, F., and Schaaf, C.: Global land cover mapping from MODIS: algorithms and early results, Remote Sens. Environ., 83, 287-302, 2002.

Friedlingstein, P., Houghton, R. A., Marland, G., Hackler, J., Boden, T. A., Conway, T. J., Canadell, J. G., Raupach, M. R., Ciais, P., and Le Quéré, C.: Update on $\mathrm{CO}_{2}$ emissions, Nat. Geosci., 3, 811-812, doi:10.1038/ngeo1022, 2010.

Fung, I. Y., Tucker, C. J., and Prentice, K. C.: Application of advanced very high resolution radiometer vegetation index to study atmosphere-biosphere exchange of $\mathrm{CO}_{2}$, J. Geophys. Res., 92, 2999-3015, doi:10.1029/JD092iD03p02999, 1987.

Garrigues, S., Lacaze, R., Baret, F., Morisette, J. T., Weiss, M., Nickeson, J. E., Fernandes, R., Plummer, S., Shabanov, N. V., Myneni, R. B., Knyazikhin, Y., and Yang, W.: Validation and intercomparison of global Leaf Area Index products derived from remote sensing data, J. Geophys. Res., 113, G02028, doi:10.1029/2007jg000635, 2008.

Gatti, L. V., Miller, J. B., D’Amelio, M. T. S., Martinewski, A., Basso, L. S., Gloor, M. E., Wofsy, S., and Tans, P.: Vertical profiler of $\mathrm{CO}_{2}$ above eastern Amazonia suggest a net carbon flux to the atmosphere and balanced biosphere between 2000 and 2009, Tellus B, 62, 581-594, doi:10.1111/j.1600-0889.2010.00484.x, 2010. 
Geibel, M. C., Messerschmidt, J., Gerbig, C., Blumenstock, T., Chen, H., Hase, F., Kolle, O., Lavrič, J. V., Notholt, J., Palm, M., Rettinger, M., Schmidt, M., Sussmann, R., Warneke, T., and Feist, D. G.: Calibration of column-averaged $\mathrm{CH}_{4}$ over European TCCON FTS sites with airborne in-situ measurements, Atmos. Chem. Phys., 12, 8763-8775, doi:10.5194/acp-12-87632012, 2012.

Gerilowski, K., Tretner, A., Krings, T., Buchwitz, M., Bertagnolio, P. P., Belemezov, F., Erzinger, J., Burrows, J. P., and Bovensmann, H.: MAMAP - a new spectrometer system for columnaveraged methane and carbon dioxide observations from aircraft: instrument description and performance analysis, Atmos. Meas. Tech., 4, 215-243, doi:10.5194/amt-4-215-2011, 2011.

Giglio, L., Descloitres, J., Justice, C. O., and Kaufman, Y. J.: An enhanced contextual fire detection algorithm for MODIS, Remote Sens. Environ., 87, 273-282, 2003.

Gloor, M., Fan, S.-M., Pacala, S., and Sarmiento, J.: Optimal sampling of the atmosphere for purpose of inverse modeling: A model study, Global Biogeochem. Cy., 14, 407-428, doi:10.1029/1999GB900052, 2000.

Gloor, M., Bakwin, P., Hurst, D., Lock, L., Draxler, R., and Tans, P.: What is the concentration footprint of a tall tower?, J. Geophys. Res., 106, 17831-17840, doi:10.1029/2001JD900021, 2001.

Gloor, M., Gruber, N., Sarmiento, J., Sabine, C. L., Feely, R. A., and Rödenbeck, C.: A first estimate of present and preindustrial air-sea $\mathrm{CO}_{2}$ flux patterns based on ocean interior carbon measurements and models, Geophys. Res. Lett., 30, 1010, doi:10.1029/2002GL015594, 2003.

Gobron, N. and Verstraete, M. M.: LAI (Leaf Area Index), Essential carbon Variables, T11, Assessment of the status of the development of the standards for the terrestrial essential climate veriables, GTOS66 (Global Terrestrial Observing System), Rome 2009.

Gobron, N., Belward, A., Pinty, B., and Knorr, W.: Monitoring biosphere vegetation 1998-2009, Geophys. Res. Lett., 37, L15402, doi:10.1029/2010g1043870, 2010.

Göckede, M., Turner, D. P., Michalak, A. M., Vickers, D., and Law, B. E.: Sensitivity of a subregional scale atmospheric inverse $\mathrm{CO}_{2}$ modeling framework to boundary conditions, J. Geophys. Res., 115, D24112, doi:10.1029/2010jd014443, 2010.

Goward, S. N., Masek, J. G., Cohen, W., Moisen, G., Collatz, G. J., Healey, S., Houghton, R. A., Huang, C., Kennedy, R., Law, B., Powell, S., Turner, D., and Wulder, M. A.: Forest disturbance and North American carbon flux, EOS Trans. AGU, 89, 105-116, 2008.

Grainger, A.: Difficulties in tracking the long-term global trend in tropical forest area, P. Natl. Acad. Sci. USA, 105, 818-823, doi:10.1073/pnas.0703015105, 2008.

Green, R. E., Bianchi, T. S., Dagg, M. J., Walker, N. D., and Breed, G. A.: An organic carbon budget for the Mississippi river turbidity plume and plume contributions to air-sea $\mathrm{CO}_{2}$ fluxes and bottom water hypoxia, Estuar. Coasts, 29, 579-597, 2006.

Gruber, N., Gloor, M., Fletcher, S., Doney, S., Dutkiewicz, S., Follows, M., Gerber, M., Jacobson, A., Joos, F., Lindsay, K., Menemenlis, D., Mouchet, A., Muller, S., Sarmiento, J., and Takahashi, T.: Oceanic sources, sinks, and transport of atmospheric $\mathrm{CO}_{2}$, Global Biogeochem. Cy., 23, GB1005, doi:10.1029/2008GB003349, 2009.
Gruber, N., Doney, S., Emerson, S., Gilbert, D., Kobayashi, T., Krtzinger, A., Johnson, G., Johnson, K., Riser, S., and U1loa, O.: Adding Oxygen to Argo: Developing a Global in-situ Observatory for Ocean Deoxygenation and Biogeochemistry, OceanObs09: Sustained Ocean Observations and Information for Society, Venice, Italy, 21-25 September 2009, 2010.

Gurney, K. R., Mendoza, D., Zhou, Y., Fischer, M., de la Rue du Can, S., Geethakumar, S., and Miller, C.: The Vulcan Project: High resolution fossil fuel combustion $\mathrm{CO}_{2}$ emissions fluxes for the United States, Environ. Sci. Technol., 43, 5535-5541, doi:10.1021/es900,806c, 2009.

Hajnsek, I. and Papathannassiou, K. P.: Tropical-forestparameter estimation by means of Pol-InSAR: The INDREXII campaign, IEEE T. Geosci. Remote, 47, 481-493, doi:10.1109/TGRS.2008.2009437, 2009.

Hall, F. G., Saatchi, S., and Dubayah, R.: DESDynl vegetation 3-D Special Issue, Remote Sens. Environ., 115, 2752, doi:10.1016/j.rse.2011.04.014, 2011.

Hansen, M., Stehman, S., and Potapov, P. V.: Quantification of global gross forest cover loss, P. Natl. Acad. Sci. USA, 107, 8650-8655, 2010.

Hansen, M. C., DeFries, R. S., Townshend, J. R. G., Carroll, M., Dimiceli, C. D., and Sohlberg, R. A.: Global percent tree cover at a spatial resolution of 500 meters: First results of the MODIS vegetation continuous fields algorithm, Earth Interact., 7, 1-15, doi:10.1175/1087-3562(2003), 2003.

Hargreaves, K. J., Fowler, D., Pitcairn, C. E. R., and Aurela, M.: Annual methane emission from Finnish mires estimated from eddy covariance campaign measurements, Theoret. Appl. Climatol., 70, 203-213, doi:10.1007/s007040170015, 2001.

Hartmann, J., Jansen, N., Dürr, H. H., Kempe, S., and Köhler, P.: Global $\mathrm{CO}_{2}$-consumption by chemical weathering: What is the contribution of highly active weathering regions?, Global Planet. Change, 69, 185-194, doi:10.1016/j.gloplacha.2009.07.007, 2009.

Henry, M.: Carbon stocks and dynamics in Sub Saharan Africa, Ph.D. Thesis, Paris Institute of Technology for Life, Food and Environmental Sciences (AgroParisTech) \& The University of Tuscia, 7 June 2010, 2010.

Henry, M., Besnard, A., Asantee, W. A., Eshunf, J., Adu-Bredug, S., Valentini, R., Bernoux, M., and Saint-André, L.: Wood density, phytomass variations within and among trees, and allometric equations in a tropical rainforest of Africa, Forest Ecol. Manag., 260, 1375-1388, doi:10.1016/j.foreco.2010.07.040, 2010.

Herold, M.: An assessment of national forest monitoring capabilities in tropical non-Annex I countries: Recommendations for capacity building. GOFC-GOLD Land Cover Project Office, available at: http://princes.3cdn.net/8453c17981d0ae3cc8_ q0m6vsqxd.pdf 2009.

Hilker, T., Coops, N. C., Hall, F. G., Nichol, C. J., Lyapustin, A., Black, T. A., Wulder, M. A., Leuning, R., Barr, A., Hollinger, D. Y., Munger, B., and Tucker, C. J.: Inferring terrestrial photosynthetic light use efficiency of temperate ecosystems from space, J. Geophys. Res., 116, G03014, doi:10.1029/2011jg001692, 2011.

Hirsch, A. I., Michalak, A. M., Bruhwiler, L. M., Peters, W., Dlugokencky, E. J., and Tans, P. P.: Inverse modeling estimates of the global nitrous oxide surface flux from 1998 to 2001, Global Biogeochem. Cy., 20, GB1008, doi:10.1029/2004gb002443, 2006. 
Hofmann, D. J., Butler, J. H., Dlugokencky, E. J., Elkins, J. W., Masarie, K. A., Montzka, S. A., and Tans, P. P.: The role of carbon dioxide in climate forcing from 1979 to 2004: Introduction of the annual greenhouse gas index, Tellus B, 58, 614-619, doi:10.111/j.1600-0889.2006.00201.x, 2006.

Hollinger, D. Y., and Richardson, A. D.: Uncertainty in eddy covariance measurements and its application to physiological models, Tree Physiol., 25, 873-885, 2005.

Hollingsworth, A., Engelen, R., Textor, C., Boucher, O., Chevallier, F., Dethof, A., Elbern, H., Eskes, H., Flemming, J., Granier, C., Kaiser, J. W., Morcrette, J. J., Rayner, P., Peuch, V. H., and Rouil, L.: Toward a monitoring and forecasting system for atmospheric composition: The GEMS Project, B. Am. Meteorol. Soc., 89, 1147, doi:10.1175/2008BAMS2355.1, 2008.

Houghton, R. A., Hall, F., and Goetz, S. J.: Importance of biomass in the global carbon cycle, J. Geophys. Res., 114, G00E03, doi:10.1029/2009JG000935, 2009.

Houweling, S., Hartmann, W., Aben, I., Schrijver, H., Skidmore, J., Roelofs, G.-J., and Breon, F.-M.: Evidence of systematic errors in SCIAMACHY-observed $\mathrm{CO}_{2}$ due to aerosols, Atmos. Chem. Phys., 5, 3003-3013, doi:10.5194/acp-5-3003-2005, 2005.

Houweling, S., Badawy, B., Baker, D. F., Basu, S., Belikov, D., Bergamaschi, P., Bousquet, P., Broquet, G., Butler, T., Canadell, J. G., Chen, J., Chevallier, F., Ciais, P., Collatz, G. J., Denning, S., Engelen, R., Enting, I. G., Fischer, M. L., Fraser, A., Gerbig, C., Gloor, M., Jacobson, A. R., Jones, D. B. A., Heimann, M., Khalil, A., Kaminski, T., Kasibhatla, P. S., Krakauer, N. Y., Krol, M., Maki, T., Maksyutov, S., Manning, A., Meesters, A., Miller, J. B., Palmer, P. I., Patra, P., Peters, W., Peylin, P., Poussi, Z., Prather, M. J., Randerson, J. T., Röckmann, T., Rödenbeck, C., Sarmiento, J. L., Schimel, D. S., Scholze, M., Schuh, A., Suntharalingam, P., Takahashi, T., Turnbull, J., Yurganov, L., and Vermeulen, A.: Iconic $\mathrm{CO}_{2}$ time series at risk, Science, 337, 1038-1040, doi:10.1126/science.337.6098.1038-b, 2012.

Huang, D., Knyazikhin, Y., Wang, W., Deering, D., Stenberg, P., Shabanov, N., Tan, B., and Myneni, R.: Stochastic transport theory for investigating the three-dimensional canopy structure from space measurement, Remote Sens. Environ., 112, 35-50, 2008.

Hudiburg, T. W., Law, B. E., Wirth, C., and Luyssaert, S.: Regional carbon dioxide implications of forest bioenergy production, Nat. Clim. Change, 1, 419-423, 2011.

Hungershoefer, K., Breon, F.-M., Peylin, P., Chevallier, F., Rayner, P., Klonecki, A., Houweling, S., and Marshall, J.: Evaluation of various observing systems for the global monitoring of $\mathrm{CO}_{2}$ surface fluxes, Atmos. Chem. Phys., 10, 10503-10520, doi:10.5194/acp-10-10503-2010, 2010.

IEA: (International Energy Agency), $\mathrm{CO}_{2}$ Emissions from fuel combustion (highlights): 2012 Edition, Paris, France, 2012.

Ji, Y. and Stocker, E.: Seasonal, intraseasonal, and interannual variability of global land fires and their effects on atmospheric aerosol distribution, J. Geophys. Res., 107, 4697, doi:10.1029/2002JD002331, 2002.

Jiménez, C., Prigent, C., Mueller, B., Seneviratne, S. I., McCabe, M. F., Wood, E. F., Rossow, W. B., Balsamo, G., Betts, A. K., Dirmeyer, P. A., Fisher, J. B., Jung, M., Kanamitsu, M., Reichle, R. H., Reichstein, M., Rodell, M., Sheffield, J., Tu, K., and Wang, K.: Global intercomparison of 12 land surface heat flux estimates, J. Geophys. Res., 116, D02102, doi:10.1029/2010JD014545, 2011.
Johnson, K. S., Berelson, W. M., Boss, E. S., Chase, Z. C., Claustre, H., Emerson, S. R., Gruber, N., Kortzinger, A., Perry, M. J., and Riser, S. C.: Observing biogeochemical cycles at global scales with profiling floats and gliders. Prospects for a global array, Oceanography, 22, 216-225, 2009.

Joiner, J., Yoshida, Y., Vasilkov, A. P., Yoshida, Y., Corp, L. A., and Middleton, E. M.: First observations of global and seasonal terrestrial chlorophyll fluorescence from space, Biogeosciences, 8, 637-651, doi:10.5194/bg-8-637-2011, 2011.

Joosten, H.: The Global Peatland $\mathrm{CO}_{2}$ Picture. Peatland Status and drainage related emissions in all countries of the world. Greifswald University, Wetlands International, Ede, www.wetlands. org, August 2010.

Jung, M., Reichstein, M., and Bondeau, A.: Towards global empirical upscaling of FLUXNET eddy covariance observations: validation of a model tree ensemble approach using a biosphere model, Biogeoschences, 6, 2001-2013, doi:10.5194/bg-6-20012009, 2009.

Jung, M., Reichstein, M., Ciais, P., Seneviratne, S. I., Sheffield, J., Goulden, M. L., Bonan, G., Cescatti, A., Chen, J., de Jeu, R., Dolman, A. J., Eugster, W., Gerten, D., Gianelle, D., Gobron, N., Heinke, J., Kimball, J., Law, B. E., Montagnani, L., Mu, Q., Mueller, B., Oleson, K., Papale, D., Richardson, A. D., Roupsard, O., Running, S., Tomelleri, E., Viovy, N., Weber, U., Williams, C., Wood, E., Zaehle, S., and Zhang, K.: Recent decline in the global land evapotranspiration trend due to limited moisture supply, Nature, 467, 951-954, 2010.

Jung, M., Reichstein, M., Margolis, H. A., Cescatti, A., Richardson, A. D., Arain, M. A., Arneth, A., Bernhofer, C., Bonal, D., Chen, J., Gianelle, D., Gobron, N., Kiely, G., Kutsch, W., Lasslop, G., Law, B. E., Lindroth, A., Merbold, L., Montagnani, L., Moors, E. J., Papale, D., Sottocornola, M., Vaccari, F., and Williams, C.: Global patterns of land-atmosphere fluxes of carbon dioxide, latent heat, and sensible heat derived from eddy covariance, satellite, and meteorological observations, J. Geophys. Res.-Biogeo., 116, G00J07, doi:10.1029/2010jg001566, 2011.

Kaiser, J. W., Heil, A., Andreae, M. O., Benedetti, A., Chubarova, N., Jones, L., Morcrette, J.-J., Razinger, M., Schultz, M. G., Suttie, M., and van der Werf, G. R.: Biomass burning emissions estimated with a global fire assimilation system based on observed fire radiative power, Biogeosciences, 9, 527-554, doi:10.5194/bg-9-527-2012, 2012.

Kaminski, T., Rayner, P. J., Voßbeck, M., Scholze, M., and Koffi, E.: Observing the continental-scale carbon balance: assessment of sampling complementarity and redundancy in a terrestrial assimilation system by means of quantitative network design, Atmos. Chem. Phys., 12, 7867-7879, doi:10.5194/acp-12-78672012, 2012.

Kasischke, E. S., Melack, J. M., and Dobson, M. C.: The use of imaging radars for ecological applications - a review, Remote Sens. Environ., 59, 141-156, 1997.

Keeling, C. D., Chin, J. F. S., and Whorf, T. P.: Increased activity of northern vegetation inferred from atmospheric $\mathrm{CO}_{2}$ measurements, Nature, 382, 146-149, 1996.

Keeling, R. F., Körtzinger, A., and Gruber, N.: Ocean deoxygenation in a warming world, Annu. Rev. Mar. Sci., 2, 199-229, doi:10.1146/annurev.marine.010908.163855, 2010.

Keppel-Aleks, G., Wennberg, P. O., Washenfelder, R. A., Wunch, D., Schneider, T., Toon, G. C., Andres, R. J., Blavier, J.-F., Con- 
nor, B., Davis, K. J., Desai, A. R., Messerschmidt, J., Notholt, J., Roehl, C. M., Sherlock, V., Stephens, B. B., Vay, S. A., and Wofsy, S. C.: The imprint of surface fluxes and transport on variations in total column carbon dioxide, Biogeosciences, 9, 875891, doi:10.5194/bg-9-875-2012, 2012.

Key, R. M., Kozyr, A., Sabine, C. L., Lee, K., Wanninkhof, R., Bullister, J. L., Feely, R. A., Millero, F. J., Mordy, C., and Peng, T. H.: A global ocean carbon climatology: Results from Global Data Analysis Project (GLODAP), Global Biogeochem. Cy., 18, GB4031, doi:10.1029/2004gb002247, 2004.

Key, R. M., Tanhua, T., Olsen, A., Hoppema, M., Jutterström, S., Schirnick, C., van Heuven, S., Kozyr, A., Lin, X., Velo, A., Wallace, D. W. R., and Mintrop, L.: The CARINA data synthesis project: introduction and overview, Earth Syst. Sci. Data, 2, 105121, doi:10.5194/essd-2-105-2010, 2010.

Kindermann, G. E., McCallum, I., Fritz, S., and Obersteiner, M.: A global forest growing stock, biomass and carbon map based on FAO statistics, Silva Fennica, 42, 387-396, 2008.

King, A. W., Hayes, D. J., Huntzinger, D. N., West, T. O., and Post, W. M.: North American carbon dioxide sources and sinks: magnitude, attribution, and uncertainty, Front. Ecol. Environ., 10, 512-519, 2012.

Knorr, W. and Kattge, J.: Inversion of terrestrial ecosystem model parameter values against eddy covariance measurements by Monte Carlo sampling, Glob. Change Biol., 11, 1333-1351, 2005.

Knyazikhin, Y., Martonchik, J. V., Myneni, R. B., Diner, D. J., and Running, S. W.: Synergistic algorithm for estimating vegetation canopy leaf area index and fraction of absorbed photosynthetically active radiation from MODIS and MISR data, J. Geophys. Res., 103, 32257-32275, doi:10.1029/98jd02462, 1998.

Krings, T., Gerilowski, K., Buchwitz, M., Reuter, M., Tretner, A., Erzinger, J., Heinze, D., Pflüger, U., Burrows, J. P., and Bovensmann, H.: MAMAP - a new spectrometer system for columnaveraged methane and carbon dioxide observations from aircraft: retrieval algorithm and first inversions for point source emission rates, Atmos. Meas. Tech., 4, 1735-1758, doi:10.5194/amt-41735-2011, 2011.

Krings, T., Gerilowski, K., Buchwitz, M., Hartmann, J., Sachs, T., Erzinger, J., Burrows, J. P., and Bovensmann, H.: Quantification of methane emission rates from coal mine ventilation shafts using airborne remote sensing data, Atmos. Meas. Tech., 6, 151-166, doi:10.5194/amt-6-151-2013, 2013.

Krol, M. C., Meirink, J. F., Bergamaschi, P., Mak, J. E., Lowe, D., Jöckel, P., Houweling, S., and Röckmann, T.: What can ${ }^{14} \mathrm{CO}$ measurements tell us about OH?, Atmos. Chem. Phys., 8, 50335044, doi:10.5194/acp-8-5033-2008, 2008.

Kroon, P. S., Vesala, T., and Grace, J. E.: Special Issue on Eddy Covariance (EC)flux measurements of $\mathrm{CH}_{4}$ and $\mathrm{N}_{2} \mathrm{O}$., Agr. Forest Meteorol., 150, 745-860, 2010.

Kucharczyk, B.: Activity of monolithic $\mathrm{Pd} / \mathrm{Al}_{2} \mathrm{O}_{3}$ catalysts in the combustion of mine ventilation air methane, Polish J. Chem. Technol., 13, 57-62, doi:10.2478/v10026-011-0050-5, 2011.

Kulawik, S. S., Jones, D. B. A., Nassar, R., Irion, F. W., Worden, J. R., Bowman, K. W., Machida, T., Matsueda, H., Sawa, Y., Biraud, S. C., Fischer, M. L., and Jacobson, A. R.: Characterization of Tropospheric Emission Spectrometer (TES) $\mathrm{CO}_{2}$ for carbon cycle science, Atmos. Chem. Phys., 10, 5601-5623, doi:10.5194/acp-10-5601-2010, 2010.
Kuppel, S., Chevallier, F., and Peylin, P.: Quantifying the model structural error in carbon cycle data assimilation systems, Geosci. Model Dev., 6, 45-55, doi:10.5194/gmdd-5-2259-2012, 2013.

Laruelle, G. G., Dürr, H. H., Slomp, C. P., and Borges, A. V.: Evaluation of sinks and sources of $\mathrm{CO}_{2}$ in the global coastal ocean using a spatially-explicit typology of estuaries and continental shelves, Geophys. Res. Lett., 37, L15607, doi:10.1029/2010g1043691, 2010.

Lassey, K. R., Lowe, D. C., and Smith, A. M.: The atmospheric cycling of radiomethane and the "fossil fraction" of the methane source, Atmos. Chem. Phys., 7, 2141-2149, doi:10.5194/acp-72141-2007, 2007.

Lasslop, G., Reichstein, M., Papale, D., Richardson, A. D., Arneth, A., Barr, A., Stoy, P., and Wohlfahrt, G.: Separation of net ecosystem exchange into assimilation and respiration using a light response curve approach: critical issues and global evaluation, Glob. Change Biol., 16, 187-208, doi:10.1111/j.13652486.2009.02041.x., 2010.

Lauvaux, T., Pannekoucke, O., Sarrat, C., Chevallier, F., Ciais, P., Noilhan, J., and Rayner, P. J.: Structure of the transport uncertainty in mesoscale inversions of $\mathrm{CO}_{2}$ sources and sinks using ensemble model simulations, Biogeosciences, 6, 1089-1102, doi:10.5194/bg-6-1089-2009, 2009.

Lauvaux, T., Schuh, A. E., Uliasz, M., Richardson, S., Miles, N., Andrews, A. E., Sweeney, C., Diaz, L. I., Martins, D., Shepson, P. B., and Davis, K. J.: Constaining the $\mathrm{CO}_{2}$ budget of the corn belt: exploring uncertainties from the assumptions in a mesoscale inverse system, Atmos. Chem. Phys., 12, 337-354, doi:10.5194/acp-12-337-2012, 2012.

Law, B. E., Arkebauer, T., Campbell, J. L., Chen, J., Sun, O., Schwartz, M., van Ingen, C., and Verma, S.: Terrestrial Carbon Observations: Protocols for Vegetation Sampling and Data Submission, FAO, Rome, 87 pp., 2008a.

Law, R. M., Peters, W., Rödenbeck, C., Aulagnier, C., Baker, I., Bergmann, D. J., Bousquet, P., Brandt, J., Bruhwiler, L., Cameron-Smith, P. J., Christensen, J. H., Delage, F., Denning, A. S., Fan, S., Geels, C., Houweling, S., Imasu, R., Karstens, U., Kawa, S. R., Kleist, J., Krol, M. C., Lin, S. J., Lokupitiya, R., Maki, T., Maksyutov, S., Niwa, Y., Onishi, R., Parazoo, N., Patra, P. K., Pieterse, G., Rivier, L., Satoh, M., Serrar, S., Taguchi, S., Takigawa, M., Vautard, R., Vermeulen, A. T., and Zhu, Z.: TransCom model simulations of hourly atmospheric $\mathrm{CO}_{2}$ : Experimental overview and diurnal cycle results for 2002, Global Biogeochem. Cy., 22, GB3009, doi:10.1029/2007gb003050, 2008b.

Le Quéré, C., Raupach, M. R., Canadell, J. G., Marland, G., Bopp, L., Ciais, P., Conway, T. J., Doney, S. C., Feely, R. A., Foster, P., Friedlingstein, P., Gurney, K., Houghton, R. A., House, J. I., Huntingford, C., Levy, P. E., Lomas, M. R., Majkut, J., Metzl, N., Ometto, J. P., Peters, G. P., Prentice, I. C., Randerson, J. T., Running, S. W., Sarmiento, J. L., Schuster, U., Sitch, S., Takahashi, T., Viovy, N., van der Werf, G. R., and Woodward, F. I.: Trends in the sources and sinks of carbon dioxide, Nat. Geosci., 2, 831-836, doi:10.1038/ngeo689, 2009.

Le Quéré, C., Canadell, J. G., Ciais, P., Dhakal, S., Patwardhan, A., Raupach, M. R., Oran, R., and Young, O. R.: An International Carbon Office to assist policy-based science, Curr. Opt. Environ. Sustain., 2, 297-300, doi:10.1016/j.cosust.2010.06.010, 2010. 
Le Quéré, C., Andres, R. J., Boden, T., Conway, T., Houghton, R. A., House, J. I., Marland, G., Peters, G. P., van der Werf, G., Ahlström, A., Andrew, R. M., Bopp, L., Canadell, J. G., Ciais, P., Doney, S. C., Enright, C., Friedlingstein, P., Huntingford, C., Jain, A. K., Jourdain, C., Kato, E., Keeling, R., Levis, S., Levy, P., Lomas, M., Poulter, B., Raupach, M. R., Schwinger, J., Sitch, S., Stocker, B. D., Viovy, N., Zaehle, S., and Zeng, N.: The global carbon budget 1959-2011, Earth Syst. Sci. Data, 5, 165-185, doi:10.5194/essd-5-165-2013, 2013.

Le Toan, T., Quegan, S., Davidson, M., Balzter, H., Paillou, P., Papathanassiou, K., Plummer, S., Saatchi, S., Shugart, H., and Ulander, L.: The BIOMASS Mission: Mapping global forest biomass to better understand the terrestrial carbon cycle, Remote Sens. Environ., 115, 2850-2860, doi:10.1016/j.rse.2011.03.020, 2011.

Lee, X., Goulden, M. L., Hollinger, D. Y., Barr, A., Black, T. A., Bohrer, G., Bracho, R., Drake, B., Goldstein, A., Gu, L., Katul, G., Kolb, T., Law, B. E., Margolis, H., Meyers, T., Monson, R., Munger, W., Oren, R., Paw U, K. T., Richardson, A. D., Schmid, H. P., Staebler, R., Wofsy, S., and Zhao, L.: Observed increase in local cooling effect of deforestation at higher latitudes, Nature, 479, 384-387, doi:10.1038/nature10588, 2011.

Lefsky, M. A., Harding, D. J., Keller, M., Cohen, W. B., Carabajal, C. C., Del Bom Espirito-Santo, F., Hunter, M. O., and de Oliveira Jr., R.: Estimates of forest canopy height and aboveground biomass using ICESat, Geophys. Res. Lett., 32, L22S02, doi:10.1029/2005GL023971, 2005.

Lefsky, M. A.: A global forest canopy height map from the Moderate Resolution Imaging Spectroradiometer and the Geoscience Laser Altimeter System, Geophys. Res. Lett., 37, L15401, doi:10.1029/2010g1043622, 2010.

Levin, I., Bösinger, R., Bonani, G., Francey, R., Kromer, B., Münnich, K. O., Suter, M., Trivett, N. B. A., and Wölfli, W.: Radiocarbon in atmospheric carbon dioxide and methane: global distribution and trends, in: Radiocarbon After Four Decades: An Interdisciplinary Perspective, edited by: Taylor, R. E., Long, A., and Kra, R. S., Springer-Verlag, New York, 503-517, 1992.

Levin, I. and Karstens, U.: Inferring high-resolution fossil fuel $\mathrm{CO}_{2}$ records at continental sites from combined ${ }^{14} \mathrm{CO}_{2}$ and CO observations, Tellus B, 59, 245-250, doi:10.1111/j.16000889.2006.00244.x., 2007.

Levin, I., Ciais, P., Langenfelds, R., Schmidt, M., Ramonet, M., Sidorov, K., Tchebakova, N., Gloor, M., Heimann, M., Schulze, E. D., Vygodskaya, N. N., Shibistova, O., and Lloyd, J.: Three years of trace gas observations over the EuroSiberian domain derived from aircraft sampling - a concerted action, Tellus B, 54, 696-712, doi:10.1034/j.1600-0889.2002.01352.x, 2002.

Lewis, S. L., Lopez-Gonzalez, G., Sonké, B., Affum-Baffoe, K., Baker, T. R., Ojo, L. O., Phillips, O. L., Reitsma, J. M., White, L., Comiskey, J. A., K, M.-N. D., Ewango, C. E. N., Feldpausch, T. R., Hamilton, A. C., Gloor, M., Hart, T., Hladik, A., Lloyd, J., Lovett, J. C., Makana, J.-R., Malhi, Y., Mbago, F. M., Ndangalasi, H. J., Peacock, J., Peh, K. S. H., Sheil, D., Sunderland, T., Swaine, M. D., Taplin, J., Taylor, D., Thomas, S. C., Votere, R., and Wöll, H.: Increasing carbon storage in intact African tropical forests, Nature, 457, 1003-1006, doi:10.1038/nature07771, 2009.

Liu, K. K., Atkinson, L., Quiñones, R., and Talaue-McManus, L. E.: Carbon and nutrient fluxes in continental margins: A global syn- thesis, IGBP book series, Springer, Heidelberg, Germany, 744 pp., 2010.

Machida, T., Matsueda, H., Sawa, Y., Nakagawa, Y., Hirotani, K., Kondo, N., Goto, K., Nakazawa, T., Ishikawa, K., and Ogawa, T.: Worldwide Measurements of Atmospheric $\mathrm{CO}_{2}$ and Other Trace Gas Species Using Commercial Airlines, J. Atmos. Ocean. Technol., 25, 1744-1754, 2008.

Maddy, E. S., Barnet, C. D., Goldberg, M., Sweeney, C., and Liu, X.: $\mathrm{CO}_{2}$ retrievals from the Atmospheric Infrared Sounder: Methodology and validation, J. Geophys. Res., 113, D11301, doi:10.1029/2007JD009402, 2008.

Maksyutov, S., Machida, T., Mukai, H., Patra, P., Nakazawa, T., Inoue, G., and TRANSCOM-3 Modelers: Effect of recent observations on Asian $\mathrm{CO}_{2}$ flux estimates by transport model inversions, Tellus B, 55, 522-529, doi:10.1034/j.1600-0560.2003.00052, 2003.

Maksyutov, S., Takagi, H., Valsala, V. K., Saito, M., Oda, T., Saeki, T., Belikov, D. A., Saito, R., Ito, A., Yoshida, Y., Morino, I., Uchino, O., Andres, R. J., and Yokota, T.: Regional $\mathrm{CO}_{2}$ flux estimates for 2009-2010 based on GOSAT and groundbased $\mathrm{CO}_{2}$ observations, Atmos. Chem. Phys., 13, 9351-9373, doi:10.5194/acp-13-9351-2013, 2013.

Marland, G., Brenkert, A., and Olivier, J.: $\mathrm{CO}_{2}$ from fossil fuel burning: a comparison of ORNL and EDGAR estimates of national emissions, Environ. Sci. Polic., 2, 265-273, 1999.

Marland, G., Hamal, K., and Jonas, M.: How uncertain are estimates of $\mathrm{CO}_{2}$ emissions?, J. Ind. Ecol., 13, 4-7, doi:10.1111/j.15309290.2009.00108.x, 2009.

Masek, J. G., Huang, C., Wolfe, R., Cohen, W., Hall, F., Kutler, J., and Nelson, P.: North American forest disturbance mapped from a decadal Landsat record, Remote Sens. Environ., 112, 2914 2926, doi:10.1016/j.rse.2008.02.010, 2008.

Matsueda, H., Machida, T., Sawa, Y., Nakagawa, Y., Hirotani, K., Ikeda, H., Kondo, N., and Goto, K.: Evaluation of atmospheric $\mathrm{CO}_{2}$ measurements from new flask air sampling of JAL airliner observations, Pap. Meteorol. Geophys., 59, 1-17, 2008.

Mayorga, E., Seitzinger, S. P., Harrison, J. A., Dumont, E., Beusen, A. H. W., Bouwman, A. F., Fekete, B. M., Kroeze, C., and Van Drecht, G.: Global nutrient export from WaterSheds 2 (NEWS 2): Model development and implementation, Environ. Modell. Softw., 25, 837-853, doi:10.1016/j.envsoft.2010.01.007, 2010.

McClain, C. R.: A decade of satellite ocean color observations, Annu. Rev. Mar. Sci., 1, 19-42, doi:10.1146/annurev.marine.010908.163650, 2009.

McKain, K., Wofsy, S. C., Nehrkorn, T., Eluszkiewicz, J., Ehleringer, J. R., and Stephens, B. B.: Assessment of groundbased atmospheric observations for verification of greenhouse gas emissions from an urban region, P. Natl. Acad. Sci. USA, 109, 8423-8428, doi:10.1073/pnas.1116645109, 2012.

Meigs, G., Turner, D., Ritts, D., Yang, Z., and Law, B. E.: Landscape-scale simulation of heterogeneous fire effects on pyrogenic carbon emissions, tree mortality, and net ecosystem production, Ecosystems, 14, 758-775, doi:10.1007/s10021-0119444-8, 2011.

Messerschmidt, J., Geibel, M. C., Blumenstock, T., Chen, H., Deutscher, N. M., Engel, A., Feist, D. G., Gerbig, C., Gisi, M., Hase, F., Katrynski, K., Kolle, O., Lavrič, J. V., Notholt, J., Palm, M., Ramonet, M., Rettinger, M., Schmidt, M., Sussmann, R., Toon, G. C., Truong, F., Warneke, T., Wennberg, P. 
O., Wunch, D., and Xueref-Remy, I.: Calibration of TCCON column-averaged $\mathrm{CO}_{2}$ : the first aircraft campaign over European TCCON sites, Atmos. Chem. Phys., 11, 10765-10777, doi:10.5194/acp-11-10765-2011, 2011.

Miller, J. B., Gatti, L. V., d'Amelio, M. T. S., Crotwell, A. M., Dlugokencky, E. J., Bakwin, P., Artaxo, P., and Tans, P. P.: Airborne measurements indicate large methane emissions from the eastern Amazon basin, Geophys. Res. Lett., 34, L10809, doi:10.1029/2006g1029213, 2007.

Mitchard, E. T. A., Saatchi, S. S., White, L. J. T., Abernethy, K. A., Jeffery, K. J., Lewis, S. L., Collins, M., Lefsky, M. A., Leal, M. E., Woodhouse, I. H., and Meir, P.: Mapping tropical forest biomass with radar and spaceborne LiDAR: overcoming problems of high biomass and persistent cloud, Biogeosciences, 9, 179-191, doi:10.5194/bg-9-179-2012, 2012.

Montzka, S. A., Krol, M., Dlugokencky, E., Hall, B., Joeckel, P., and Lelieveld, J.: Small interannual variability of global atmospheric hydroxyl, Science, 331, 67-69, doi:10.1126/science.1197640, 2011.

Murata, A., Kumamoto, Y., Watanabe, S., and Fukasawa, M.: Decadal increases of anthropogenic $\mathrm{CO}_{2}$ in the South Pacific subtropical ocean along 32 degrees S, J. Geophys. Res.-Oceans, 112, C05033, doi:10.1029/2005jc003405, 2007.

Myneni, R. B., Keeling, C. D., Tucker, C. J., Asrar, G., and Nemani, R. R.: Increased plant growth in the northern high latitudes from 1981 to 1991, Nature, 386, 698-702, 1997.

Myneni, R. B., Hoffman, S., Knyazikhin, Y., Privette, J. L., Glassy, J., Tian, Y., Wang, Y., Song, X., Zhang, Y., Smith, G. R., Lotsch, A., and Friedl, M.: Global products of vegetation leaf area and fraction absorbed PAR from year one of MODIS data, Remote Sens. Environ., 83, 214-231, 2002.

NRC: (National Research Council), Verifying Greenhouse Gas Emissions: Methods to Support International Climate Agreements, National Academies Press, Washington, DC, ISBN: 0309-15212-7, 124 pp., 2010.

Ohara, T., Akimoto, H., Kurokawa, J., Horii, N., Yamaji, K., Yan, X., and Hayasaka, T.: An Asian emission inventory of anthropogenic emission sources for the period 1980-2020, Atmos. Chem. Phys., 7, 4419-4444, doi:10.5194/acp-7-4419-2007, 2007.

Pacala, S. and Socolow, R.: Stabilization wedges: Solving the climate problem for the next 50 years with current technologies, Science, 305, 968-972, doi:10.1126/science.1100103, 2004.

Pacala, S. W., Breidenich, C., and Brewer, P. G.: Verifying Greenhouse Gas Emissions: Methods to Support International Climate Agreements, National Research Council of the National Academies, National Academies Press, Washington, DC., Committee on Methods for Estimating Greenhouse Gas Emissions, Board on Atmospheric Sciences and Climate Division on Earth and Life Studies, 124 pp., 2010.

Pan, Y., Chen, J. M., Birdsey, R., McCullough, K., He, L., and Deng, F.: Age structure and disturbance legacy of North American forests, Biogeosciences, 8, 715-732, doi:10.5194/bg-8-7152011, 2011a.

Pan, Y. D., Birdsey, R. A., Fang, J. Y., Houghton, R., Kauppi, P. E., Kurz, W. A., Phillips, O. L., Shvidenko, A., Lewis, S. L., Canadell, J. G., Ciais, P., Jackson, R. B., Pacala, S. W., McGuire, A. D., Piao, S. L., Rautiainen, A., Sitch, S., and Hayes, D.: A large and persistent carbon sink in the world's forests, Science, 333, 988-993, doi:10.1126/science.1201609, 2011 b.

Papale, D., Reichstein, M., Aubinet, M., Canfora, E., Bernhofer, C., Longdoz, B., Kutsch, W., Rambal, S., Valentini, R., Vesala, T., and Yakir, D.: Towards a standardized processing of net ecosystem exchange measured with eddy covariance technique: algorithms and uncertainty estimation, Biogeosciences, 3, 571-583, doi:10.5194/bg-3-571-2006, 2006.

Paris, J.-D., Ciais, P., Nedelec, P., Stohl, A., Belan, B. D., Arshinov, M. Y., Carouge, C., Golitsyn, G. S., and Granberg, I. G.: New insights on the chemical composition of the Siberian air shed from the YAK AEROSIB aircraft campaigns, B. Am. Meteorol. Soc., 91, 625-641, doi:10.1175/2009BAMS2663.1, 2010.

Parresol, B. R.: Assessing tree and stand biomass: A review with examples and critical comparisons, Forest Sci., 45, 573-593, 1999.

Pelletier, J., Ramankutty, N., and Potvin, C.: Diagnosing the uncertainty and detectability of emission reductions for REDD+ under current capabilities: an example for Panama, Environ. Res. Lett., 6, 024005, doi:10.1088/1748-9326/6/2/024005, 2011.

Peters, W., Jacobson, A. R., Sweeney, C., Andrews, A. E., Conway, T. J., Masarie, K., Miller, J., Bruhwiler, L. M. P., Petron, G., Hirsch, A. I., Worthy, D. E. J., van der Werf, G. R., Randerson, J. T., Wennberg, P. O., Krol, M. C., and Tans, P. P.: An atmospheric perspective on North American carbon dioxide exchange: Carbontracker, P. Natl. Acad. Sci. USA, 104, 18925-18930, 2007.

Pétron, G., Tans, P., Frost, G., Chao, D., and Trainer, M.: Highresolution emissions of $\mathrm{CO}_{2}$ from power generation in the USA, J. Geophys. Res., 113, G04008, doi:10.1029/2007jg000602, 2008.

Pfeil, G. B., Olsen, A., Bakker, D. C. E., Hankin, S., Koyuk, H., Kozyr, A., Malczyk, J., Manke, A., Metzl, N., Sabine, C. L., Akl, J., Alin, S. R., Bellerby, R. G. J., Borges, A. V., Boutin, J., Brown, P. J., Cai, W.-J., Chavez, F. P., Chen, A., Cosca, C. E., Fassbender, A. J., Feely, R. A., González-Dávila, M., Goyet, C., Hardman-Mountford, N., Heinze, C., Hood, E. M., Hoppema, M., Hunt, C. W., Hydes, D., Ishii, M., Johannessen, T., Jones, S. D., Key, R. M., Körtzinger, A., Landschützer, P., Lauvset, S. K., Lefèvre, N., Lenton, A., Lourantou, A., Merlivat, L., Midorikawa, T., Mintrop, L. J., Miyazaki, C., Murata, A., Nakadate, A., Nakano, Y., Nakaoka, S.-I., Nojiri, Y., Omar, A. M., Padin, X. A., Park, G.-H., Paterson, K., Pérez, F. F., Pierrot, D., Poisson, A., Ríos, A. F., Santana-Casiano, Magdalena, J., Salisbury, J., Sarma, V. V. S. S., Schlitzer, R., Schneider, B., Schuster, U., Sieger, R., Skjelvan, I., Steinhoff, T., Suzuki, T., Takahashi, T., Tedesco, K., Telszewski, M., Thomas, H., Tilbrook, B., Tjiputra, J., Vandemark, D., Veness, T., Wanninkhof, R., Watson, A. J., Weiss, R. F., Wong, C. S., and Yoshikawa-Inoue, H.: A uniform, quality controlled Surface Ocean $\mathrm{CO}_{2}$ Atlas (SOCAT), Earth System Science Data, 5, 125-143, doi:10.5194/essd-5-125-2013, 2013.

Phillips, D. L., Brown, S. L., Schroeder, P. E., and Birdsey, R. A.: Toward error analysis of large-scale forest carbon budgets, Global Ecol. Biogeogr., 9, 305-313, 2000.

Phillips, F. A., Leuning, R., Baigent, R., Kelly, K. B., and Denmead, O. T.: Nitrous oxide flux measurements from an intensively managed irrigated pasture using micrometeorological techniques, Agr. Forest Meteorol., 143, 92-105, 2007.

Phillips, O. L., Malhi, Y., Higuchi, N., Laurance, W. F., Núñez, P. V., Vásquez, R. M., Laurance, S. G., Ferreira, L. V., Stern, M., Brown, S., and Grace, J.: Changes in the carbon balance of trop- 
ical forests: evidence from long-term plots, Science, 282, 439442, doi:10.1126/science.282.5388.439, 1998.

Phillips, O. L., Aragao, L., Lewis, S. L., Fisher, J. B., Lloyd, J., Lopez-Gonzalez, G., Malhi, Y., Monteagudo, A., Peacock, J., Quesada, C. A., van der Heijden, G., Almeida, S., Amaral, I., Arroyo, L., Aymard, G., Baker, T. R., Banki, O., Blanc, L., Bonal, D., Brando, P., Chave, J., de Oliveira, A. C. A., Cardozo, N. D., Czimczik, C. I., Feldpausch, T. R., Freitas, M. A., Gloor, E., Higuchi, N., Jimenez, E., Lloyd, G., Meir, P., Mendoza, C., Morel, A., Neill, D. A., Nepstad, D., Patino, S., Penuela, M. C., Prieto, A., Ramirez, F., Schwarz, M., Silva, J., Silveira, M., Thomas, A. S., ter Steege, H., Stropp, J., Vasquez, R., Zelazowski, P., Davila, E. A., Andelman, S., Andrade, A., Chao, K. J., Erwin, T., Di Fiore, A., Honorio, E., Keeling, H., Killeen, T. J., Laurance, W. F., Cruz, A. P., Pitman, N. C. A., Vargas, P. N., Ramirez-Angulo, H., Rudas, A., Salamao, R., Silva, N., Terborgh, J., and Torres-Lezama, A.: Drought sensitivity of the Amazon rainforest, Science, 323, 1344-1347, doi:10.1126/science.1164033, 2009.

Piao, S. L., Ciais, P., Friedlingstein, P., Peylin, P., Reichstein, M., Luyssaert, S., Margolis, H., Fang, J. Y., Barr, A., Chen, A. P., Grelle, A., Hollinger, D. Y., Laurila, T., Lindroth, A., Richardson, A. D., and Vesala, T.: Net carbon dioxide losses of northern ecosystems in response to autumn warming, Nature, 451, 49-52, doi:10.1038/nature06444, 2008.

Picard, G., Quegan, S., Delbart, N., Lomas, M. R., Woodward, F. I., and Le Toan, T.: Bud-burst modelling in Siberia and its impact on quantification of the carbon budget, Glob. Change Biol., 11, 2164-2176, 2005.

Ping, C.-L., Michaelson, G. J., Jorgenson, M. T., Kimble, J. M., Epstein, H., Romanovsky, V. E., and Walker, D. A.: High stocks of soil organic carbon in the North American Arctic region, Nat. Geosci., 1, 615-619, doi:10.1038/ngeo284, 2008.

Pinty, B., Lavergne, T., Voßbeck, M., Kaminski, T., Aussedat, O., Giering, R., Gobron, N., Taberner, M., Verstraete, M. M., and Widlowski, J. L.: Retrieving surface parameters for climate models from Moderate Resolution Imaging Spectroradiometer (MODIS)-Multiangle Imaging Spectroradiometer (MISR) albedo products, J. Geophys. Res., 112, D10116, doi:10.1029/2006jd008105, 2007.

Plummer, S. E., Arino, O., Simon, M., and Steffen, W.: Establishing an Earth Observation Product Service for the Terrestrial Carbon Community: The GLOBCARBON Initiative, Mitigation and Adaptation Strategies for Global Change, 11, 97-111, 2006.

Pregger, T., Scholz, Y., and Friedrich, R.: Documentation of the anthropogenic GHG emission data for Europe provided in the Frame of CarboEurope GHG and CarboEurope IP, Institut für Energiewirtschaft und Rationelle Energieanwendung, Universität Stuttgart, Stuttgart, Germany, 2007.

Prinn, R. G., Huang, J., Weiss, R. F., Cunnold, D. M., Fraser, P. J., Simmonds, P. G., McCulloch, A., Harth, C., Salameh, P., O'Doherty, S., Wang, R. H. J., Porter, L., and Miller, B. R.: Evidence for substantial variations of atmospheric hydroxyl radicals in the past two decades, Science, 292, 1882-1888, doi:10.1126/science.1058673, 2001.

Pu, R., Li, Z., Gong, P., Csiszar, I., Fraser, R., Hao, W.-M., Kondragunta, S., and Weng, F.: Development and analysis of a 12year daily $1-\mathrm{km}$ forest fire dataset across North America from
NOAA/AVHRR data, Remote Sens. Environ., 108, 198-208, 2007.

Qualife, T., Lewis, P., De Kauwe, M., Williams, M., Law, B. E., Disney, M., and Bowyer, P.: Assimilating canopy reflectance data into an ecosystem model with an Emsemble Kalman Filter, Remote Sens. Environ., 4, 1347-1364, doi:10.1016/j.rse.2007.05.020, 2008

Randerson, J. T., Still, C. J., Ballé, J. J., Fung, I. Y., Doney, S. C., Tans, P. P., Conway, T. J., White, J. W. C., Vaughn, B., Suits, N., and Denning, A. S.: Carbon isotope discrimination of arctic and boreal biomes inferred by remote atmospheric measurements and biosphere-atmosphere models, Global Biogeochem. Cy., 16, 1028, doi:10.1029/2001GB001435, 2002.

Rast, M., Bézy, J. L., and Bruzzi, S.: The ESA Medium Resolution Imaging Spectrometer MERIS - a review of the instrument and its mission, Int. J. Remote Sens., 20, 1681-1702, doi:10.1080/014311699212416, 1999.

Raupach, M. R., Rayner, P. J., Barrett, D. J., DeFries, R. S., Heimann, M., Ojima, D. S., Quegan, S., and Schmullius, C. C.: Model-data synthesis in terrestrial carbon observation: methods, data requirements and data uncertainty specifications, Glob. Change Biol., 11, 378-397, doi:10.1111/j.13652486.2005.00917.x, 2005.

Raymond, P. A., Oh, N.-H., Turner, R. E., and Broussard, W.: Anthropogenically enhanced fluxes of water and carbon from the Mississippi river, Nature, 451, 449-452, doi:10.1038/nature06505, 2008.

Rayner, P. J., Enting, I. G., and Trudinger, C. M.: Optimizing the $\mathrm{CO}_{2}$ observing network for constraining sources and sinks, Tellus B, 48, 433-444, 1996.

Rayner, P. J., Scholze, M., Knorr, W., Kaminski, T., Giering, R., and Widmann, H.: Two decades of terrestrial carbon fluxes from a carbon cycle data assimilation system (CCDAS), Global Biogeochem. Cy., 19, GB2026, doi:10.1029/2004GB002254, 2005.

Rayner, P. J., Raupach, M. R., Paget, M., Peylin, P., and Koffi, E.: A new global gridded data set of $\mathrm{CO}_{2}$ emissions from fossil fuel combustion: Methodology and evaluation, J. Geophys. Res., 115, D19306, doi:10.1029/2009JD013439, 2010.

Regnier, P., Friedlingstein, P., Ciais, P., Mackenzie, F. T., Gruber, N., Janssens, I. A., Laruelle, G. G., Lauerwald, R., Luyssaert, S., Andersson, A. J., Arndt, S., Arnosti, C., Borges, A. V., Dale, A. W., Gallego-Sala, A., Godderis, Y., Goossens, N., Hartmann, J., Heinze, C., Ilyina, T., Joos, F., LaRowe, D. E., Leifeld, J., Meysman, F. J. R., Munhoven, G., Raymond, P. A., Spahni, R., Suntharalingam, P., and Thullner, M.: Anthropogenic perturbation of the carbon fluxes from land to ocean, Nat. Geosci., 6, 597-607, doi:10.1038/ngeo1830, 2013.

Reichstein, M., Falge, E., Baldocchi, D., Papale, D., Valentini, R., Aubinet, M., Berbigier, P., Bernhofer, C., Buchmann, N., Gilmanov, T., Granier, A., Grünwald, T., Havránková, K., Janous, D., Knohl, A., Laurela, T., Lohila, A., Loustau, D., Matteucci, G., Meyers, T., Miglietta, F., Ourcival, J.-M., Rambal, S., Rotenberg, E., Sanz, M., Seufert, G., Vaccari, F., Vesala, T., and Yakir, D.: On the separation of net ecosystem exchange into assimilation and ecosystem respiration: review and improved algorithm, Glob. Change Biol., 11, 1424-1439, 2005. 
Reuter, M., Bovensmann, H., Buchwitz, M., Burrows, J. P., Connor, B. J., Deutscher, N. M., Griffith, D. W. T., Heymann, J., Keppel-Aleks, G., Messerschmidt, J., Notholt, J., Petri, C., Robinson, J., Schneising, O., Sherlock, V., Velazco, V., Warneke, T., Wennberg, P. O., and Wunch, D.: Retrieval of atmospheric $\mathrm{CO}_{2}$ with enhanced accuracy and precision from SCIAMACHY: Validation with FTS measurements and comparison with model results, J. Geophys. Res., 116, D04301, doi:10.1029/2010jd015047, 2011.

Rinne, J., Riutta, T., Pihlatie, M., Aurela, M., Haapanala, S., Tuovinen, J.-P., Tuittila, E.-S., and Vesala, T.: Annual cycle of methane emission from a boreal fen measured by the eddy covariance technique, Tellus B, 59, 449-457, doi:10.1111/j.16000889.2007.00261.x, 2007.

Roberts, G. and Wooster, M. J.: Fire detection and fire characterization over Africa using Meteosat SEVIRI, IEEE T. Geosci. Remote, 46, 1200-1218, doi:10.1109/TGRS.2008.915751, 2008.

Roemmich D., Boehme L., Claustre, H., Freeland, H., Fukasawa, M., Goni, G, Gould, W. J, Gruber, N, Hood, M, Kent, E, Lumpkin, R, Smith, S, and Testor, P.: Integrating the ocean observing system: mobile platforms, in: Proceedings of OceanObs'09: Sustained Ocean Observations and Information for Society (vol. 1), edited by: Hall, J., Harrison, D. E., and Stammer, D., Venice, Italy, 21-25 September 2009: ESA Publication WPP-306, 2010.

Running, S., Nemani, R., Heinsch, F., Zhao, M., Reeves, M., and Hashimoto, H.: A continuous satellite-derived measure of global terrestrial primary production, BioSciences, 54, 547-560, 2004.

Ryan, C. M., Williams, M., and Grace, J.: Above- and belowground carbon stocks in a Miombo woodland landscape of Mozambique, Biotropica, 43, 423-432, doi:10.1111/j.17447429.2010.00713.x, 2011.

Saatchi, S. S., Houghton, R. A., Alvala, R., Soares, J. V., and Yu, Y.: Distribution of aboveground live biomass in the Amazon basin, Glob. Change Biol., 13, 816-837, doi:10.1111/j.13652486.2007.01323.x, 2007.

Saatchi, S. S., Harris, N. L., Brown, S., Lefsky, M., Mitchard, E. T. A., Salas, W., Zutta, B. R., Buermann, W., Lewis, S. L., Hagen, S., Petrova, S., White, L., Silman, M., and Morel, A.: Benchmark map of forest carbon stocks in tropical regions across three continents, P. Natl. Acad. Sci. USA, 108, 98999904, doi:10.1073/pnas.1019576108, 2011.

Sabine, C. and Tanhua, T.: Estimation of anthropogenic $\mathrm{CO}_{2}$ inventories in the ocean, Annu. Rev. Mar. Sci., 2, 175-198, 2010.

Sabine, C. L., Feely, R. A., Gruber, N., Key, R. M., Lee, K., Bullister, J. L., Wanninkhof, R., Wong, C., Wallace, D., Tilbrook, B., Millero, F., Peng, T., Kozyr, A., Ono, T., and Rios, A.: The oceanic sink for anthropogenic $\mathrm{CO}_{2}$, Science, 305, 367-371, 2004

Sabine, C. L., Feely, R. A., Millero, F. J., Dickson, A. G., Langdon, C., Mecking, S., and Greeley, D.: Decadal changes in Pacific carbon, J. Geophys. Res.-Oceans, 113, C07021, doi:10.1029/2007jc004577, 2008.

Sabine, C. L., Hankin, S., Koyuk, H., Bakker, D. C. E., Pfeil, B., Olsen, A., Metzl, N., Kozyr, A., Fassbender, A., Manke, A., Malczyk, J., Akl, J., Alin, S. R., Bellerby, R. G. J., Borges, A., Boutin, J., Brown, P. J., Cai, W.-J., Chavez, F. P., Chen, A., Cosca, C., Feely, R. A., González-Dávila, M., Goyet, C., Hardman-Mountford, N., Heinze, C., Hoppema, M., Hunt, C. W., Hydes, D., Ishii, M., Johannessen, T., Key, R. M., Körtzinger,
A., Landschützer, P., Lauvset, S. K., Lefèvre, N., Lenton, A., Lourantou, A., Merlivat, L., Midorikawa, T., Mintrop, L., Miyazaki, C., Murata, A., Nakadate, A., Nakano, Y., Nakaoka, S., Nojiri, Y., Omar, A. M., Padin, X. A., Park, G.-H., Paterson, K., Perez, F. F., Pierrot, D., Poisson, A., Ríos, A. F., Salisbury, J., Santana-Casiano, J. M., Sarma, V. V. S. S., Schlitzer, R., Schneider, B., Schuster, U., Sieger, R., Skjelvan, I., Steinhoff, T., Suzuki, T., Takahashi, T., Tedesco, K., Telszewski, M., Thomas, H., Tilbrook, B., Vandemark, D., Veness, T., Watson, A. J., Weiss, R., Wong, C. S., and Yoshikawa-Inoue, H.: Surface Ocean $\mathrm{CO}_{2}$ Atlas (SOCAT) Gridded Data Products, Earth Syst. Sci. Data, 5, 145-153, doi:10.5194/essdd-5-781-2012, 2013.

Salisbury, J. E., Vandemark, D., Hurt, C. W., Campbell, J. W., McGillis, W. R., and McDwell, W. H.: Seasonal observations of surface waters in two Gulf of Maine estuary-plume systems: Relatioships between watershed attributes, optical measurements and surface $p \mathrm{CO}_{2}$ Estuar. Coast. Shelf Sci., 77, 245-252, 2008.

Santaren, D., Peylin, P., Viovy, N., and Ciais, P.: Optimizing a process based ecosystem model with eddy-covariance flux measurements: Part 1. Functionning of a Pine forest in southern France, Global Biogeochem. Cy., 21, doi:10.1029/2006GB002834, 2007.

Schaaf, C. L., Martonchik, J., Pinty, B., Govaerts, Y., Gao, F., Lattanzio, A., Liu, J., Strahler, A. H., and Taberner, M.: Retrieval of Surface Albedo from Satellite Sensors, in: Advances in Land Remote Sensing: System, Modeling, Inversion and Application, edited by: Liang, S., Springer, 219-243, 2008.

Schmidt, A., Hanson, C., Chan, S. W., and Law, B. E.: Empirical assessment of uncertainties of meteorological parameters and turbulent fluxes in the AmeriFlux network, J. Geophys. Res., 117, G04014, doi:10.1029/2012JG002100, 2012.

Schmitgen, S., Geiß, H., Ciais, P., Neininger, B., Brunet, Y., Reichstein, M., Kley, D., and Volz-Thomas, A.: Carbon dioxide uptake of a forested region in southwest France derived from airborne $\mathrm{CO}_{2}$ and $\mathrm{CO}$ measurements in a quasi-Lagrangian experiment, $\mathrm{J}$ Geophys. Res., 109, D14302, doi:10.1029/2003jd004335, 2004.

Schulze, E. D., Luyssaert, S., Ciais, P., Freibauer, A., Janssens, I. A., Soussana, J. F., Smith, P., Grace, J., Levin, I., Thiruchittampalam, B., Heimann, M., Dolman, A. J., Valentini, R., Bousquet, P., Peylin, P., Peters, W., Rodenbeck, C., Etiope, G., Vuichard, N., Wattenbach, M., Nabuurs, G. J., Poussi, Z., Nieschulze, J., Gash, J. H., and Team, C.: Importance of methane and nitrous oxide for Europe's terrestrial greenhouse-gas balance, Nat. Geosci., 2, 842-850, 2009.

Sellers, P. J., Dickinson, R. E., Randall, D. A., Betts, A. K., Hall, F. G., Berry, J. A., Collatz, G. J., Denning, A. S., Mooney, H. A., Nobre, C. A., Sato, N., Field, C. B., and Henderson-Sellers, A.: Modeling the exchanges of energy, water, and carbon between continents and the atmosphere, Science, 275, 502-509, doi:10.1126/science.275.5299.502, 1997.

Smeets, C. J. P. P., Holzinger, R., Vigano, I., Goldstein, A. H., and Röckmann, T.: Eddy covariance methane measurements at a Ponderosa pine plantation in California, Atmos. Chem. Phys. 9, 8365-8375, doi:10.5194/acp-9-8365-2009, 2009.

Stephens, B. B., Gurney, K. R., Tans, P. P., Sweeney, C., Peters, W., Bruhwiler, L., Ciais, P., Ramonet, M., Bousquet, P., Nakazawa, T., Aoki, S., Machida, T., Inoue, G., Vinnichenko, N., Lloyd, J., Jordan, A., Heimann, M., Shibistova, O., Langenfelds, R. L., Steele, L. P., Francey, R. J., and Denning, A. 
S.: Weak northern and strong tropical land carbon uptake from vertical profiles of atmospheric $\mathrm{CO}_{2}$, Science, 316, 1732-1735, doi:10.1126/science.1137004, 2007.

Stöckli, R., Rutishauser, T., Baker, I., Liniger, M. A., and Denning, A. S.: A global reanalysis of vegetation phenology, J. Geophys. Res., 116, G03020, doi:10.1029/2010JG001545, 2011.

Stolaroff, J. K., Bhattacharyya, S., Smith, C. A., Bourcier, W. L., Cameron-Smith, P. J., and Aines, R. D.: Review of methane mitigation technologies with application to rapid release of methane from the Arctic, Environ. Sci. Technol., 46, 6455-6469, doi:10.1021/es204686w, 2012.

Taguchi, S., Law, R. M., Rödenbeck, C., Patra, P. K., Maksyutov, S., Zahorowski, W., Sartorius, H., Levin, I.: TransCom continuous experiment: Comparison of ${ }^{222} \mathrm{Rn}$ transport in Germany, Atmos. Chem. Phys., 11, 10071-10084, doi:10.5194/acp-1110071-2011, 2011.

Takahashi, T., Sutherland, S. C., Wanninkhof, R., Sweeney, C., Feely, R. A., Chipman, D. W., Hales, B., Friederich, G., Chavez, F., Sabine, C., Watson, A., Bakker, D. C. E., Schuster, U., Metzl, N., Yoshikawa-Inoue, H., Ishii, M., Midorikawa, T., Nojiri, Y., Kortzinger, A., Steinhoff, T., Hoppema, M., Olafsson, J., Arnarson, T. S., Tilbrook, B., Johannessen, T., Olsen, A., Bellerby, R., Wong, C. S., Delille, B., Bates, N. R., and de Baar, H. J. W.: Climatological mean and decadal change in surface ocean $p \mathrm{CO}_{2}$, and net sea-air $\mathrm{CO}_{2}$ flux over the global oceans, Deep-Sea Res. Pt. II, 56, 554-577, doi:10.1016/j.dsr2.2008.12.009, 2009.

Tarnocai, C., Canadell, J. G., Schuur, E. A. G., Kuhry, P., Mazhitova, G., and Zimov, S.: Soil organic carbon pools in the northern circumpolar permafrost region, Global Biogeochem. Cy., 23, Gb2023, doi:10.1029/2008gb003327, 2009.

Telszewski, M., Chazottes, A., Schuster, U., Watson, A. J., Moulin, C., Bakker, D. C. E., González-Dávila, M., Johannessen, T., Körtzinger, A., Lüger, H., Olsen, A., Omar, A., Padin, X. A., Ríos, A. F., Steinhoff, T., Santana-Casiano, M., Wallace, D. W. R., and Wanninkhof, R.: Estimating the monthly $p \mathrm{CO}_{2}$ distribution in the North Atlantic using a self-organizing neural network, Biogeosciences, 6, 1405-1421, doi:10.5194/bg-6-14052009, 2009.

Tjiputra, J. F., Polzin, D., and Winguth, A. M. E.: Assimilation of seasonal chlorophyll and nutrient data into an adjoint threedimensional ocean carbon cycle model: Sensitivity analysis and ecosystem parameter optimization, Global Biogeochem. Cy., 21, GB1001, doi:10.1029/2006GB002745, 2007.

Treuhaft, R. N., Asner, G. P., and Law, B. E.: Structure-based forest biomass from fusion of radar and hyperspectral observations, Geophys. Res. Lett., 30, 1472, doi:10.1029/2002GLO16857, 2003.

Tucker, C. J., Pinzon, J. E., Brown, M. E., Slayback, D. A., Pak, E. W., and Mahoney, R.: An extended AVHRR 8-km NDVI data set compatible with MODIS and SPOT vegetation NDVI data, Int. J. Remote Sens., 26, 4485-4498, 2005.

Uitz, J., Claustre, H., Gentili, B., and Stramski, D.: Phytoplankton class-specific primary production in the world's oceans: Seasonal and interannual variability from satellite observations, Global Biogeochem. Cy., 24, GB3016, doi:10.1029/2009GB003680, 2010.

UN-REDD: UN Collaborative Programme On Reducing Emissions From Deforestation And Forest Degradation In Developing Countries (UN-REDD), 2008.
Van der Werf, G. R., Randerson, J. T., Collatz, G. L., and Giglio, L.: Carbon emissions from fires in tropical and subtropical ecosystems, Glob. Change Biol., 9, 547-562, 2003.

van der Werf, G. R., Randerson, J. T., Giglio, L., Collatz, G. J., Mu, M., Kasibhatla, P. S., Morton, D. C., DeFries, R. S., Jin, Y., and van Leeuwen, T. T.: Global fire emissions and the contribution of deforestation, savanna, forest, agricultural, and peat fires (19972009), Atmos. Chem. Phys., 10, 11707-11735, doi:10.5194/acp10-11707-2010, 2010.

Velazco, V. A., Buchwitz, M., Bovensmann, H., Reuter, M., Schneising, O., Heymann, J., Krings, T., Gerilowski, K., and Burrows, J. P.: Towards space based verification of $\mathrm{CO}_{2}$ emissions from strong localized sources: fossil fuel power plant emissions as seen by a CarbonSat constellation, Atmos. Meas. Tech., 4, 2809-2822, doi:10.5194/amt-4-2809-2011, 2011.

Vogelmann, J. E., Tolk, B., and Zhu, Z.: Monitoring forest changes in the southwestern United States using multitemporal Landsat data, Remote Sens. Environ., 113, 1739-1748, 2009.

Walsh, J. J.: Importance of continental margins in the marine biochemical cycling of carbon and nitrogen, Nature, 350, 53-55, doi:10.1038/350053a0, 1991.

Wang, R., Tao, S., Ciais, P., Shen, H. Z., Huang, Y., Chen, H., Shen, G. F., Wang, B., Li, W., Zhang, Y. Y., Lu, Y., Zhu, D., Chen, Y. C., Liu, X. P., Wang, W. T., Wang, X. L., Liu, W. X., Li, B. G., and Piao, S. L.: High-resolution mapping of combustion processes and implications for $\mathrm{CO}_{2}$ emissions, Atmos. Chem. Phys., 13, 5189-5203, doi:10.5194/acp-13-5189-2013, 2013.

Wang, Y. P. and McGregor, J.: Estimating regional terrestrial carbon fluxes for the Australian continent using a multipleconstraint approach, Tellus B, 55, 290-304, doi:10.1034/j.16000889.2003.00030.x, 2003.

Wanninkhof, R., Doney, S. C., Bullister, J. L., Levine, N. M., Warner, M., and Gruber, N.: Detecting anthropogenic $\mathrm{CO}_{2}$ changes in the interior Atlantic Ocean between 1989 and 2005, J. Geophys. Res.-Oceans, 115, C11028, doi:10.1029/2010jc006251, 2010.

Watson, A., Schuster, U., Bakker, D., Bates, N., Corbiere, A., Gonzalez-Davila, M., Friedrich, T., Hauck, J., Heinze, C., Johannessen, T., Kortzinger, A., Metzl, N., Olafsson, J., Olsen, A., Oschlies, A., Padin, X., Pfeil, B., Santana-Casiano, J., Steinhoff, T., Telszewski, M., Rios, A., Wallace, D., and Wanninkhof, R.: Tracking the variable North Atlantic sink for atmospheric $\mathrm{CO}_{2}$, Science, 326, 1391-1393, doi:10.1126/science.1177394, 2009.

Wennberg, P. O., Mui, W., Wunch, D., Kort, E. A., Blake, D. R., Atlas, E. L., Santoni, G. W., Wofsy, S. C., Daskin, G. S., Jeong, S., and Fischer, M. L.: On the sources of methane to the Los Angeles atmosphere, Environ. Sci. Technol., 46, 9282-9289, doi:10.1021/es301138y, 2012.

West, T. O., Marland, G., Singh, N., Bhaduri, B. L., and Roddy, A.: The human carbon budget: an estimate of the spatial distribution of metabolic carbon consumption and release in the United States, Biogeochemistry, 94, 29-41, doi:10.1007/s10533009-9306-z, 2009.

White, M. A., Running, S. W., and Thornton, P. E.: The impact of growing-season length variability on carbon assimilation and evapotranspiration over 88 years in the eastern US deciduous forest, Int. J. Biometeorol., 42, 139-145, 1999. 
Williams, M., Richardson, A. D., Reichstein, M., Stoy, P. C., Peylin, P., Verbeeck, H., Carvalhais, N., Jung, M., Hollinger, D. Y., Kattge, J., Leuning, R., Luo, Y., Tomelleri, E., Trudinger, C. M., and Wang, Y.-P.: Improving land surface models with FLUXNET data, Biogeosciences, 6, 1341-1359, doi:10.5194/bg-6-13412009, 2009.

Wirth, C., Schumacher, J., and Schulze, E. D.: Generic biomass functions for Norway spruce in Central Europe. Ameta-analysis approach toward prediction and uncertainty estimation, Tree Physiol., 24, 121-139, 2004.

WMO: Greenhouse Gas Bulletin, The State of Greenhouse Gases in the Atmosphere Using Global Observations through 2008, World Meteorological Organization, 5, 2009.

WMO: Greenhouse Gas Bulletin, The State of Greenhouse Gases in the Atmosphere Based on Global Observations through 2009, World Meteorological Organization, 6, 24 November, 2010.

WMO: Greenhouse Gas Bulletin, The State of Greenhouse Gases in the Atmosphere Based on Global Observations through 2011. World Meteorological Organization, 8, 19 November, 2012.

Wooster, M. J., Zhukov, B., and Oertel, D.: Fire radiative energy for quantitative study of biomass burning: derivation from the BIRD experimental satellite and comparison to MODIS fire products, Remote Sens. Environ., 86, 83-107, 2003.

Wooster, M. J., Roberts, G., Perry, G. L. W., and Kaufman, Y. J.: Retrieval of biomass combustion rates and totals from fire radiative power observations: FRP derivation and calibration relationships between biomass consumption and fire radiative energy release, J. Geophys. Res., 110, D24311, doi:10.1029/2005JD006318, 2005.

Wunch, D., Toon, G. C., Wennberg, P. O., Wofsy, S. C., Stephens, B. B., Fischer, M. L., Uchino, O., Abshire, J. B., Bernath, P., Biraud, S. C., Blavier, J.-F. L., Boone, C., Bowman, K. P., Browell, E. V., Campos, T., Connor, B. J., Daube, B. C., Deutscher, N. M., Diao, M., Elkins, J. W., Gerbig, C., Gottlieb, E., Griffith, D. W. T., Hurst, D. F., Jiménez, R., Keppel-Aleks, G., Kort, E. A., Macatangay, R., Machida, T., Matsueda, H., Moore, F., Morino, I., Park, S., Robinson, J., Roehl, C. M., Sawa, Y., Sherlock, V., Sweeney, C., Tanaka, T., and Zondlo, M. A.: Calibration of the Total Carbon Column Observing Network using aircraft profile data, Atmos. Meas. Tech., 3, 1351-1362, doi:10.5194/amt3-1351-2010, 2010.

Wunch, D., Toon, G. C., Blavier, J.-F. L., Washenfelder, R. A., Notholt, J., Connor, B. J., Griffith, D. W. T., Sherlock, V., and Wennberg, P. O.: The total carbon column observing network, P. T. Roy. Soc. A, 369, 2087-2112, doi:10.1098/rsta.2010.0240, 2011a.
Wunch, D., Wennberg, P. O., Toon, G. C., Connor, B. J., Fisher, B., Osterman, G. B., Frankenberg, C., Mandrake, L., O’Dell, C., Ahonen, P., Biraud, S. C., Castano, R., Cressie, N., Crisp, D., Deutscher, N. M., Eldering, A., Fisher, M. L., Griffith, D. W. T., Gunson, M., Heikkinen, P., Keppel-Aleks, G., Kyrö, E., Lindenmaier, R., Macatangay, R., Mendonca, J., Messerschmidt, J., Miller, C. E., Morino, I., Notholt, J., Oyafuso, F. A., Rettinger, M., Robinson, J., Roehl, C. M., Salawitch, R. J., Sherlock, V., Strong, K., Sussmann, R., Tanaka, T., Thompson, D. R., Uchino, O., Warneke, T., and Wofsy, S. C.: A method for evaluating bias in global measurements of $\mathrm{CO}_{2}$ total columns from space, Atmos. Chem. Phys., 11, 12317-12337, doi:10.5194/acp11-12317-2011, $2011 b$.

Wunch, D., Wennberg, P. O., Messerschmidt, J., Parazoo, N. C., Toon, G. C., Deutscher, N. M., Keppel-Aleks, G., Roehl, C. M., Randerson, J. T., Warneke, T., and Notholt, J.: The covariation of Northern Hemisphere summertime $\mathrm{CO}_{2}$ with surface temperature in boreal regions, Atmos. Chem. Phys., 13, 9457-9459, doi:10.5194/acp-13-9447-2013, 2013.

Xiao, J., Zhang, Q., Law, B. E., Baldocchi, D. D., Chen, J., Richardson, A. D., Melillo, J., Davis, K. J., Hollinger, D. Y., Wharton, S., Oren, R., Noormets, A., Fischer, M. L., Verma, S., Cook, D. R., Sun, G., McNulty, S., Wofsy, S. C., Bolstad, P. V., Burns, S. P., Curtis, P. S., Drake, B. G., Falk, M., Foster, D. R., Gu, L., Hadley, J. L., Katul, G. G., Litvak, M., Ma, S., Martin, T. A., Matamala, R., Meyers, T. P., Monson, R. K., Munger, J. W., Oechel, W. C., Paw U, K. T., Schmid, H. P., Scott, R. L., Starr, G., Suyker, A. E., and Torn, M. S.: Assessing net ecosystem carbon exchange of U. S. terrestrial ecosystems by integrating eddy covariance flux measurements and satellite observations, Agr. Forest Meteorol., 151, 60-69, 2011.

Xiong, X., Barnet, C., Maddy, E., Sweeney, C., Liu, X., Zhou, L., and Goldberg, M.: Characterization and validation of methane products from the Atmospheric Infrared Sounder (AIRS), J. Geophys. Res., 113, G00A01, doi:10.1029/2007jg000500, 2008.

Yoshida, Y., Kikuchi, N., Morino, I., Uchino, O., Oshchepkov, S., Bril, A., Saeki, T., Schutgens, N., Toon, G. C., Wunch, D., Roehl, C. M., Wennberg, P. O., Griffith, D. W. T., Deutscher, N. M., Warneke, T., Notholt, J., Robinson, J., Sherlock, V., Connor, B., Rettinger, M., Sussmann, R., Ahonen, P., Heikkinen, P., Kyrö, E., and Yokota, T.: Improvement of the retrieval algorithm for GOSAT SWIR $\mathrm{XCO}_{2}$ and $\mathrm{XCH}_{4}$ and their validation using TCCON data, Atmos. Meas. Tech., 6, 949-988, doi:10.5194/amtd6-949-2013, 2013.

Yu, Z: Holocene carbon flux histories of the world's peatlands: Global carbon-cycle implications, The Holocene, 21, 761-774, doi:10.1177/0959683610386982, 2011.

Zupanski, D., Hou, A. Y., Zhang, S. Q., Zupanski, M., Kummerow, C. D., and Cheung, S. H.: Applications of information theory and ensemble data assimilation, Q. J. Roy. Meteor. Soc., 133, 15331545, 2007. 